Al110ट 561167

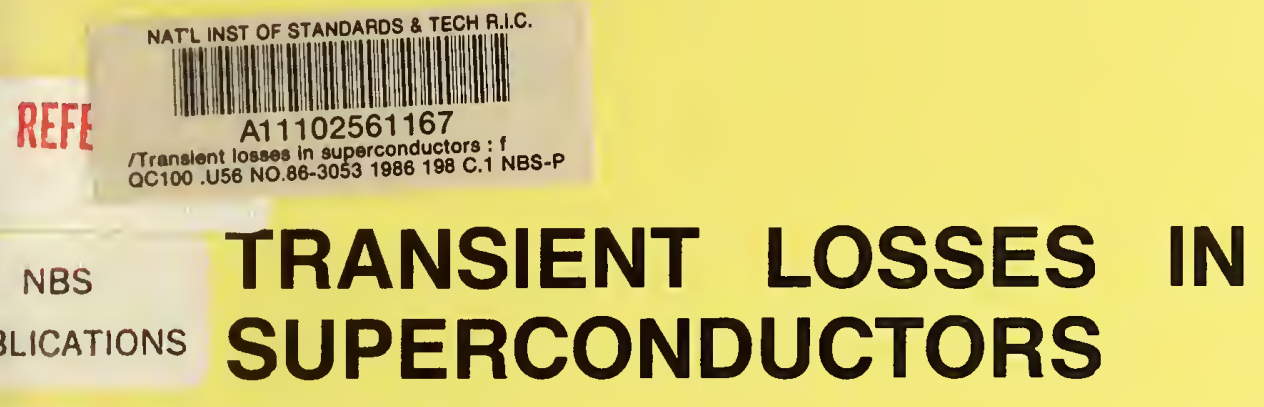

\section{TRANSIENT LOSSES IN SUPERCONDUCTORS}

Final Report

\author{
R. B. Goldfarb, Editor
}

National Bureau of Standards

U.S. Department of Commerce

Boulder, Colorado 80303

June 1986

$-Q C$

100

.456

$86-3053$

1986 



\section{TRANSIENT LOSSES IN SUPERCONDUCTORS}

Final Report

R. B. Goldfarb, Editor

Electromagnetic Technology Division

Center for Electronics and Electrical Engineering

National Engineering Laboratory

National Bureau of Standards

Boulder, Colorado 80303

June 1986

Prepared for:

Air Force Office of Scientific Research

Bolling Air Force Base

Washington, DC 20332

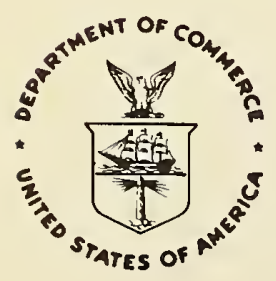

U.S. DEPARTMENT OF COMMERCE, Malcolm Baldrige, Secretary 



\title{
TRANSIENT LOSSES IN SUPERCONDUCTORS
}

Final Report

\author{
R. B. Goldfarb, Editor \\ Electromagnetic Technology Division \\ Center for Electronics and Electrical Engineering \\ National Engineering Laboratory \\ National Bureau of Standards \\ Boulder, Colorado 80303
}

Under steady-state conditions, there are no losses in superconducting wires. However, when subjected to alternating or transient magnetic fields or transport currents, losses in type-II superconductors can become significant. This report deals with hysteresis losses at $4 \mathrm{~K}$ measured by magnetization and complex magnetic susceptibility. The theoretical and experimental relationships between ac susceptibility and magnetization as functions of dc field were examined in terms of the critical-state model as developed by Carr and Clem. Minor-loop hysteresis loss was shown to be obtainable by direct measurement of loop area, from the imaginary component of ac susceptibility, and from the reversible susceptibility plus the critical current density or fullpenetration field. Hysteresis and transport losses measured simultaneously in a $\mathrm{Nb}-\mathrm{Ti}$ superconducting coll were found to agree substantially with the predictions of Minervini's two-dimensional model. Hysteresis loss measurements in a series of fine-filament $\mathrm{Nb}_{3} \mathrm{Sn}$ superconductors showed that the effective filament diameter is a function of interfilament separation and local area ratio of matrix material to $\mathrm{Nb}$. A review of internal fields in superconductors showed the importance of demagnetization factors and internal fields for the correct analysis of magnetic data. A theoretical method of calibrating ac susceptometers for cylindrical specimens, which is based on a mutualinductance calculation, was developed.

Key words: ac losses; hysteresis; magnetization; magnetometers; niobium-tin; niobium-titanium; superconductors; susceptibility; susceptometers; transient losses. 

Final Report

\section{EXECUTIVE SUMMARY}

Under steady-state conditions, there are no losses in superconducting wires. However, when type-II superconductors are subjected to alternating or transient magnetic fields or transport currents, losses can become significant. Consequently, they are an important design consideration in many practical superconductor applications. AC losses may be categorized into hysteresis losses, eddy-current and coupling losses, and self-field losses.

This report deals mostly with hysteresis losses at $4 \mathrm{~K}$. The experimental methods developed primarily involve the measurement of (1) magnetization as a function of field, and (2) complex magnetic susceptibility as functions of dc field and ac-field amplitude and frequency. Most measurements were made on variations of commercial multifilamentary $\mathrm{Nb}-\mathrm{Ti}$ conductors with no transport current in longitudinal fields. However, some results are reported for $\mathrm{Nb}-\mathrm{Ti}$ with transport current and $\mathrm{Nb}_{3} \mathrm{Sn}$ conductors, both in transverse fields. In general, the experimental relationship between complex ac susceptibility and magnetization as a function of dc magnetic field was examined in terms of the critical-state model as developed by Carr and $\mathrm{Clem}$. Good agreement between experiment and theory was found.

While the dc magnetic methods measure only the hysteresis component of total loss, hysteresis is usually the largest component of loss below $1 \mathrm{kHz}$. Additionally, magnetic hysteresis measurements give information on the remanent magnetization due to trapped flux in superconducting wires. This information is useful in selecting conductors for specific applications. For these reasons, it is likely that magnetic methods will emerge as a standard measurement technique for quantifying ac losses.

In addition to magnetic techniques, two other ways to measure transient losses in superconductors were evaluated. These methods were an electrical wattmeter and a calorimeter. These two other methods were found to be experimentally rather difficult compared to the magnetic methods. The electrical method requires the measurement of very small changes in phase angle between nonsinusoidal voltage and current. The calorimetric method requires the measurement of very small incremental helium flows above the normal static boil-off. More development would be required, compared to the magnetic methods, for the rapid acquisition of useful materials information.

\section{Program Objectives}

The following were program objectives and their related outputs:

1. Correlate hysteretic losses in a given material for different sample configurations.

Paper I: Hysteretic losses were studied in Nb-Ti superconductors with different filament diameters, numbers of filaments, and ratios of matrix 
material to superconductor. Hysteresis decreased with decreasing filament diameter and was independent of conductor cross-sectional shape. The loss per volume of superconductor, expected to be independent of matrix-tosuperconductor ratio, sometimes showed significant unexplained dependence.

2. Study the effect of matrix material on the losses for a given filamentary superconductor. Study coupling losses as a function of filament density and filament-matrix bonding.

Paper V: The effect of local area ratio of matrix material to superconductor was studied in fine-filament $\mathrm{Nb}_{3} \mathrm{Sn}$ conductors. The hysteresis losses depended on the interfilament separation and area ratio.

3. Extend existing theoretical model for transient transport current and transient external field.

Paper IV: The two-dimensional model for shielding-hysteresis and transportcurrent losses was experimentally verified for the first time.

$\underline{\text { Results }}$

A summary of significant results follows:

1. Hysteresis loss was shown to be accurately predicted within a few percent, using the London-Bean critical-state model, from the full-penetration field as a function of maximum applied field. It was shown that the full-penetration field could be deduced directly from the hysteresis loop, without reference to the critical current density. (See paper I.)

2. Minor-loop hysteresis loss was shown to be obtainable in three ways: by direct measurement of loop area, from the imaginary component of ac susceptibility, and from the reversible susceptibility plus the critical current density. The loss expressions derived by Carr were shown to be the same as those derived by $\mathrm{Clem}$ in the limit where the reversible susceptibility is zero. This was the first correlation of the different experimental magnetic methods. The relationships between complex magnetic susceptibility and permeability were discussed. (See paper II.)

3. A theoretical expression for the reversible susceptibility plus experimental measurements of full-penetration field were found to predict the measured real and imaginary components of ac susceptibility as functions of applied field using Clem's model. This was the first test of the applicability of the model to practical superconductors. The full-penetration field was found to be inversely proportional to applied longitudinal field, thus following a Kim-type relationship. The shape of the hysteresis loop was used to deduce the superconductor penetration depth and approximate the lower critical field. (See paper III.)

4. Hysteresis and transport losses measured simultaneously in a $\mathrm{Nb}-\mathrm{Ti}$ superconducting coil were found to substantially agree with the predictions of Minervini's cylindrical model. This was the first experimental verification of the two-dimensional theory. (See paper IV.) 
5. Systematic hysteresis loss measurements in a series of fine-filament $\mathrm{Nb}_{3} \mathrm{Sn}$ superconductors showed that the effective filament diameter is a function of interfilament separation and local area ratio of matrix material to $\mathrm{Nb}$. The effective filament diameter was obtained by applying the critical-state model to measured hysteresis loops. There would be little filament interaction due to bridging for $\mathrm{Nb}_{3} \mathrm{Sn}$ interfilament separation greater than $2 \mu \mathrm{m}$. This was the first study of filament coupling in $\mathrm{Nb}_{3} \mathrm{Sn}$. The study is expected to have an impact on the design of practical wires. (See paper V.)

6. A review of internal fields in superconductors was prepared. The importance of demagnetization factors and internal fields for the correct analysis of magnetic data was discussed. The review will be a useful guide for the calibration of magnetometers used in measuring hysteresis losses in superconductors. (See paper VI.)

7. A new theoretical method of calibrating ac susceptometers for cylindrical specimens that is based on a mutual-inductance calculation was developed. The results were in excellent agreement with calibrations using standard reference materials. (See paper VII.)

8. A multifunction circuit was designed to protect instruments connected or coupled to a superconducting magnet against large voltage surges in the event of a quench. (See paper VIII.)

9. A review was prepared of the methods used for characterizing alloys, especially superconductors, with regard to matrix-to-superconductor volume ratio, filament radius, density, and weight and atomic percents. This review will be useful for some users and manufacturers of multifilamentary wires. (See paper IX.)

This project required the development of instrumentation for magnetic measurements and computer programs for data acquisition and processing. It resulted in the publication of five papers, the preparation of four other manuscripts (three of which will be submitted for publication), and participation in a workshop on problems in superconductivity [Cryogenics 24, 378 (1984)]. 

Abstract . . . . . . . . . . . . . . . . . iii

Executive Summary . . . . . . . . . . . . . . . . v

I. Hysteretic Losses in Nb-Ti Superconductors

R. B. Goldfarb and A. F. Clark ............ 1

II. Magnetic Hysteresis and Complex Susceptibility as Measures

of AC Losses in a Multifilamentary NbTi Superconductor

R. B. Goldfarb and A. F. Clark .......... . 5

III. AC Losses in Nb-Ti Measured by Magnetization and Complex

Susceptibility

R. B. Goldfarb and A. F. Clark . . . . . . . . . 9

IV. Losses in a Nb-Ti Superconductor as Functions of AC Field

Amplitude and DC Transport Current

M. Dragomirecky, J. V. Minervini, J. W. Ekin,

R. B. Goldfarb, and A. F. Clark .......... 17

V. Hysteresi. Losses in Fine-Filament Internal-Tin

Superconductors

R. B. Goldfarb and J. W. Ekin . . . . . . . . 23

VI. Internal Fields in Magnetic Materials and Superconductors

R. B. Goldfarb . . . . . . . . . . . . 35

VII. Calibration of AC Susceptometer for Cylindrical Specimens

R. B. Goldfarb and J. V. Minervini . . . . . . . . 43

VIII. Quench Circuit for Electronic Instruments Used with Superconducting Magnets

R. G. Benson, R. B. Goldfarb, and E. S. Pittman . . . . 47

IX. Characterization of Alloys

R. B. Goldfarb . . . . . . . . . . . 53

X. Units for Magnetic Properties

R. B. Goldfarb and F. R. Fickett . . . . . . . . 57 



\title{
Hysteretic losses in $\mathrm{Nb}$-Ti superconductors
}

\author{
R. B. Goldfarb and A. F. Clark \\ Electromagnetic Technology Division, National Bureau of Standards, Boulder, Colorado 80303
}

When subjected to transient magnetic fields, superconductors exhibit losses. At low frequencies, most of the dissipation is hysteretic. Magnetization was measured in an axial field for eight multifilamentary $\mathrm{Nb}$-Ti superconducting wires with different filament sizes and different ratios of copper to superconductor. The full-penetration field $H_{\rho}$ was estimated from the high-field ends of the hysteresis loops. The estimate of $H_{p}$ provides a method to assess the critical current density $J_{c}$. There was good agreement between measured losses and those predicted from $H_{p}$ and the peak applied field.

\section{INTRODUCTION}

An ideal type I superconductor is perfectly diamagnetic below its critical temperature $T_{c}$ and critical field $H_{c}$. This is a consequence of the Meissner effect,

$$
B=\mu_{0}(H+M)=0, \quad \chi=M / H=-1,
$$

in SI units, where $B$ is the magnetic flux density, $H$ is the magnetic field strength, $M$ is the magnetization, and $\chi$ is the susceptibility. The diamagnetism arises from circulating persistent surface currents.

In type II superconductors the pure Meissner state appears only below $H_{c 1}$. Between $H_{c 1}$ and $H_{c 2}$ (lower and upper critical fields) the "mixed" state occurs in which surface currents coexist with magnetic vortices, usually containing one flux quantum each, formed by local persistent currents. These vortices are analogous to paramagnetic moments.' The effective magnetization (magnetic moment per unit volume), owing to surface and vortex currents, can be measured in the same way as the magnetization of magnetic materials.

According to the "critical state" model, as the applied field increases above $H_{c l}$, the magnetic flux and a current density $J$ penetrate toward the center of the superconductor. The magnitude of $J$ is $J_{c}$, the critical current density, taken to be independent of field. The field at which complete penetration occurs is termed the full-penetration field $H_{p}$. For a cylindrical filament with a field applied axially,

$$
H_{p}=J_{c} r \text {, }
$$

where $r$ is the filament radius.

In "hard" type II superconductors, such as Nb-Ti, pinning sites impede the motion of flux vortices, which gives a higher value of $J_{c}$. Consequently, when the applied field is cycled, hysteresis occurs. Flux pinning is the largest source of bulk hysteresis, and hysteresis is the largest component of losses for ac fields below about $1 \mathrm{kHz}$. It is important to minimize these losses in non-dc superconducting-magnet applications in fusion, accelerators, and pulsed power sources. To minimize hysteresis, almost all commercial $\mathrm{Nb}$ $\mathrm{Ti}$ wires are composed of many fine superconductor filaments, 1 to $25 \mu \mathrm{m}$ in radius, within a thermally stabilizing $\mathrm{Cu}$ matrix. The weak diamagnetic contribution of the $\mathrm{Cu}$ to the effective magnetization is negligible.

Simple magnetic measurements can be useful to fabricators and users of superconductors. In this paper, measured hysteresis losses are compared to those predicted from theory for a number of superconductors.

\section{EXPERIMENT}

A vibrating-sample magnetometer (VSM) was used to obtain dc hysteresis loops at about $4.3 \mathrm{~K}$. The magnetic field was supplied by a superconducting magnet. Field accuracy was estimated to be within $\pm 4 \mathrm{kA} / \mathrm{m}(50 \mathrm{Oe})$, and magnetization accuracy to be within $\pm 5 \%$.

Each sample consisted of about 5-14 1.5-cm-long segments of insulated multifilamentary $\mathrm{Nb}$ - $\mathrm{Ti}$ wire, bundled together. For such lengths the filaments may be treated as uncoupled. The field and all measurements were along the longitudinal axis. There was no transport current applied to the wires.

Magnetization was calculated per volume of superconductor filaments. Demagnetization factor effects were negligible; the internal field was taken to be the same as the exter-

\begin{tabular}{|c|c|c|c|c|}
\hline $\begin{array}{l}\text { Sample } \\
\text { number }\end{array}$ & $\begin{array}{l}\text { Dimensions without } \\
\text { insulation }(\mathrm{mm})\end{array}$ & $\begin{array}{l}\text { Number of } \\
\text { filaments }\end{array}$ & $\begin{array}{l}\text { Filament } \\
\text { radius }(\mu \mathrm{m})\end{array}$ & $\begin{array}{c}\mathrm{Cu} / \mathrm{Nb}-\mathrm{Ti} \text { volume } \\
\text { ratio }\end{array}$ \\
\hline 1 & $d=0.51$ & 180 & 12.2 & 1.46 \\
\hline 2 & $0.57 \times 0.84$ & 132 & 13.0 & 4.98 \\
\hline 3 & $d=0.68$ & 2046 & 4.3 & 2.08 \\
\hline 4 & $d=0.64$ & 180 & 15.0 & 1.50 \\
\hline 5 & $0.52 \times 0.70$ & 180 & 16.4 & 1.30 \\
\hline 7 & $d=1.01$ & 114 & 19.5 & 4.84 \\
\hline 8 & $0.63 \times 0.88$ & 240 & 19.3 & 0.91 \\
\hline
\end{tabular}

TABLE I. Physical properties of multifilamentary Nb-Ti superconductors. 

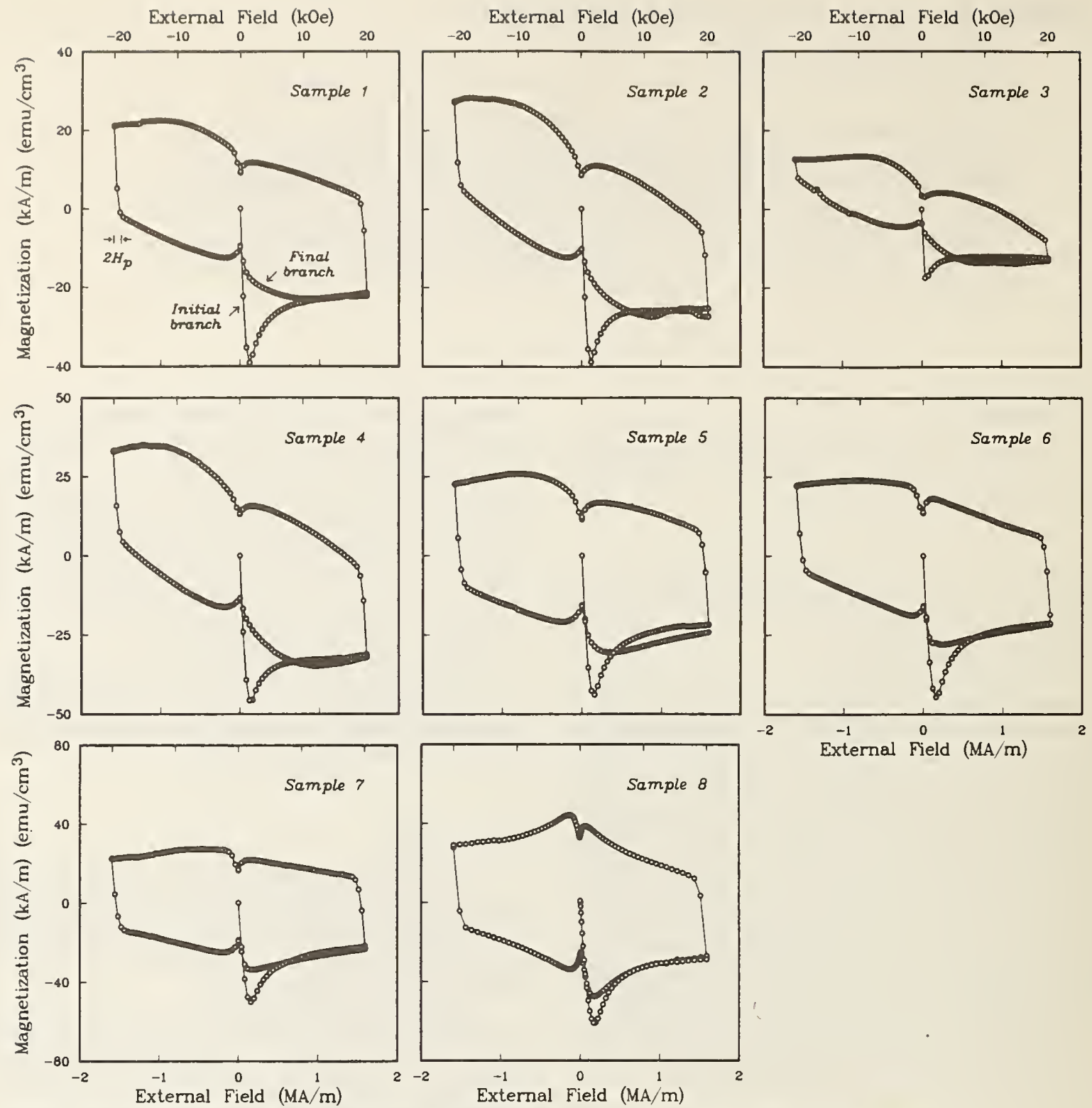

FIG. 1. dc hysteresis loops for eight multifilamentary Nb-Ti superconductors. Note that the vertical scales are not all the same.

nal applied field. Before each set of measurements was made, the sample was warmed above $T_{c}$ (about $10.2 \mathrm{~K}$ for $\mathrm{Nb}-\mathrm{Ti}$ ) and then cooled in zero field.

\section{MEASUREMENT OF HYSTERESIS}

Table I summarizes the physical properties of the superconductor wires studied. Figure 1 shows the hysteresis loops for the samples for a peak applied field $H_{0}$ of 1.6 $\mathrm{MA} / \mathrm{m}$ (20 kOe). Occasional spurious nonsmooth behavior is accounted for by slight deviations in temperature during measurement. The area enclosed by each loop is equal to the loss $W$,

$$
W=\mu_{0} \oint H d M \cong \mu_{0} \oint M d H,
$$

where $H$ ranges from $+H_{0}$ to $-H_{0}$.

The full-penetration field $H_{p}$ can be estimated from the hysteresis loop. As the loop is traversed, the filaments go from full penetration in one direction to full penetration in the other direction. Therefore, at a high-field end of the loop, $H_{p}$ is approximately one-half the field required to reverse the magnetization. This reversal field $2 H_{p}$ is determined by a peak in $d^{2} M / d H^{2}$ and is indicated on the loop for sample 1 in Fig. 1.

For the case when the peak applied field $H_{0}$ is greater than $H_{p}$, Carr derived an expression for the loss, assuming $J_{c}$ to be independent of magnetic field. ${ }^{2}$ In SI units,

$$
\mathrm{W}=\left(4 \mu_{0} H_{0} H_{p} / 3\right)\left(1-H_{p} / 2 H_{0}\right) \text {. }
$$

Clearly $H_{0}$ is much larger than $H_{\rho}$ for the loops in Fig. 1. 
TABLE II. Hysteresis loss $W$ for a peak field $H_{0}$ of $1.6 \mathrm{MA} / \mathrm{m}(20 \mathrm{kOe})$.

\begin{tabular}{|c|c|c|c|c|}
\hline \multirow{2}{*}{$\begin{array}{l}\text { Sample } \\
\text { number }\end{array}$} & \multirow{2}{*}{$\begin{array}{l}\text { Loss from loop } \\
\text { area }\left(\mathrm{kJ} / \mathrm{m}^{3}\right)\end{array}$} & \multicolumn{2}{|c|}{$H_{p}$} & \multirow{2}{*}{$\begin{array}{l}\text { Loss from } \\
H_{p}\left(\mathrm{~kJ} / \mathrm{m}^{3}\right)\end{array}$} \\
\hline & & $(\mathrm{kA} / \mathrm{m})$ & $(\mathrm{Oe})$ & \\
\hline 1 & 114 & 45 & 550 & 120 \\
\hline 2 & 116 & 45 & 550 & 120 \\
\hline 3 & 50 & 20 & 250 & 50 \\
\hline 4 & 152 & 50 & 650 & 130 \\
\hline 5 & 158 & 65 & 800 & 170 \\
\hline 6 & 141 & 60 & 750 & 160 \\
\hline 7 & 177 & 65 & 800 & 170 \\
\hline 8 & 224 & 80 & 1000 & 210 \\
\hline
\end{tabular}

Losses calculated numerically using Eq. (3) and computed using Eq. (4) are compared in Table II. Considering the approximate nature of the $H_{p}$ determination, the agreement is good.

Based on Eq. (2), $J_{c}$ can be estimated from $H_{p}$. This could be useful for new superconductor materials where it is difficult to measure $J_{c}$ directly in wire samples. In this paper, $J_{c}$ is the critical current density for the filaments, not the entire wire. For $H_{0}>H_{\rho}$, Eqs. (4) and (2) give $J_{c}$ in terms of measured loop area $W$ :

$$
J_{c}=3 W / 4 \mu_{0} H_{0} r
$$

\section{COMPARISON OF HYSTERESIS LOOPS}

Although different wires from different manufacturers are listed in the tables, some comparisons may be made. Equations (4) and (2) indicate the well-known fact that hysteresis decreases with decreasing filament radius. This is illustrated in a comparison of the losses in samples 1 and 4. The wires are virtually identical except for filament radius. An extreme case is sample 3, with a large number of very fine filaments. A comparison of samples 4 and 5 shows that conductor geometry (round vs. rectangular cross section) has no significant effect on the loss.

Since magnetization is plotted per unit volume of superconductor $(\mathrm{Nb}-\mathrm{Ti})$ rather than per unit wire volume, the copper-to-superconductor volume ratio is not expected to have a large effect on the magnetization values. A comparison of samples 1 and 2 shows little difference. However, samples 6 and 8 , with similar filament radii, show significant differences in measured losses.
The shapes of the loops are somewhat intriguing. The loops for samples $1,2,3$, and 4 are generally trapezoidal and negatively sloped. Those for samples 5, 6, 7, and 8 are generally hexagonal and more hysteretic. The difference in types is highlighted if the initial branch of each loop is compared to the final branch (see Fig. 1, sample 1). For the hexagonal set, there is an attempt, upon increasing the field from zero, to retrace the peak of the initial branch. These curves most resemble the ideal reversible magnetization curve that is expected from the critical state model.

\section{CONCLUSION}

Measured hysteresis losses for eight multifilamentary $\mathrm{Nb}$ - Ti superconductors were found to be in good agreement with predicted values based on the maximum applied field $H_{0}$ and the full-penetration field $H_{p}$. The latter, a function of critical current density $J_{c}$ and filament radius $r$, was estimated from the hysteresis loop. This estimate of $H_{p}$ can be a convenient method of assessing the critical current density.

\section{ACKNOWLEDGMENT}

This work was sponsored by the Air Force Office of Scientific Research.

${ }^{1}$ W. J. Carr, Jr., IEEE Trans. Magn. MAG-21, 355 (1985).

'W. J. Carr, Jr., AC Loss and Macroscopic Theory of Superconductors (Gor don and Breach, New York, 1983), p. 70. 

MAGNETIC HYSTERESIS AND COMPLEX SUSCEPTIRILITY AS MEASURES OF AC LOSSES IN A MULTIFILAMENTARY NbTI SUPERCONDUCTOR

R. B, Goldfarb and A, F. Clark

F.1ectromagnet1c Technology Division

National Bureau of Standards

Boulder, Colorado 80303

\section{Abatract}

Magnetization and ac susceptibility of a standard NbT 1 superconductor were measured as a function of longltudinal de magnetic field. The ac-field-amplitude and frequency dependences of the complex susceptib1lity are examined. The magnetization is related to the susceptiblity by means of a theoretical derivation based on the fleld dependence of the critical current denaity. Hysteresia losses, obtained directly from dc hyatereals loopa and derived theoretically from ac susceptibility and critical current density, were in reasonable agreement.

\section{Introduction}

When subjected to alternating or translent magnet1c fields, superconducting wires exhibit losses. These may be categorized 1nto hysteres1s losses, eddy-current losses, coupling losses, and self-fleld losses. Bulk hystereals losses are frequency independent and arise mostly from flux pinning in the superconducting filaments. There may be, in addition, hysteretic losses due to pinning at the filament surface. At high frequencles, eddy-current losaes occur within the matrix and on the wire surface (skin effect). Coupling losses in the matrlx, 1mportant over about $1 \mathrm{kHz}$, are caused by the transfer of coupling currents between f1laments. If there is a transport current, matrix eddy-current losses arise from the self fleld.

There are a few general methods of measuring ac loaaes in superconductors. The most drect is calorimetric, In which a superconducting coil is exposed to tranalent flelds and the dissipated heat is measured by the boll-off of liquid hellum. Another method is electrical, by measuring the phase angle between voltage and current. Wattmeters work on this principle.

The final methods are magnet1c. Magnetization meaaurements are possible because magnetic moments are asaoclated with circulating persistent surface currents and, in type-1I superconductors in the mixed state, flux vortices. There are basically two types of magnetic methods. In the first, magnetization (magnet1c moment per unit volume) is measured directly using. for example, a vibrating-sample magnetometer. Though lock-1n detection at the frequency of vibration is used, this is a dc measurement, since the time required to cycle the fleld is on the order of 30 minutes. Measurements may be made while slowly ramping or stepping the fleld. The latter gives more accurate results if there is any imbalance in the pick-up colls.

In the second type of magnetic measurement, a sinuaoldal ac field is applied (sometimes superimposed upon a dc fleld) and the derivative of the magnetization is detected by induction in a plckup coll. If the plckup coll is uncompensated, the induced voltage is proportional to the permeability $\mu$. If the coll is compensated (1.e., zero voltage when no sample is present), the Induced voltage is proportional to the susceptibility $x$. In SI units,

Contribution of the National Bureau of Standards, not subject to copyright.

Manuacript recelved September 10, 1984.

$$
\begin{aligned}
& \mu=\mu^{\prime}-1 \mu^{\prime \prime}=\mu_{0}(1+x)=\mu_{0}\left(1+x^{\prime}-1 x^{\prime \prime}\right), \\
& \mu^{\prime}=\mu_{0}\left(1+x^{\prime}\right), \\
& \mu^{\prime \prime}=\mu_{0} x^{\prime \prime},
\end{aligned}
$$

where single primes indicate the real (dispersive, inductive) components, the double primes indicate the imaginary (absorptive, resistive, loss) components, and $\nu_{0}$ 1s the permeability of free space. The induced voltages may be integrated with respect to fleld (or with respect to time, since fleld is swept as a function of time) to yleld the frequency-dependent magnetization.

The area enclosed by the dc or low-frequency ac hysteresis loop of magnetization vs. fleld is a direct measure of the hysteresis loss. Alternately, the 1maginary component of susceptibility (or permeability) at low frequencles is an indirect measure of the hysteresis loss. This paper will discuss dc hysteres1s loops and complex susceptibllity. The commonly used method of integrated voltages will not be discussed. The conductor carries no transport current.

\section{Experimental Methods}

DC hysteresis loops at about $4.1 \mathrm{~K}$ were obtained using a vibrating-sample magnetometer (VSM). Field values up to $1.6 \mathrm{MA} / \mathrm{m}$ ( $20 \mathrm{kOe}$ ) were determined from the current in a multifllamentary $\mathrm{Nb}-\mathrm{T} 1$ superconducting magnet. No correction was made for trapped flux; zerofleld-value errors are thus estimated to be $\pm 4 \mathrm{kA} / \mathrm{m}$ $(50 \mathrm{Oe})$.

AC susceptioility was measured at $4 \mathrm{~K}$ with a lock-in amplifier and a compensated susceptometer of the type described in Ref. 2. If the Induced waveform is nonsinusoldal, the lock-1n amplifier w1ll detect only the fundamental-frequency component. Losses that appear as harmonics are not jetected. Therefore, this method is most sultable for relatively small ac field amplitudes. For very small ac fleld amplitudes, $x "$ is known to be about zero, and this fact is used to adjust the phase $\phi$ on the lock-1n amplifler:

$$
\begin{aligned}
& x^{\prime}=|x| \cos \phi, \\
& x^{\prime \prime}=|x| \sin \phi .
\end{aligned}
$$

The phase setting was kept constant for all flelds, but was readjusted for each frequency. The background signal in the absence of a sample was subtracted from all measurements. The susceptometer was positioned in the bore of the same superconducting magnet as used with the VSM. Both apparatus were computer controlled. Magnet1zation and susceptibllity accuracles are est1mated to be within $5 \%$.

The sample consisted of an 1nsulated, Nb-T1 wire, cut into 14 straight segments $1.5 \mathrm{~cm}$ long, and bundled together. At low frequencles and for short samples (or short twist pitch), the fllaments may be taken to be uncoupled. The fleld and all measurements were along the longitudinal axis. Before each set of measurements was made, the sample was warmed to above 1 ts critical temperature and then cooled in zero field. Demagnetization-factor corrections were negligible; the internal fleld was taken to be the same a the external applied 
ficld. Magnetization and susceptibility were calculated per volume of superconductor f1laments. Mass and volume measurements were made on a length of the wire, before and after dissolving the $\mathrm{Cu}$ matrix in $\mathrm{HNO}_{3}$, to experimentally determine the filament radius and the volume and density of NbT1. The characteristics of the wire are given in Table I. ${ }^{3}$

\section{AC Fleld Dependence of Complex Susceptiblitity}

The ac susceptibllity of the sample was measured for a few ficld amplitudes and frequencles as the dc blas field was stepped. Figures la-e show a comparison of the results. Only three branches are shown for each case to avold redundancy. The shapes of the $x^{\prime}$ and $x^{\prime \prime}$ curves are dependent upon both field amplitude and frequency. The frequency dependence 1s small, which is evidence that hysteresis is the mafor loss mechanism. For the smaller fleld amplitudes there are large differences between ascending and descending branches, and the branches are not symetrical for positive and negative external dc flelds (F1gs. la-c). These effects may be attributed to relatively large filamentsurface lossea when the ac fleld 1s small. Bualere and $\mathrm{Clem}^{4}$ discuss the applicable case when losses are assoclated with the bending of vortices trapped at a high angle to the surface, and the fleld is much less than the lower critical fleld $\mathrm{H}_{\mathrm{cl}}$. Short samples facilitate this effect.
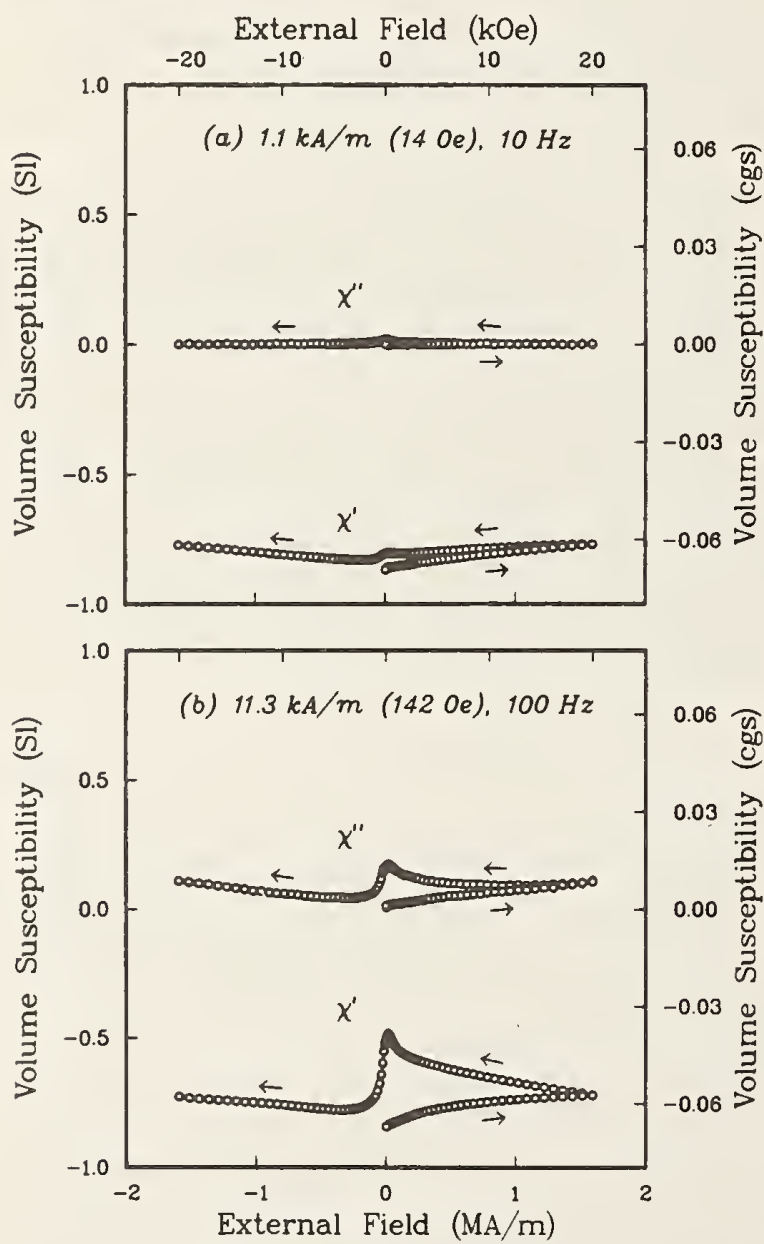

Table I. Characteristics of NBS SRM 1457

Number of fllamenta: 180

F1lament radius: $12.20 \mu \mathrm{m}$

Copper-to-NbTi volume rat1o: 1.456

Density of NbT1 aljoy: $6.004 \mathrm{~g} / \mathrm{cm}^{3}$

NbT1-to-1nsulated-wire mass rat10: 0.3025
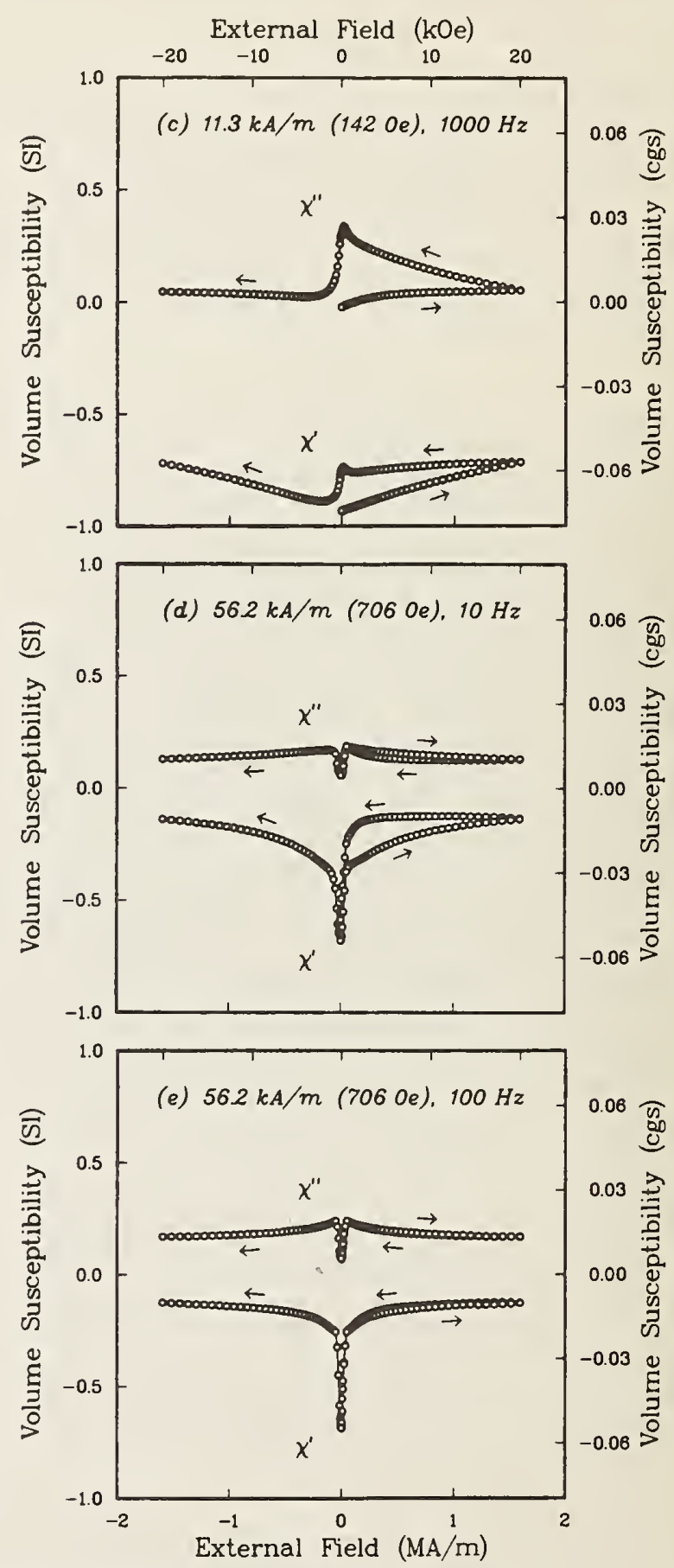

Figure 1. Imaginary $\left(x^{\prime \prime}\right)$ and real $\left(x^{\prime}\right)$ components of ac susceptibility aa a function of applied longltudinal dc fleld at $4 \mathrm{~K}$. AC fleld amplitudea and frequencles are shown.

Erratum: Page 333, first column, next-to-last sentence: "field" should be "ac field" 


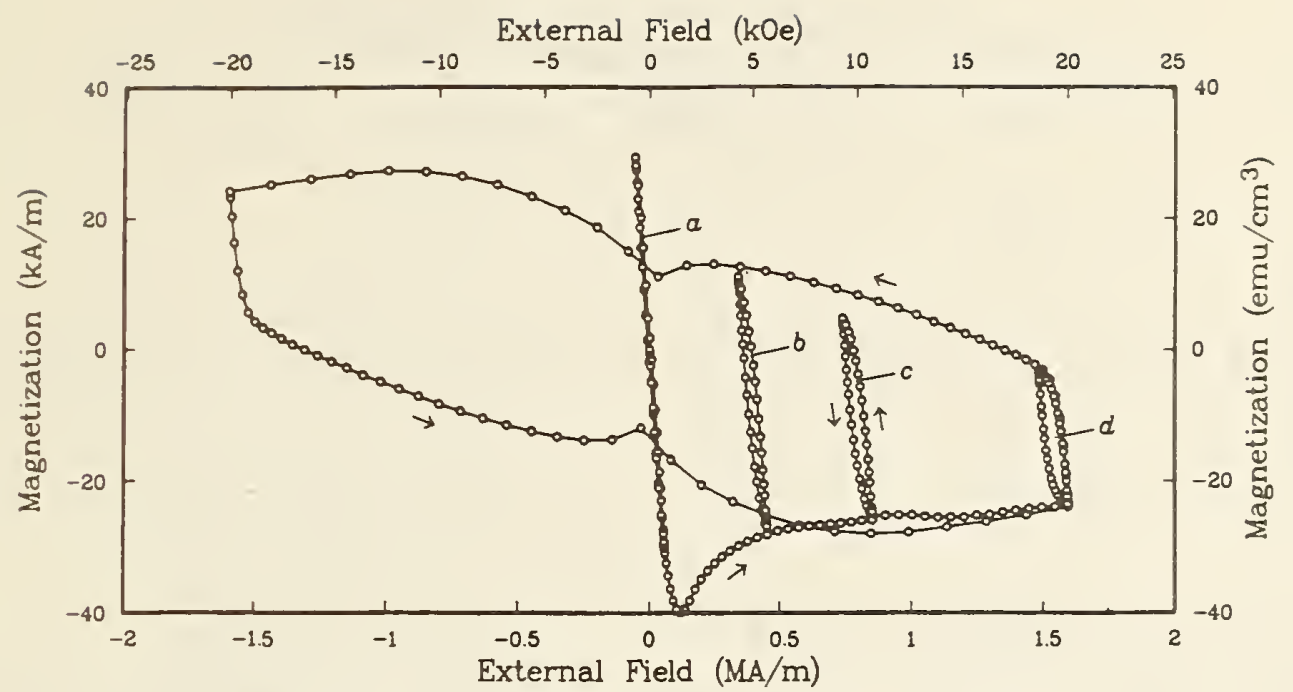

Figure 2. Magnetization $M$ v8. de fleld H at 4.1 R obtained with a vSM. The initial branch for zero trapped flux and four minor loops (a-d) are shown.

\section{Theoretical Derivation of Complex Susceptib111ty}

The following theoretical description of complex susceptibllity is based on the development by clem for the case of bulk-pinning hysteret1c losses in type-II superconductors. 5 The model applies when the ac field amplitude $1 \mathrm{~s}$ small and the fleld equations can be

linearlzed. It w11l be shown that the dc hysteresis loop and the fleld dependence of the critical current density are predictive of the ac susceptibility.

The critical current as a function of transverse fleld $d^{6}$ for the sample was converted to critical current density $J$ using the total superconductor crosssectional ${ }^{c}$ area (not including matrix material). A good fit was obtained to the $\mathrm{K} 1 \mathrm{~m}$ equation,

$$
J_{c}(H)=J_{c}(0) /\left(1+H / H_{0}\right) \text {, }
$$

for fields H up to $4.8 \mathrm{MA} / \mathrm{m}(60 \mathrm{kOe})$. The sdjustable parameters $J_{(}(0)$ and $H_{0}$ were found to be $9.2 \mathrm{GA} / \mathrm{m}^{2}$ snd 1. $1 \mathrm{MA} / \mathrm{m}\left(14^{\mathrm{C}} \mathrm{kOe}\right)$, respectively. While the longleudinal-field $J$ 18 larger than the transverse-field $\mathrm{J}$, they are, of course, Identical at zero field. C The full-penetrstion longltudinal field $\mathrm{H}_{1 \mathrm{~s}}$ a function of $H$ owing to the field dependence of $J_{c}$ :

$$
H_{P}(H)=J_{C}{ }^{r},
$$

where $t$ is the filament radius. It 18 useful to define a parameter $x$ as

$$
x(H)=h / H_{p}=h / J_{c} r,
$$

where $h$ is the peak amplitude of the ac field that is superimposed upon $\mathrm{H}$.

As shown by $\mathrm{Clew}$. snd using Eqs. 1, the complex susceptibllity may be expressed in terms of an 1dealized differential susceptibility for type-II superconductors $x_{r e v}$ :

$$
\begin{aligned}
& x^{\prime}=\left(1+x_{\text {rev }}\right) 8_{1}(x)-1, \\
& x^{\prime \prime}=\left(1+x_{r e v}\right) 8_{2}(x),
\end{aligned}
$$

where

$$
x_{r e v}=d M_{r e v} / d H
$$

where $M_{\text {rev }} 18$ the reversible magnetization, and

$$
8_{1}(x)=x-5 x^{2} / 16, \quad 0<x<1,
$$

$8_{1}(x)=\left[\left(-1+x-5 x^{2} / 16\right) \theta+\left(-4 / 3 x+2-7 x / 4+13 x^{2} / 24\right) \sin \theta\right.$

$$
\begin{aligned}
& +\left(-1 / 2+x / 2-x^{2} / 6\right) \sin 2 \theta+\left(-x / 12+x^{2} / 24\right) \sin 3 \theta \\
& \left.+\left(-x^{2} / 192\right) \sin 4 \theta\right] / \pi+1, \quad x>1,
\end{aligned}
$$

where $\theta(x)=2 \sin ^{-1}\left(x^{-\frac{1}{2}}\right), \theta(1)=\pi, \theta(\infty)=0$, and

$$
\begin{aligned}
& g_{2}(x)=\left(4 x-2 x^{2}\right) / 3 \pi, \quad 0<x<1, \\
& g_{2}(x)=\left(4 / x-2 / x^{2}\right) / 3 \pi, \quad x>1 .
\end{aligned}
$$

Using Eq5. 6 and 7, $x^{\prime}$ and $x^{\prime \prime}$ will be calculated for the sample. The major hysteresis loop for the sample 1s shown in F1g. 2. The lower critical field $\mathrm{H}_{\mathrm{Cl}}$ is

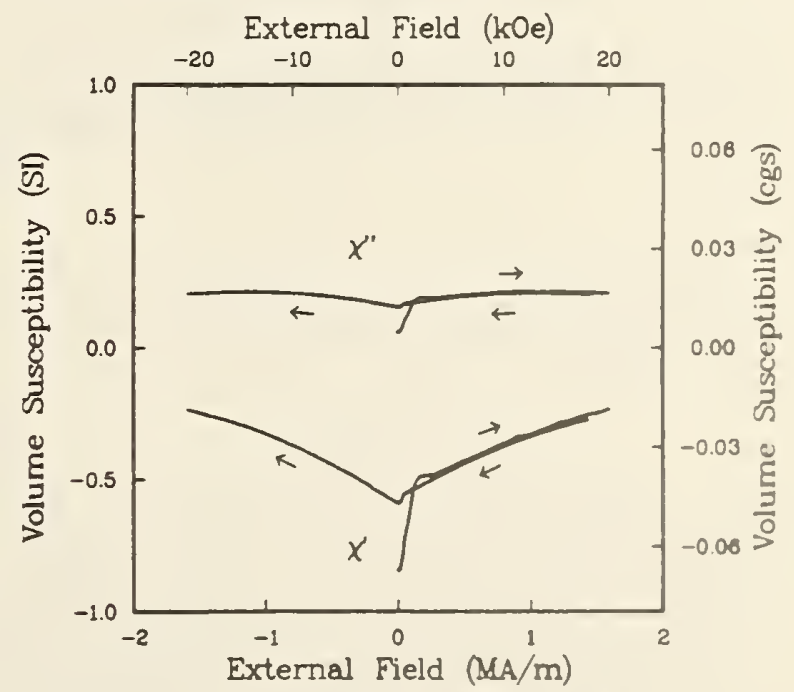

P1gure 3. Imaginary $\left(x^{\prime \prime}\right)$ and real $\left(x^{\prime}\right)$ cooponents of ac susceptibllity calculated for an ac fleld aplicude of $56.2 \mathrm{kA} / \mathrm{m}(706 \mathrm{Oe})$ using the theoretical model. the data in F1g. 2, and the field dependence of $\mathrm{J}_{\mathrm{C}}$ (Eq. 3 ). 
Table II. Comparison of hysteretic losses obtained by $\mathrm{dc}$ and ac methods for a field amplitude of $56.2 \mathrm{kA} / \mathrm{m}$ (706 Oe).

\begin{tabular}{|c|c|c|c|c|}
\hline $\begin{array}{l}\text { Center } \\
(\mathrm{kA} / \mathrm{m})\end{array}$ & $\begin{array}{l}\text { fleld } \\
(\mathrm{kOe})\end{array}$ & $\begin{array}{l}\text { Loss from minor- } \\
\text { loop area }\left(\mathrm{kJ} / \mathrm{m}^{3}\right)\end{array}$ & $\begin{array}{l}\text { Loss from } x^{\prime \prime} \\
\mathrm{Eq} .11\left(\mathrm{~kJ} / \mathrm{m}^{3}\right) \\
\end{array}$ & $\begin{array}{l}\text { Loss from Eqs. } \\
12,13\left(\mathrm{~kJ} / \mathrm{m}^{3}\right)\end{array}$ \\
\hline 0 & 0 & 0.6 & 0.7 & 0.9 \\
\hline 400 & 5.0 & 1.3 & 2.0 & 2.1 \\
\hline 800 & 10.0 & 1.4 & 1.8 & 2.6 \\
\hline 1540 & 19.3 & 1.3 & 1.6 & 2.6 \\
\hline
\end{tabular}

about $0.12 \mathrm{MA} / \mathrm{m}(1.5 \mathrm{kOe})$. The tangent to the curve at any $H$ is the differential susceptibility $x_{d c^{*}}$ As an approximation, $x_{d}$ will be used for $x_{\text {. }}$. ${ }^{2}$ This 1 somewhat reasonable ${ }^{\mathrm{dc}}$ for the initial branch of the hysteresis loop, but rather unreasonable for the later irreversible branches. However, theoretical $x_{\text {and }}$ and experimental $x_{\text {dc }}$ are both about zero for field sev much larger than $\mathrm{H}_{\mathrm{cl}}$ and therefore do not greatly affect the computation.

A program was written to compute, for each value of

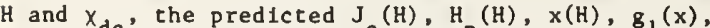
$g_{2}(x),{ }^{d} c^{\prime}(x)$, and $x^{\prime \prime}(x), g^{c}$ iven $r^{p}$ and $h$. For $h^{1}=56.2$ $\mathrm{kA} / \mathrm{m}(706 \mathrm{Oe}), x^{\prime}$ and $x^{\prime \prime}$ as computed are ploted as a function of $\mathrm{H}$ in Fig. 3. As in Fig. 1, only the first three branches are shown. No adjustable parameters were used. A comparison with actual measured $x^{\prime}$ and $x^{\prime \prime}$ in Figs. 1d,e shows good agreement in both shape and magnitude. Ideally, the computed curves in Fig. 3 would be symmetrical with respect to the external dc fleld and show no difference between the initial segment and the return portion, as expected from critical state theory. ${ }^{5}$ Deviations from this are because $x_{\mathrm{dc}}$ was used Instead of $x_{\text {rev }}$.

\section{Hysteres1s Loss}

In this section, the minor loops in Fig. 2 are examined. The loss corresponding to each is calculated in three ways: minor-loop area, from $\chi^{\prime \prime}$, and from $J$.

The energy loss per unte volume per cycle $1 \mathrm{~s}^{5}$

$$
w=\pi \mu_{0} h^{2} x^{\prime \prime} .
$$

Substituting for $x^{\prime \prime}$ using Eqs. $7,10 \mathrm{~b}$, and 5 for full fleld penetration ( $x>1)$,

$$
W=\left(1+x_{r e v}\right)\left(4 \mu_{0} h J_{c} r / 3\right)\left(1-J_{c} r / 2 h\right) .
$$

Except for the factor $(1+x \ldots y)$, the same equation is derived, in cgs emu, by Carr. 7 But for $H \gg H$ $\cong 0$. For partial fleld penetration $(x<1)$, using Eqs. 7, 10a, and 5, Eq. 11 may be expressed as

$$
w=\left(1+x_{r e v}\right)\left(4 \mu_{0} h^{3} / 3 J_{c} r\right)\left(1-h / 2 J_{c} r\right),
$$

again similar to Carr's expression for this case.

Figure 2 shows four minor dc hysteresis loops for the sample determined experimentally with the VSM. The peak amplitude for each minor loop is $56.2 \mathrm{kA} / \mathrm{m}$ (706 $0 e)$. The area enclosed by each loop was calculated numertcally by

$$
W=\mu_{0} \oint_{H d M} \approx \mu_{0} \oint M d H .
$$

This hysteresis loss is compared in Table II to the losses derived from Eq. 11 , using $x^{\prime \prime}$ measured at $10 \mathrm{~Hz}$ in $56.2 \mathrm{kA} / \mathrm{m}$ (706 Oe) peak fleld (Fig. 1d). Another comparison can be made with losses obtained using Eqs. 12 and 13, with J (at the center fleld) from Eq. 3 . For the first minor loop, $x<1$. Once again, $x_{\text {re }}$ is approximated by $x_{d c}$ from the initial branch of rev the hysteres1s loop. ${ }^{2}$ The agreement is reasonable, indicating that hysteretic lossea may be measured directly with a hysteresis loop, or estimated by measurement of the Imaginary component of low-frequency ac susceptibility, or from a reasonable estimate of $J_{C}(H)$.
Possible Inaccuractes owing to the following should be considered: (1) I $(\mathrm{H})$ was measured in transverse rather than longltudinal field; (2) losses are not entrely hysteretic; (3) Induced voltage in susceptometer plckup coll contalns higher-order harmonics; (4) applied ac fleld amplitude was not small enough to allow 11nearizet fleld equations. Only the first of these is belleved to be of significance, affecting the data in the last column of Table II.

\section{Conclusion}

The technique used to measure hyateretic loases might depend on one's application. If a fleld is stepped slowly, a dc hysteresis loop is obtained. If an alternating fleld is swept and the induced voltage integrated, an ac hysteresis loop may be obtalned. For the general case, a dc blas fleld may be superimposed upon the stepped or alternating field. If the induced voltage is not integrated, but separated into real and 1maginary parts, the cortelex suscept1bility is obtained. Of ten, an ac susceptibility measurement is a conventent method. In this paper, it was shown that the complex susceptibility in an ac field could be reasonably predicted from the dc hysceresis loop, the critical current density, and the f1lament radius. Hysteresis losses obtalned directly (Eq. 14) were compared to those obtained indirectly using experimental measurements of $x^{\prime \prime}$ (Eq. 11) and average values of $J_{c}$ and $x_{d c}$ (Eqs. 12 and 13).

\section{Acknowledgments}

The authors are grateful to J. R. Clem for critical comments on an earller draft of the manuscript. Th1a work was sponsored by the Alr Force Office of Sclentific Research.

\section{References and Footnotea}

1. W. A. Fletz, "Electronic Integration Technique for Measuring Magnetization of Hysteretic SuperconductIng Materials," Rev. Sc1. Instrum. 36, Pp. 1621-26 (1965).

2. R. B. Goldfarb and J. V. Minervini, "Calibration of AC Susceptometer for Cylindrical Specimens," Rev. Sc1. Instrum. 55, pp. 761-64 (1984).

3. NbTi wire, Standard Reference Material 1457 for critical current measurements, avallable from Office of Standard Reference Materials, National Bureau of Standards, Galthersburg, MD 20599. The data on this wire in Table I are not certifled by NBS.

4. J. F. Bussiere and J. R. Clem, "Effect of trapped magnetic flux on ac losses of Nb $\mathrm{Sn}$," IEEE Trana. Magn. MAG-15, PP. 264-67 (1979). ${ }^{3}$

5. J. R. Clem, "AC Losses in Type-II Superconductors," Ames Lab. Tech. Rept. IS-M 280, 1979.

6. Critical current was measured at $4 \mathrm{~K}$ by L. F. Goodrich using a transport current technique with a $0.2 \mu \mathrm{V} / \mathrm{cm}$ criterion. The self-fleld contribution was not included. The demagnetization field, which would correct values of applied fleld, is about $0.6 \%$ at $1.6 \mathrm{MA} / \mathrm{m}(20 \mathrm{kOe})$ and $0.2 \%$ at $4.8 \mathrm{MA} / \mathrm{m}(60 \mathrm{kOe})$.

7. W. J. Carr, Jr., AC Loss and Macroscoplc Theory of Supercorductors, New York: Gordon and Breach, 1983, p. 70. 
International Cryogenic Materials Conference - ICMC

Cambridge, Massachusetts - August 1985

Paper DZ-8

To be published in:

"Advances in Cryogenic Engineering (Materials)"

Vol. 32, R. P. Reed and A. F. Clark, eds.

Plenum Press, New York (1986)

AC LOSSES IN Nb-T1 MEASURED BY MAGNETIZATION AND COMPLEX SUSCEPTIBILITY

R. B. Goldfarb and A, F. Clark

Electromagnetic Technology Division

National Bureau of Standards

Boulder, Colorado

ABSTRACT

DC magnetization and complex ac susceptibility were measured at $4 \mathrm{~K}$ as functions of longltudinal dc field for a multifilamentary Nb-TI superconductor with no transport current. Minor hysteresis loops were obtained In the dc measurements. The full-penetration fleld, $H$, a function of applied fleld, H, was deduced directly for each minor 1 bop. The values for $H$ were fit to the Kim-type equation, $H_{(}(H)=H_{p}(0) /\left(1+H_{1} / H_{k}\right)$, where $H_{1}(0)$ ahd $\mathrm{H}_{4}$ are constants. The minor hysteresis-loop areas gave losses that were In excellent agreement with Carr's theoretical critical-state equation, $W=\left(4 \mu_{0} \mathrm{H}_{0} \mathrm{H}_{\mathrm{p}} / 3\right)\left(1-\mathrm{H}_{\mathrm{p}} / 2 \mathrm{H}_{0}\right)$, where $\mathrm{H}_{0}$ is the maximum applied field for each loop.

An expression was obtained for the ideal reversible differential susceptibllity: $\chi_{\text {rev }}=\phi_{0} / 8 \pi \mu_{0}\left(\mathrm{H}-\mathrm{H}_{\mathrm{cl}}\right) \lambda^{2}$, where $\phi_{0}$ is the flux quantum, $\mathrm{H}_{\mathrm{cl}}$ is the lower critical fleld, and $\lambda^{c}$ ss the penetration depth. $H_{c}$ and $\lambda$ Clem's theoretical expressions for the real $\left(x^{\prime}\right)$ and imaginary $\left(x^{\prime \prime}\right)$ components of ac susceptibility are functions of $\chi_{\text {rev }} H_{p}$, and ac fleld amplitude, $h$. The predicted susceptibllities based on the expressions were in good agreement with measured curves of $\chi^{\prime}$ and $\chi^{\prime \prime}$ as functions of $h$ and $\mathrm{H}$. The measured $X^{\prime}$ and $\chi^{\prime \prime}$ were independent of frequency up to $1 \mathrm{kHz}$, as expected when bulk hysteresis is the primary loss mechanism.

\section{INTRODUCTION}

In an earlier work ${ }^{1}$ we discussed the relationshlp between dc magnetization and ac susceptibility in a type-II superconductor. That work described how magnetic measurements provide information on hysteresis losses. In this paper, as in Ref. 1, we examine magnetization and susceptibility for longltudinal flelds and no transport current. Here, however, we obtain the full-penetration flelds, H, directly from the hysteresis loops rather than estimate $\mathrm{H}$ from measuremefis of critical current density, $J_{c} \cdot$ Also, we derive an expression for the reversible susceptibility, $x_{\text {cey }}$, rather than using the experimental susceptibility, $x_{d c}$, as an approximation. A superconducting wire whose low-field magnetization approached a reversible curve was selected for study. ${ }^{2}$ Several minor hysteresis loops were obtained in addition to the major loop. The susceptibility curves were more nearly reversible and virtually independent of frequency, as expected from theory. 


Cross section bare wire: $0.63 \times 0.88 \mathrm{~mm}$
Twist length: $1.7 \mathrm{~cm}$
Cu/Nb-T1 volume ratio: 0.91
Number of fllaments: 240.
Filament radius: $19.3 \mu \mathrm{m}$
Density of Nb-T1 alloy: $6.20 \mathrm{~g} / \mathrm{cm}^{3}$

\section{EXP ER IMENT}

The magnetization measurements were made with a vibrating-sample magnetometer (VSM) at $4 \mathrm{~K}$. Magnetization was computed as magnetic moment per unit volume of $\mathrm{Nb}-\mathrm{T} 1$. The volume of the $\mathrm{Cu}$ matrix was not included.

It is useful to compare the advantages of the VSM method vis-à-vis the popular integration method of Fletz. ${ }^{3}$ The VSM method (1) is useful for small samples, (2) Is a dc measurement, not sensitive to coupling losses, (3) does not require preclse pick-up coll balance when the applied field is stepped, and (4) is not subject to integrator drift. The integration method (1) measures frequency dependences, (2) detects flux jumps, and (3) Is easily adaptable to measurements with transport current.

The experimental methods are more fully described in Ref. 1. The sample in this study is different and its length is 3.0 rather than $1.5 \mathrm{~cm}$. The purpose of a longer sample was to avold significant end effects. The characteristics of the wire are given in Table 1 . This is the same wire as sample 8 in Ref. 2 .

\section{HYSTERESIS LOOP}

\section{Full-Penetration Field}

The major and minor hysteresis loops are shown in Fig. 1. The fullpenetration fleld, $H$, a function of applied fleld, $H$, may be estimated directly for each mifor loop. ${ }^{2}$ As the loops are traversed, the filaments go from full penetration in one direction to full penetration in the other direction. Therefore, at a high-fleld end of a loop, $H$ is approximately one-half the fleld required to reverse the magnetizatioh. The reversal fleld, $2 \mathrm{H}_{\mathrm{p}}$, for the major loop is shown in FIg. 1 .

The well-known K1m model for critical current density is ${ }^{4}$

$$
J_{c}(H)=J_{c}(0) /\left(1+H / H_{k}\right) \text {, }
$$

where $J_{c}(0)$ and $H_{k}$ are constants. In the critical-state model, for a fleld applied ${ }^{c}$ axlally,

$$
\mathrm{H}_{\mathrm{p}}=\mathrm{J}_{\mathrm{c}} \mathrm{r} \text {, }
$$

where $r$ is the fllament radius. We did a linear least-squares fit of each loop's $H_{p}$ to the expression

$$
\mathrm{H}_{\mathrm{p}}(\mathrm{H})=\mathrm{H}_{\mathrm{p}}(0) /\left(1+\mathrm{H} / \mathrm{H}_{\mathrm{k}}\right) \text {, }
$$

where $H(0)$ is a constant equal to $J(0) r$. The fit was excellent. We obtained $\mathrm{P}_{\mathrm{H}}(0)=140 \mathrm{kA} / \mathrm{m}(1.76 \mathrm{kOe})$ and $\mathrm{H}_{\mathrm{k}}=1.33 \mathrm{MA} / \mathrm{m}(16.7 \mathrm{kOe})$. 


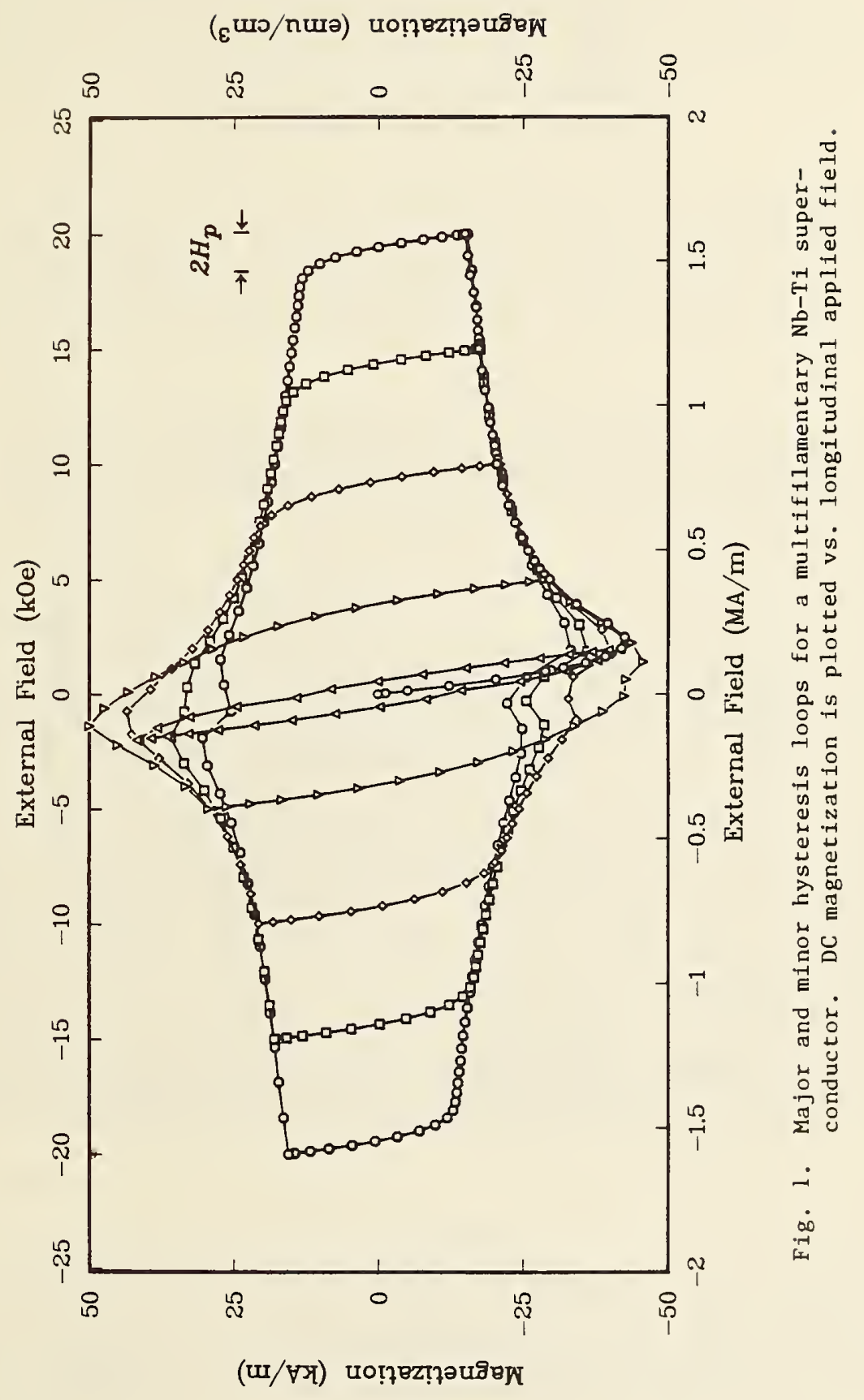


Table 2. Comparison of Losses Obtained from Eq. 4 and Loop Area.

\begin{tabular}{rrrr}
\hline${ }_{0}^{\mathrm{H}_{0}}$ & ${ }_{(\mathrm{kA} / \mathrm{m})}{ }^{\mathrm{H}} \mathrm{Eq} \cdot{ }^{4}$ & Area \\
\hline 1591 & 63 & 165 & 159 \\
1194 & 74 & 143 & 136 \\
796 & 87 & 110 & 105 \\
398 & 108 & 62 & 58 \\
\hline
\end{tabular}

\section{Hysteres1s Loss}

For the case when the peak applied fleld, $\mathrm{H}_{0}$, is greater than $\mathrm{H}_{\mathrm{p}}$, Carr derived an expression for the loss, assuming $J$ to be spatially constant

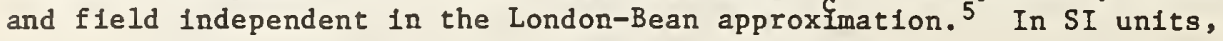

$$
W=\left(4 \mu_{0} \mathrm{H}_{0} \mathrm{H}_{\mathrm{p}} / 3\right)\left(1-\mathrm{H}_{\mathrm{p}} / 2 \mathrm{H}_{0}\right) \text {. }
$$

Clearly $\mathrm{H}_{0}$ is much larger than $\mathrm{H}_{\text {for }}$ for the loops in Fig. 1. Losses calculated by numerically integrating ${ }^{\mathrm{P}}$ the loops are compared in Table 2 to losses obtalned from Eq. 4. They agree to within $6 \%$.

\section{REVERSIBLE SUSCEPTIBILITY $x_{\text {rev }}$}

An exact equation for the 1deal, reversible magnetization-versus-field curve of a type-II superconductor, $\mathrm{H}>\mathrm{H}$, is not obtainable in analytic form. The usual procedure is to divide the fleld into three regions: 1mmediately above $\mathrm{H}_{\mathrm{cl}}\left(\mathrm{H}_{\mathrm{cl}} \lesssim \mathrm{H}\right)$, the middle region $\left(\mathrm{H}_{\mathrm{cl}}<\mathrm{H}<\mathrm{H}_{\mathrm{c} 2}\right)$, and

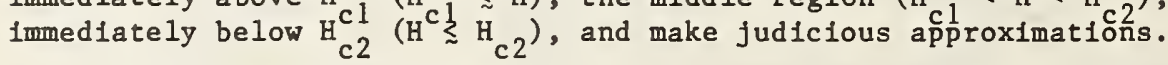

One tractable case is $\mathrm{H}<\mathrm{H}<\mathrm{H}$, when the separation between flux vortices is larger than the coherence fength, $\xi$, but much smaller than the penetration depth, $\lambda$. Thus the Ginzburg-Landau parameter $\kappa \equiv \lambda / \xi$ is much greater than 1. For $\mathrm{Nb}-\mathrm{T} 1$ at $4 \mathrm{~K},{ }^{6} \lambda \cong 394 \mathrm{~nm}$ and $\xi \cong 5 \mathrm{~nm}$, and this case is applicable. To first order, the magnetization as a function of magnetic field strength $M(H){ }^{7}{ }^{7}$

$$
M=\left(\phi_{0} / 8 \pi \mu_{0} \lambda^{2}\right)\left\{\ln \left[4 \pi \mu_{0}\left(H-H_{c 1}\right) \lambda^{2} / \phi_{0}\right]+\alpha\right\}-H_{c l},
$$

where $\phi_{0}$ is the magnetic flux quantum $=\mathrm{h} / 2 \mathrm{e}=2.068 \times 10^{-15} \mathrm{~Wb}\left(\mathrm{~T} \cdot \mathrm{m}^{2}\right)$ and $\alpha$ is a constant on the order of unity. The functional dependence of $M(H)$ can be seen by dropping the $\alpha$ term and using the relationship ${ }^{8}$

$$
\mathrm{H}_{\mathrm{cl}}=\left(\phi_{0} / 4 \pi \mu_{0} \lambda^{2}\right) \ln (\lambda / \xi) \text {. }
$$

Thus,

$$
M=-\left(\phi_{0} / 8 \pi \mu_{0} \lambda^{2}\right) \ln \left[\phi_{0} / 4 \pi \mu_{0}\left(H-H_{c l}\right) \xi^{2}\right] .
$$

The volume magnetic susceptibility $X=\mathrm{dM} / \mathrm{dH}$ can be obtained from either Eq. 5 or 7 and is simply

$$
X=\phi_{0} / 8 \pi \mu_{0}\left(H-H_{c 1}\right) \lambda^{2} \text {. }
$$

We take this $x$ to be equal to the ideal reversible susceptibility $x_{\text {rey }}$ in

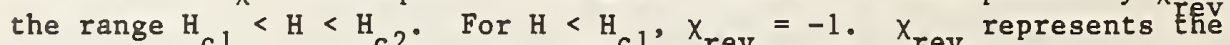
susceptibilfty under conditions of Ehermodynamic equilibrium. 
Our goal is to obtain numerical values for $x_{\text {fey }}$ for our wire. The differential slope of the third-quadrant branch of the major magnetization curve (F1g. 1), from 0.2 to $1.6 \mathrm{MA} / \mathrm{m}(2.5$ to $20 \mathrm{kOe})$, was f1t to Eq. 8 using linear least squares. While this portion of the magnetization curve itself is not reversible, we expect that 1 ts slope w111 simulate $\chi_{\text {rey }}$. For the adjustable parameters $\mathrm{H}_{\mathrm{cl}}$ and $\lambda$, we obta1n $92 \mathrm{kA} / \mathrm{m}(1 \mathrm{kOe})$ and $98 \mathrm{~nm}$, respectively. These values are not too unreasonable, though this fit risks overestimating $\mathrm{H}$ with values closer to $\mathrm{H}_{\mathrm{f}}(0)$. Substituting into Eq. 8 we get $x_{\text {rev }}$ for Ehis wire for $\mathrm{H}_{\mathrm{cl}}<\mathrm{H}<\mathrm{H}_{\mathrm{c} 2}$ (SI units):

$$
x_{\text {rev }}=10772 /(\mathrm{H}-91751) \text {. }
$$

This equation w1ll be used in the next section to calculate $\chi^{\prime}$ and $\chi^{\prime \prime}$. An alternate approach would be to use textbook values of $H$ and $\lambda$ in Eq. 8.9 This would give slightly different values of $\chi^{\prime}$ and $\chi^{\prime \prime}$ for $\mathrm{H} Z \mathrm{H}_{\mathrm{cl}}$. For larger flelds, the differences are negligible.

MEASURED AND IDEAL $\chi^{\prime}$ AND $\chi^{\prime \prime}$

The real and 1maginary components of susceptibility, $\chi^{\prime}$ and $\chi^{\prime \prime}$, were measured as functions of frequency $(10,100$ and $1000 \mathrm{~Hz})$, sinusoldal ac fleld amplitude, $h$ [ 11 and $56 \mathrm{kA} / \mathrm{m}$ (140 and $700 \mathrm{Oe})]$, and $\mathrm{dc}$ blas fleld, $\mathrm{H}$ $[0-1.6 \mathrm{MA} / \mathrm{m}(0-20 \mathrm{kOe})]$. The susceptibllitles were independent of frequency to within $3 \%$. Since $\chi^{\prime \prime}$ is a measure of the losses and hysteresis is known to be frequency independent, bulk hysteresis is probably the primary loss mechan1sm. Frequency-dependent eddy-current and coupling losses are 11kely insignificant for this sample.

Figures 2 and 3 show $\chi^{\prime}$ and $\chi^{\prime \prime}$ measured at $10 \mathrm{~Hz}$. The initial and decreasing-field branches are plotted. Some irreversibility may be seen. In Fig. 3, h $1 \mathrm{~s}$ on the order of $\mathrm{H}^{\prime}$. As shown by $\mathrm{Clem}, 10 \chi^{\prime}$ and $\chi^{\prime \prime}$ as functions of $\mathrm{H}$ may be predicted ffom $\mathrm{h}, \mathrm{H}_{\mathrm{p}}$, and $\chi_{\mathrm{rev}}$. For our cases, $h<H_{p}$, the equations are: 1,10

$$
\begin{aligned}
& \chi^{\prime}=\left(1+\chi_{\text {rev }}\right)\left(h_{\mathrm{H}_{\mathrm{p}}}-5 \mathrm{~h}^{2} / 16 \mathrm{H}_{\mathrm{p}}{ }^{2}\right)-1, \\
& \chi^{\prime \prime}=\left(1+\chi_{\mathrm{rev}}\right)\left(4 \mathrm{~h} / \mathrm{H}_{\mathrm{p}}-2 \mathrm{~h}^{2} / \mathrm{H}_{\mathrm{p}}{ }^{2}\right) / 3 \pi .
\end{aligned}
$$

Using the expressions for $H_{\text {and }} \chi_{\text {rey }}$ (Eqs. 3 and 9), we computed the theoretical curves of $\chi^{\prime}$ and $\chi^{\prime \prime} \mathrm{fBr}_{\mathrm{r}}$ this wire for ac fleld amplitudes of 11 and $56 \mathrm{kA} / \mathrm{m}$ ( 140 and $700 \mathrm{Oe}$ ). They are shown in F1gs. 4 and 5 . They compare quite favorably with the actual curves in Figs. 2 and 3 . For $H<H$, $X^{\prime}=-1$ and $X^{\prime \prime}=0$. There are discontinulties at $H^{\prime}$, as expected. In Ehe actual curves these are rounded owing to flux pinning.

\section{CONCLUSION}

DC magnetization curves and measurements of complex susceptibility provide information on hysteretic losses in multifllamentary superconductors such as Nb-T1. These measurements may be performed on small samples. Interpretation of the data ylelds information on full-penetration field, critical current density, lower critical fleld, and penetration depth. The frequency independence of susceptibility suggests bulk hysteresis as the primary loss mechanism.

\section{ACKNOWL EDGMENT}

Th1s work was sponsored by the Alr Force Office of Sclentific Research. 


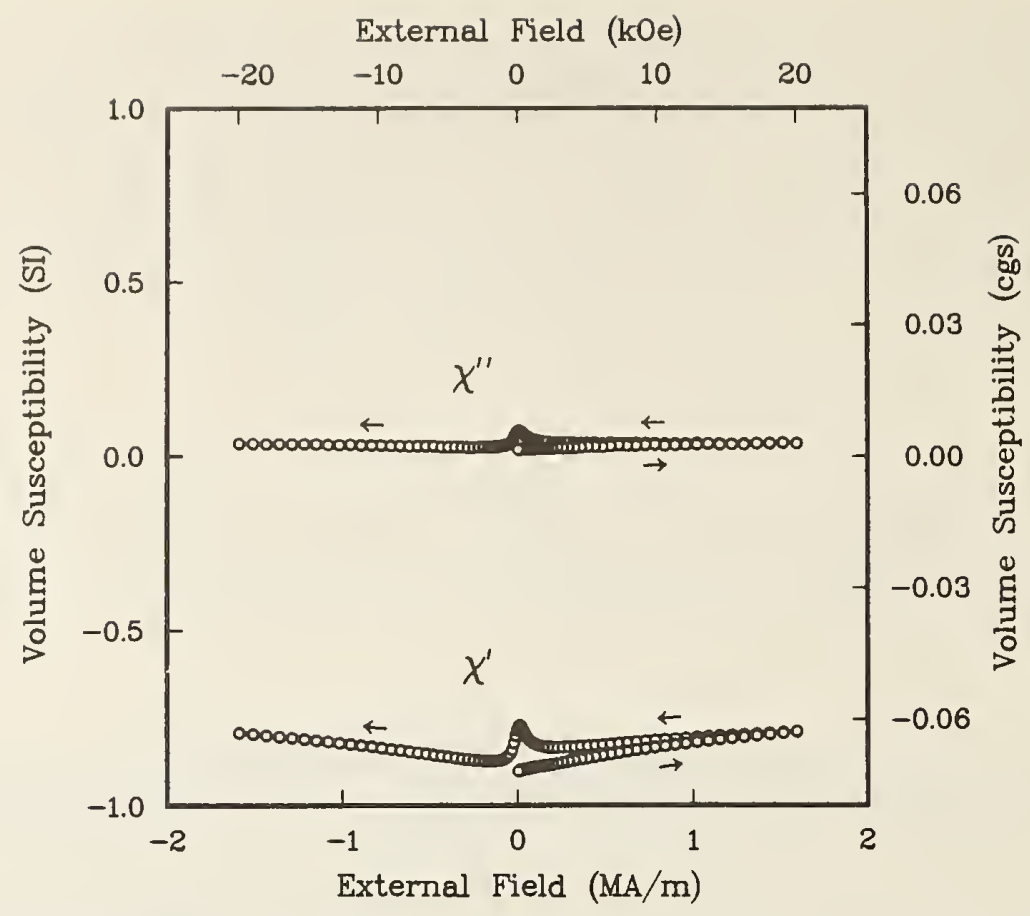

Fig. 2. Complex ac susceptibility as a function of dc bias field. The ac field amplitude is $11 \mathrm{kA} / \mathrm{m}(140 \mathrm{Oe})$ at $10 \mathrm{~Hz}$.

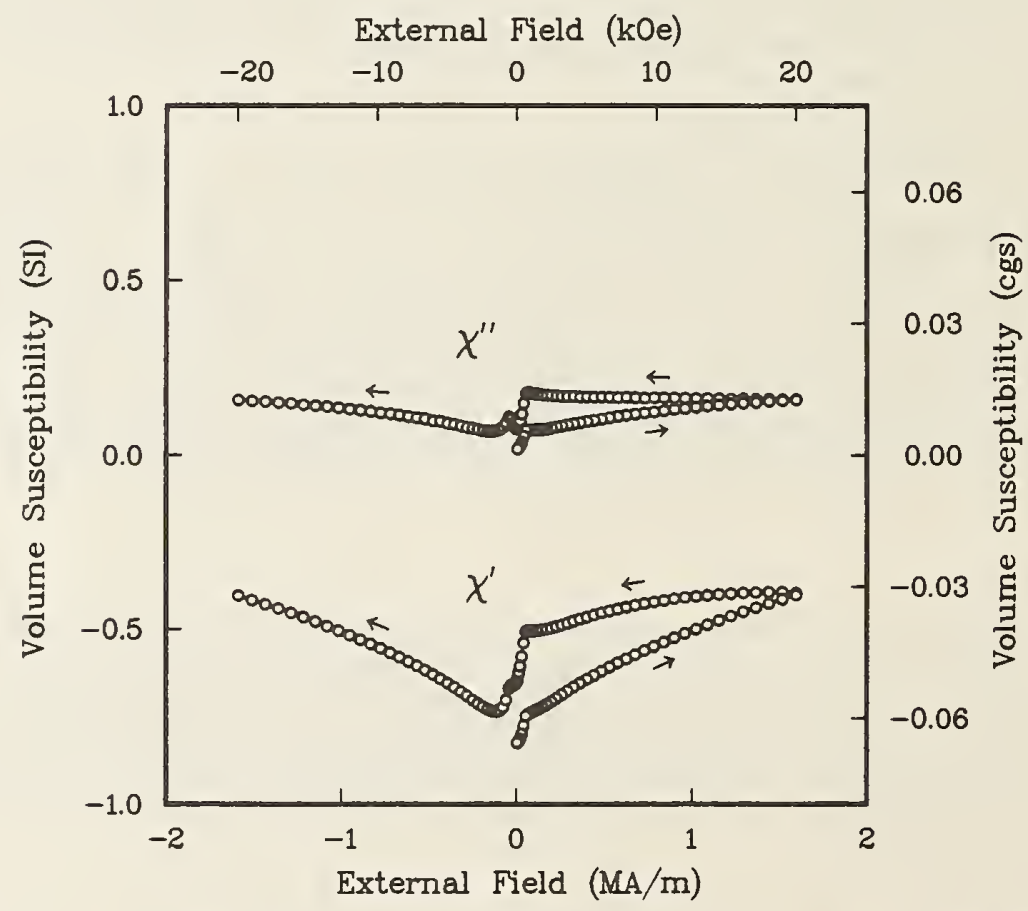

Fig. 3. Complex ac susceptibility as a function of dc bias field. The ac field amplitude is $56 \mathrm{kA} / \mathrm{m}$ (700 0e) at $10 \mathrm{~Hz}$. 


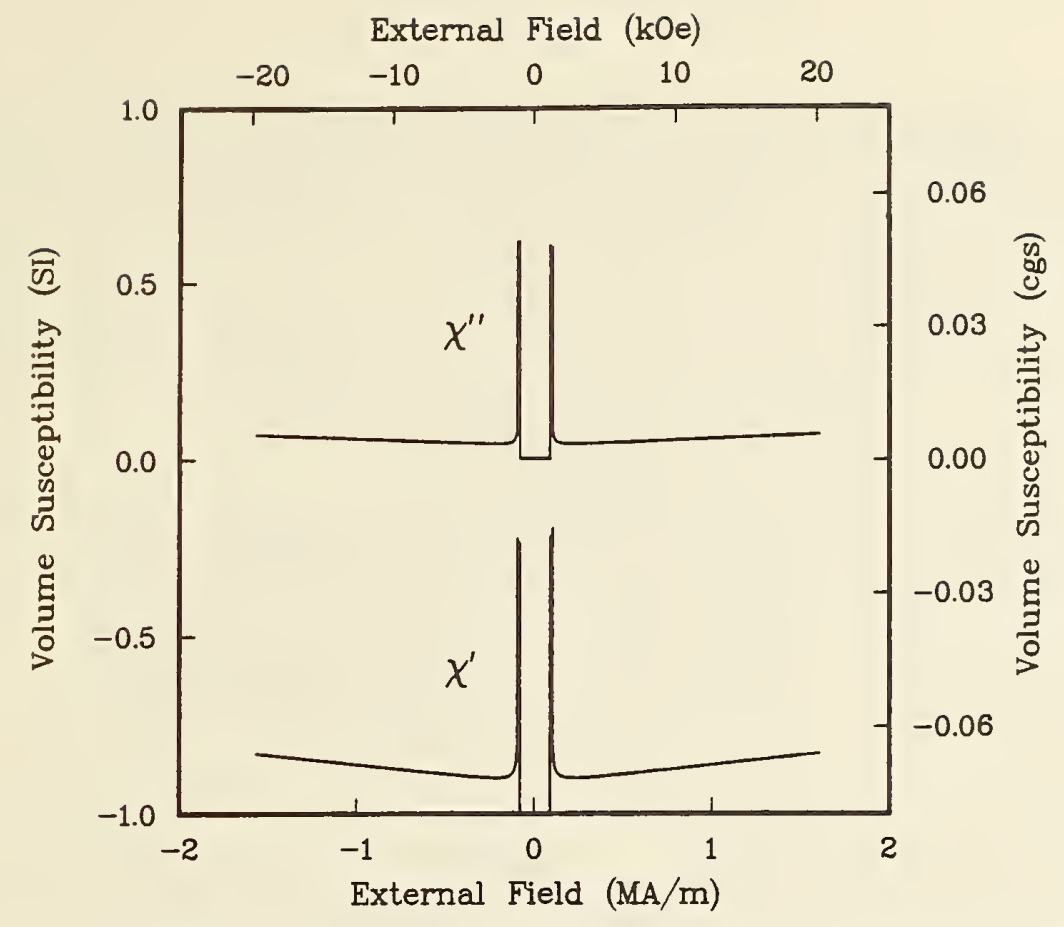

Fig. 4. Theoretical complex susceptibility vs. dc bias field for an ac field amplitude of $11 \mathrm{kA} / \mathrm{m}$ ( $140 \mathrm{0e})$.

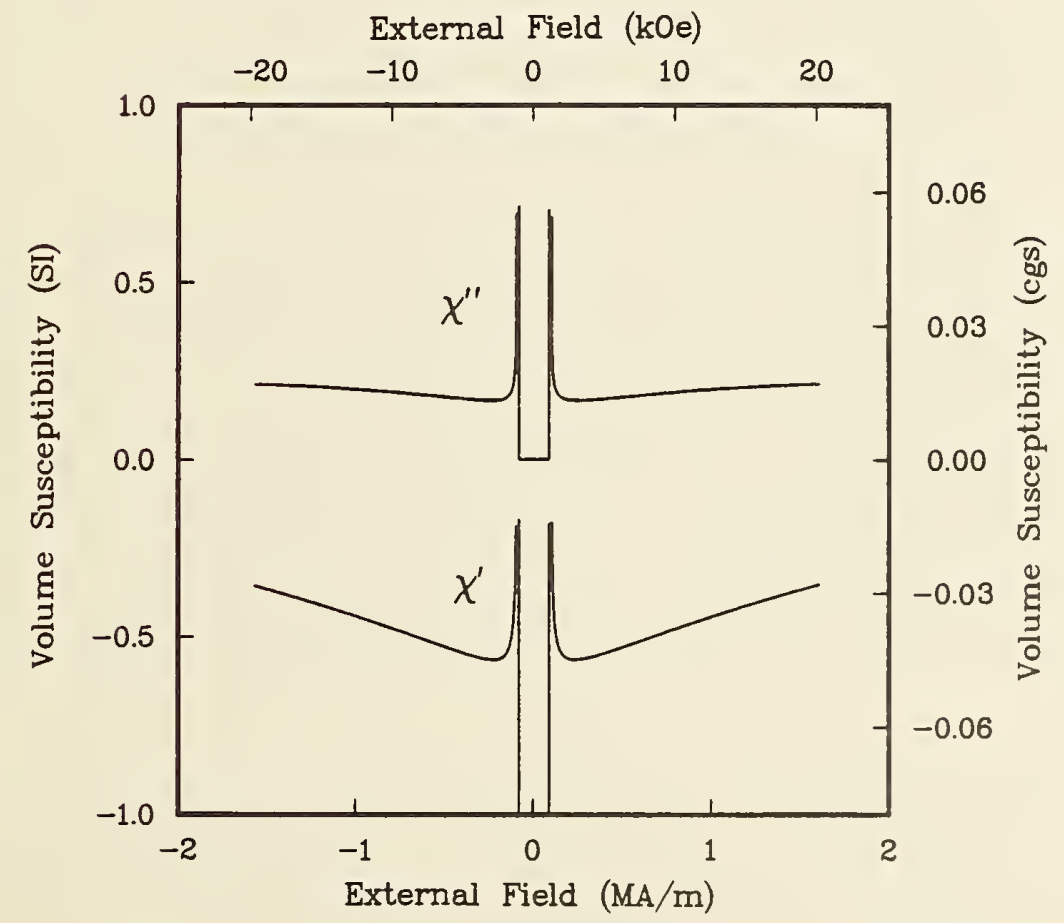

Fig. 5. Theoretical complex susceptibility vs. dc bias field for an ac field amplitude of $56 \mathrm{kA} / \mathrm{m}$ (700 0e). 
1. R. B. Goldfarb and A. F. Clark, Magnetic hysteresis and complex susceptibility as measures of ac losses in a multifilamentary NbT 1 superconductor, IEEE Trans. Magn. MAG-21:332 (1985).

2. R. B. Goldfarb and A. F. Clark, Hysteretic losses in Nb-T1 superconductors, J. App1. Phys. 57:3809 (1985).

3. W. A. Fletz, Electronic integration technique for measuring magnetization of hysteretic superconducting materials, Rev. Sc1. Instrum. $36: 1621$ (1965).

4. Y. B. Kim, C. F. Hempstead, and A. R. Strnad, Magnetization and critical supercurrents, Phys. Rev. 129:528 (1963).

5. W. J. Carr, Jr., "AC Loss and Macroscopic Theory of Superconductors," Gordon and Breach, New York (1983), P. 70.

6. M. R. Beasley and T. P. Orlando, clted by R. J. Donnelly, in: "Physics Vade Mecum," H. L. Anderson, ed., American Institute of Physics, New York (1981), ch. 7, p. 121.

7. A. L. Fetter and P. C. Hohenberg, in: "Superconductivity," R. D. Parks, ed., Marcel Dekker, New York (1969), ch. 14, p. 838.

8. A. L. Fetter and P. C. Hohenberg, in: "Superconductivity," R. D. Parks, ed., Marcel Dekker, New York (1969), ch. 14, p. 843.

9. Cf. H $\cong 8 \mathrm{kA} / \mathrm{m}(100 \mathrm{Oe})$, in: A. K. Ghosh and W. B. Sampson, Magnet1zation and critical currents of NbTi wires with fine filaments, paper DZ-7, this conference.

10. J. R. Clem, "AC Losses in Type-II Superconductors," Ames Lab. Tech. Rept. IS-M 280, Iowa State University, Ames (1979), pp. 23-24. 
LOSSES IN A Nb-TI SUPERCONDUCTOR AS FUNCTIONS OF AC FIELD AMPLITUDE AND DC TRANSPORT CURRENT

M. Dragomirecky, J.V. Minervinf, J.W. Ekin, R.B. Goldfarb, and A.F. Clark

National Bureau of Standards, Boulder, Colorado 80303, USA

\begin{abstract}
Hysteretic shielding losses and transport losses were measured in a multifilamentary $\mathrm{Nb}-\mathrm{Ti}$ superconducting coll as functions of transverse ac field amplitude and dc transport current. The conductor was biased with a dc field. There was significant agreement with the predictions of Minervini's two-dimensional theoretical model.
\end{abstract}

\title{
INTRODUCTION
}

AC losses for the case of current-carrying conductors in transient applied magnetic fields are of importance in practical applications. The theory for the one-dimenslonal slab model is well known and a few experimental studies have been made. Predominant among these is the work of Ogaswara, et al. [1-4]. For multifilamentary conductors, they emphasize the dependence of loss on the rate of change of the Field. Their field amplitudes were rather large, on the order of $200 \mathrm{kA} / \mathrm{m}(2.5$ $\mathrm{kOe})$. Clazynski also examined the dependence of hysteresis and transport losses on the sweep rate of the applied field. The analysis was in terms of an equivalent electrical network [5]. Bruzzone and Kwasnitza discussed the dependence of the hysteresis loss on the ratio of ac field amplitude to full-penetration field [6]. References [1-6] are primarily concerned with coupling losses in multifilamentary conductors. De Reuver et al. [7] recently reported measurements of losses in conductors carrying dc transport current in a transverse ac field. They analyzed their data in terms of the slab model and found qualitative agreement.

The first complete two-dimensional analysis for a cylindrical conductor with a transport current in a transverse ac fleld was presented by Minervini in 1981 [8]. The theory is based on the London-Bean approximation where the critical current density, $J$, is independent of fleld, H. Ignoring eddy-current and coupling losses (for low-frequency ac flelds), the total ac loss can be separated into two components. (1) Shielding hysteresis loss occurs in the outer volume of the superconductor filament not occupled by transport current. (2) Transport loss occurs owing to flux motion through the central portion of the superconductor filament when the shielding region is saturated with shielding currents. The shielding hysteresis loss, $W_{S}$, and transport loss, $W_{t}$, as functions of transport current density, $J$, are shown in Figs. 1 and 2 [8]. The total loss would be equal to the sum of $W_{s}$ and $W_{t}$. Curves are shown for different ac field amplitudes, $h$. The energies ${ }^{S} W_{S}$ and ${ }^{t} W_{t}$ are normalized to $W_{0}$ ' $J$ is normalized to $J_{C}$, and $h$ is normalized to $\mathrm{H}_{\mathrm{p}}(0)$, where, ${ }^{\mathrm{t}}$ for filaments of diameter $\mathrm{d}$,

$$
\mathrm{H}_{\mathrm{p}}(0)=\mathrm{d} \mathrm{J}_{\mathrm{c}} / \pi
$$

is the full-penetration field for zero transport current $(J=0)$, and

$$
\mathrm{W}_{0}=4 \quad \mu_{0} \mathrm{H}_{\mathrm{p}}^{2}(0) / 3
$$

is the volume energy density when $h=H_{0}(0)$ and $J=0[9]$. H $(J)$ is a monotonically decreasing function of $\mathrm{J}$. In this paper we report measufements of shielding hysteresis loss and transport loss that were made in an effort to test the twodimensional model. The results are in good agreement with the model. More experimental data are needed to adequately determine the detailed shape of the curves. 


\section{EXPERIMENT AND RESULTS}

A multifilamentary $\mathrm{Nb}-\mathrm{T} 1$ conductor was noninductively wound on a coll form. Inner and outer balanced pick-up colls were wound coaxlally. The sample was immersed in 11quid helium. It was exposed to a $3-\mathrm{MA} / \mathrm{m}(40-\mathrm{kOe}) \mathrm{dc}$ blas fleld. The purpose of the blas fleld was primarlly to operate on the relatively flat portion of the $\mathrm{J}^{-}$ versus-H curve, where, as assumed in the London-Bean approximation, $J$ is not a strong function of $\mathrm{H}[10]$. A secondary purpose of the blas field was ${ }^{C}$ to reduce $\mathrm{J}$ to a value more accesstble in the laboratory and to operate under conditions similar to those in practical applications.

The wire selected for study had a dlameter of $0.635 \mathrm{~mm}, 180$ filaments $30 \mu \mathrm{m}$ in diameter, and a copper-to-superconductor volume ratio of 1.50 . This wire was the same as sample 4 in Ref. [11]. The sample was $18 \mathrm{~m}$ long, wound in two layers of 72 and 74 turns. The critical current while in the blas field was $310 \mathrm{~A}$, giving a filament $J_{c}$ of $2.44 \times 10^{9} \mathrm{~A} / \mathrm{m}^{2}$ at $3 \mathrm{MA} / \mathrm{m}(40 \mathrm{kOe}) . \mathrm{H}_{\mathrm{p}}(0)$ was $2.33 \times 10^{4} \mathrm{~A} / \mathrm{m}$ (2900e) and $W_{0}$ was $910 \mathrm{~J} / \mathrm{m}^{3}$.

Data were acquired with a computer-controlled, four-channel digital recording oscilloscope. The voltage waveform of the plck-up coil was integrated with respect to time to give magnetization, which was plotted as a function of the ac-fleld waveform. The resulting hysteresls loop was numerlcally integrated to get the shielding hysteresis loss. The energy for the loss was provided by the ac-fleld power supply.

The magnetization axis was calibrated by noting that the maximum magnetization value for ac fields greater than $H_{(}(0)$ for zero transport current is $2 \mathrm{H}(0) / 3$ [9]. An alternate calibration would be $\mathrm{P}_{\text {to }}$ use the inftial susceptibility $1 \mathrm{n}^{\mathrm{P}}$ zero bias fleld with an ac field amplitude less than the lower critical field, $H$. However, the external susceptibility when the fleld is applied along the axis of the sample coll depends on the effective demagnetization factor, a function of how tightly the coil is wound [12]. This could not be determined accurately.

Transport loss was numerically computed as the integral, over two complete cycles, of the product of sample voltage and transport current. The energy for the transport loss was provided by the transport-current power supply.

The frequency of the ac fleld was $1 \mathrm{~Hz}$, far below the frequency for which coupling currents or eddy currents become important. Unlike in earlier studies [1-7], the frequency of the ac field was not a varlable. The experimental set-up is shown in Fig. 3. Particular care was taken to avoid ground loops and thermal voltages.

Very low-noise $(<3 \mu \mathrm{V})$ preamplifiers were used. Any dc offsets of the ampliflers were subtracted from the measured waveforms. The results are shown in Figs. 4 and 5 .

\section{DISCUSSION}

Generally speaking, this was a difficult experiment. The agreement of the exper1mental results (FIgs. 4 and 5) with the theory (F1gs. 1 and 2) is fairly good. The need for more data to f111-in the curves is noted.

For the case $\mathrm{J}=0$ and $\mathrm{h} \geq \mathrm{H}_{\mathrm{p}}(0)$, the theoretical expression for $\mathrm{W}_{\mathrm{s}} / \mathrm{W}_{0}$ reduces to

$$
\mathrm{W}_{\mathrm{s}} / \mathrm{W}_{0}=2 \mathrm{~h} / \mathrm{H}_{\mathrm{p}}(0)-1 \text {. }
$$

Thus, the consistency of the values for $h / H(0)$ and $W_{s} / W_{0}(J=0)$ in $F i g .4$ can be evaluated with reference to Fig. 1. For example, the curve for $h / H(0)=1$ should intercept the $\mathrm{W}_{\mathrm{S}} / \mathrm{W}_{0}$ axis at unity.

The theoretical curves for the one-dimensional siab model are only qualitatively slmilar to those for the two-dimensional cylindrical model. However, when the data 
were normalized to the values of $H_{(0)}$ and $W_{0}$ for the slab model and compared to the theoretical slab-model curves, the quantitative agreement was poor. For shlelding loss, the measured values were greater by a factor of about 2. For transport loss, the measured curves had a different curvature. Furthermore, the total-loss curves $\left(W_{+}+W_{*}\right)$ for our data are in excellent quantitative agreement with the theoretical ${ }^{s}$ total-loss curves for the two-dimensional model [8] but in poor agreement with the theoretical curves for the slab model $[1-4,7]$.

Though our data do not include large ac field amplitudes, we consider this case for the purpose of comparison to the high-field work of others. When $h / H_{p}(0)>1$, $\mathrm{W}_{\mathrm{s}} / \mathrm{W}_{0}=2 \mathrm{~h} / \mathrm{H}_{\mathrm{p}}(0)$. In this limit, from Eqs. 2 and 3 ,

$$
\mathrm{W}_{\mathrm{s}}=8 \mu_{0} \mathrm{H}_{\mathrm{p}}(0) \mathrm{h} / 3 \text {, }
$$

in agreement with Carr's derivation [13].

\section{CONCLUSION}

The two-dimensional cylindrical model seems to be better than the one-dimensional slab model for analyzing shielding hysteresis losses and transport losses in multifilamentary conductors with round filaments.

\section{ACKNOWLEDGEMENT}

This work was sponsored by the Air Force Office of Scientific Research.

\section{REFERENCES}

I Ogaswara, T., Takahashi, Y., Kanbara, K., Kubota, Y., Yasohama, K., and Yasukochi, K., 'Alternating field losses in superconducting wires carrying dc transport current. Part 1: single core conductors'. Cryogenics, vol. 19 (1979), Pp. 736-740.

2 Ogaswara, T., Takahashi, Y., Kanbara, K., Kubota, Y., Yasohama, K., and Yasukochi, K., 'Transient field losses in multifilamentary composite conductors carrying de transport currents'. Cryogenics, vol. 20 (1980), pp.216-222.

3 Ogaswara, T., Takahash1, Y., Kanbara, K., Kubota, Y., Yasohama, K., and Yasukochi, K., 'Alternating field losses in superconducting wires carrying dc transport current. Part 2: multifilamentary composite conductors'. Cryogenics, vol. 21 (1981), pp.97-101.

4 Ogaswara, T., Itoh, M., Kubota, Y., Kanbara, K., Takahash1, Y., Yasohama, K., and Yasukochi, K., 'Transient field losses in multifilamentary composite conductors carrying transport currents'. IEEE Trans. Magn., vol. MAG-17 (1981), pp.967-970.

5 Ciazynski, D,, 'Effect of a transport current on the losses of a superconducting composite under fast changing magnetic field'. IEEE Trans. Magn., vol. MAG-21 (1985), pp.169-172.

6 Bruzzone, P. and Kwasnitza, K., 'Scaling law for filamentary superconductor hysteresis losses in superimposed dc and ac magnetic fields'. J. Physique Collog. Cl, vol. 45 (1984), pp.483-487.

7 De Reuver, J.L., Beunk, H.D., Roovers, A.J.M., and Van der Klundert, L.J.M., 'AC field losses in a dc current-carrying conductor containing one layer of NbTi filaments'. Int1. Conf. Magnet Tech., MT-9, Marinucc1, C. and Weymuth, P., eds., Swiss Inst. Nuc1. Res., Zurich (1985), pp.501-504. 
8 Minervini, J.V., 'Two-dimensional analysis of ac loss in superconductors carrying transport current'. Advances in Cryogenic Engineering (Materials), Vol. 28, Reed, R.P. and Clark, A.F., eds., Plenum, New York (1982), pp.587-599.

9 Pang, C.Y., McLaren, P.G., and Campbe11, A.M., 'Losses in superconducting cylinders in transverse fields'. Intl. Cryo. Engr. Conf., Vol. 8, Rizzuto, C., ed., IPC Sc1. and Tech. Press, Surrev, England (1980), PP.739-743.

10 Carr, Jr., W.J., AC Loss and Macroscopic Theory of Superconductors, Gordon and Breach, New York (1983), p.55.

11 Goldfarb R.B. and Clark, A.F., 'Hysteretic losses in Nb-Ti superconductors'. J. Appl. Phys., vol. 57 (1985), pp.3809-3811.

12 Sumiyosh1, F., Irte, F., and Yoshida, K., 'The effect of demagnetization on the eddy-current loss in a single-layered multifilamentary superconducting coil'. J. App1. Phys., vol. 51 (1980), pp.3807-3811.

13 Carr, Jr., W.J., AC Loss and Macroscopic Theory of Superconductors, Gordon and Breach, New York (1983), p.67.

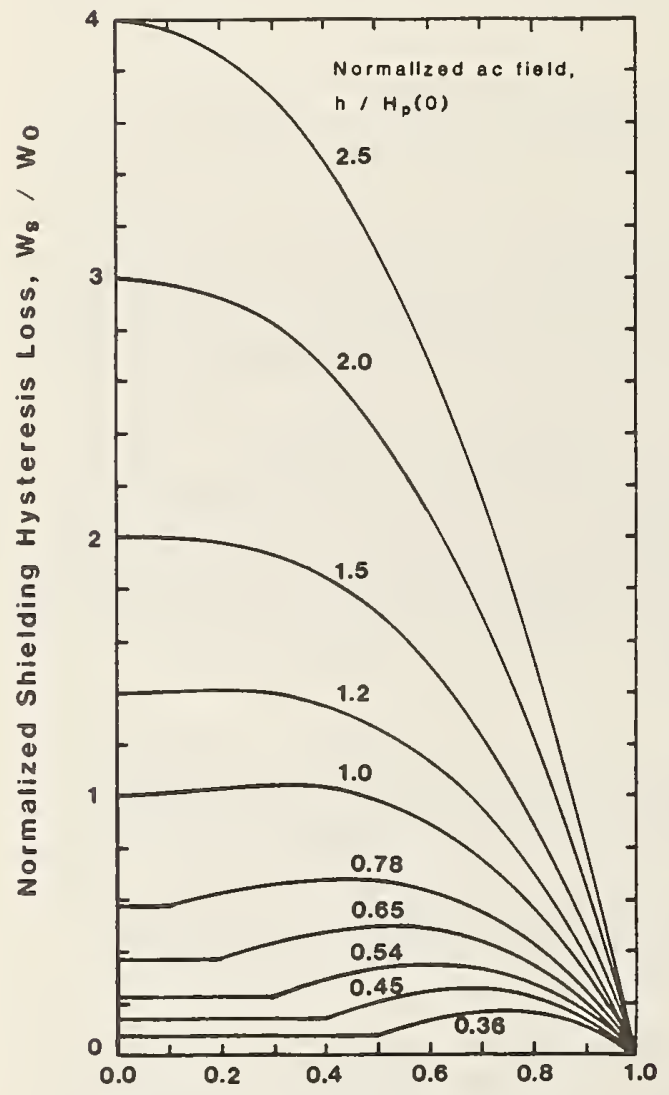

Normalized Current Density, $J / J c$

Fig. 1 Theoretical shlelding hysteresis loss for different ac flelds [8].

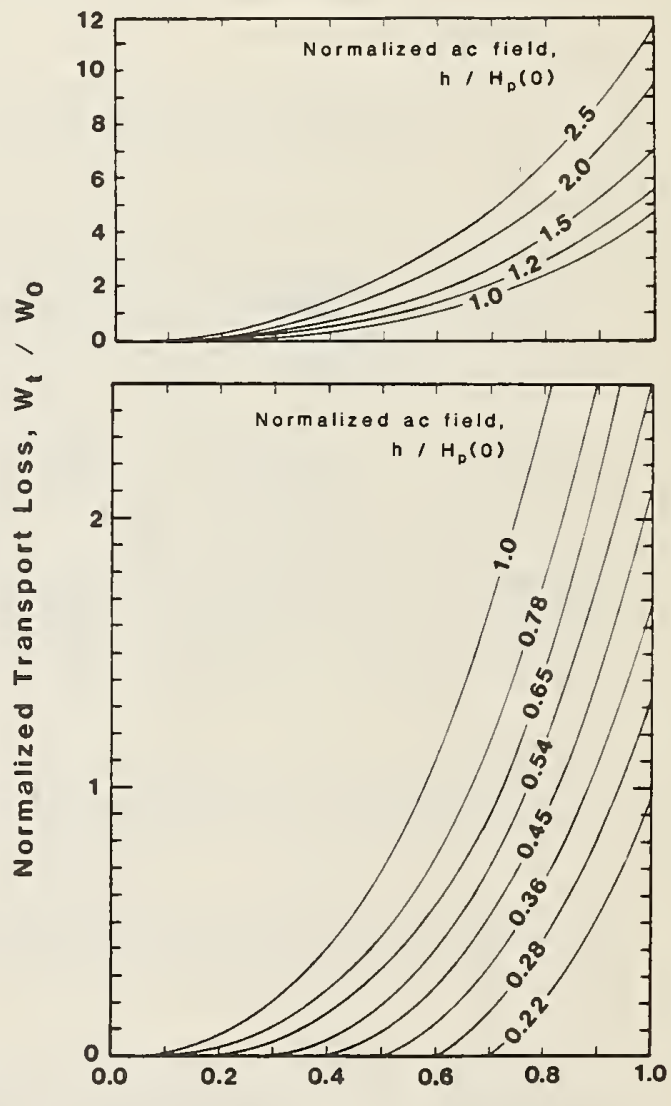

Normalized Current Density, $J / J_{C}$

Fig. 2 Theoretical transport loss for different ac fields [8]. 


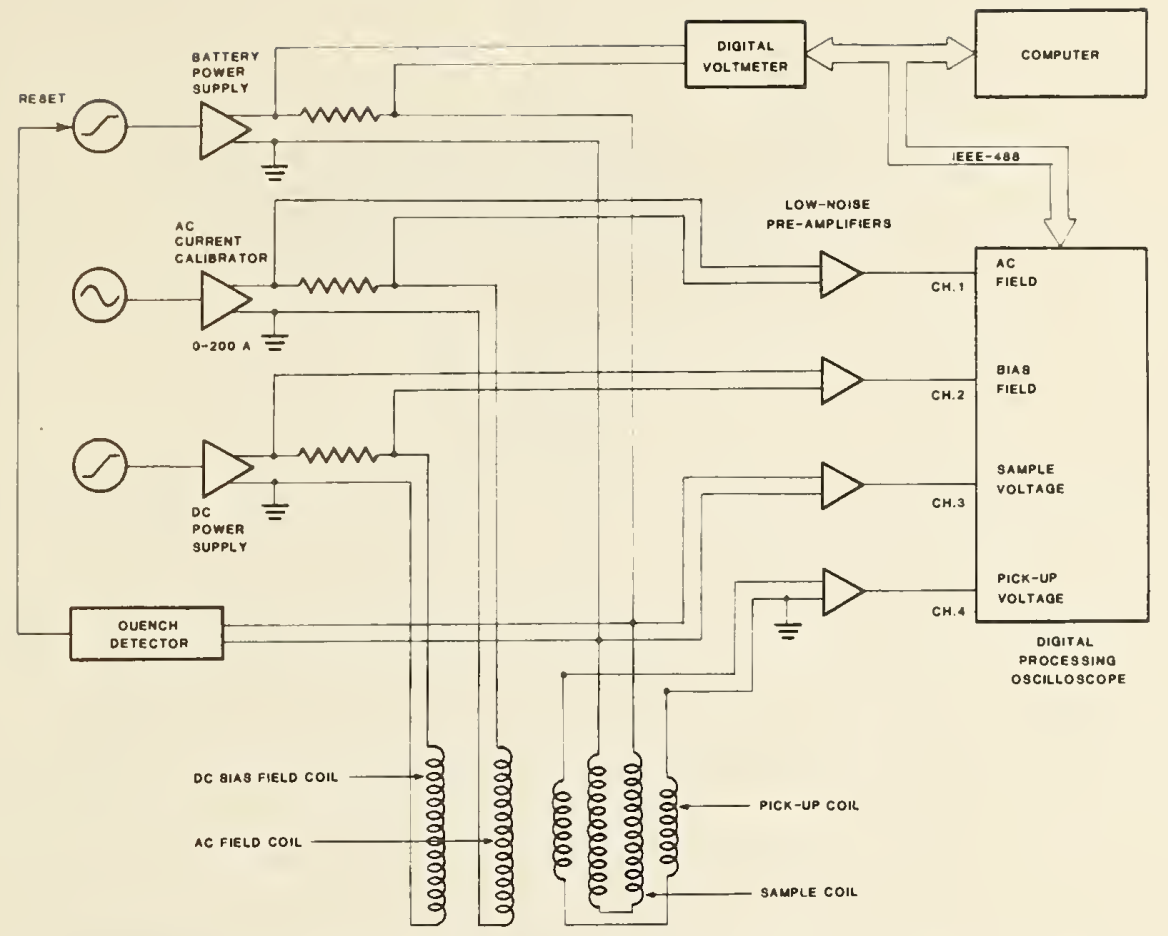

Fig. 3 Experiment for measuring shielding hysteresis loss and transport loss. The coils are immersed in liquid helium.

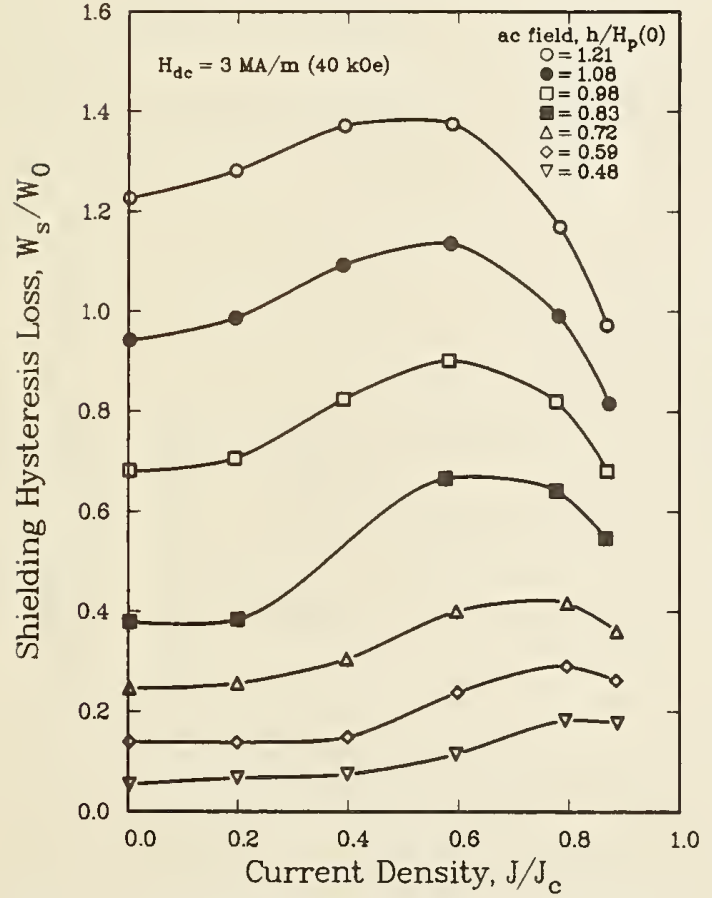

Fig. 4 Experimental shielding hysteresis loss for different ac fields.

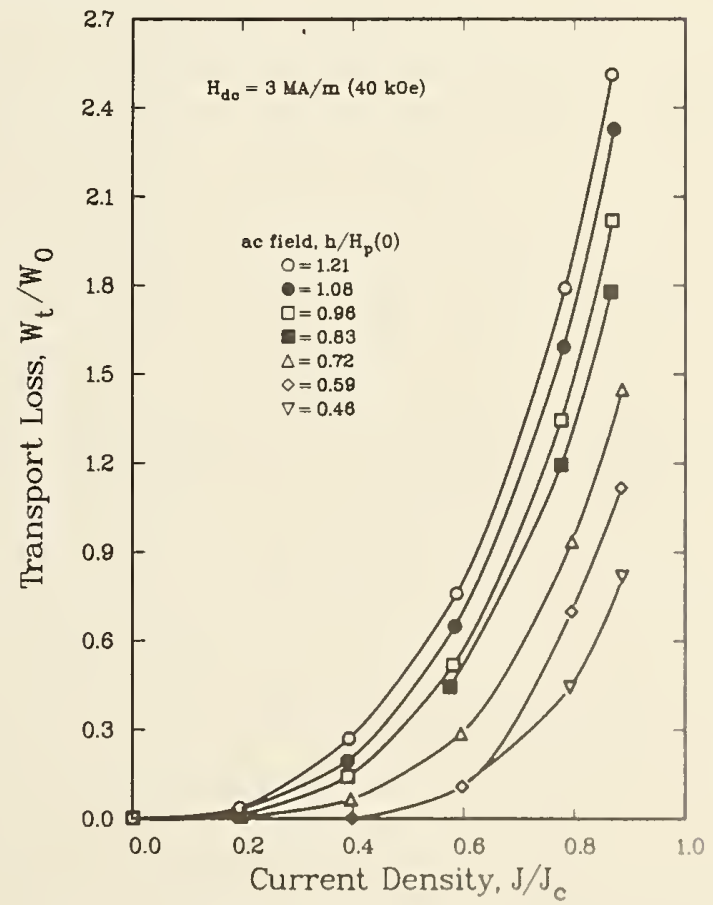

Fig. 5 Experimental transport loss for different ac fields. 



\author{
R. B. Goldfarb and J.W. Ekin \\ Electromagnetic Technolggy Division \\ National Bureau of Standards \\ Boulder, Colorado 80303
}

\begin{abstract}
Hysteresis losses were measured on a series of fine-filament $\mathrm{Nb}_{3} \mathrm{Sn}$
\end{abstract} superconductors made by the internal-tin process. Hysteresis was measured as a function of filament diameter and interfilament separation using a vibratingsample magnetometer in transverse field. Losses were greater than expected from the critical-state model that expresses loss as a function of filament diameter. Micrographs of the reacted wire cross sections showed some interfilament bridging for all wires. This gave rise to effective filament diameters that were greater than actual diameters. The critical interfilament separation, above which the losses would be expected to follow the critical-state model, was determined.

\title{
INTRODUCTION
}

Fine-filament superconductors are of interest in ac-loss studies because, according to the critical-state model, hysteresis loss is proportional to filament diameter. Thus, one would expect that wires composed of fine filaments would exhibit small losses. In this study we used a vibrating-sample magnetometer in transverse magnetic field to measure the dc hysteresis loss for a series of $\mathrm{Nb}_{3} \mathrm{Sn}$ superconductors made by the internal-tin process. There was no transport current. Filament diameter and edge-to-edge interfilament separation were systematically varied to determine whether filament coupling caused larger-than-expected hysteresis 1osses. Such magnified losses may be 
expressed in terms of an effective filament diameter that is greater than the actual filament diameter. The effective diameter is deduced from the hysteresis loss using the critical-state model.

There has been some previous work on hysteresis losses in fine-filament superconductors. Dubots et al. compared measured and calculated hysteresis in $\mathrm{Nb}-\mathrm{Ti}$ conductors with filament diameters ranging from 10 to $0.1 \mu \mathrm{m}[1]$. They found that, for diameters smaller than $1 \mu \mathrm{m}$, effective filament diameters remained about $1 \mu \mathrm{m}$. Information on interfilament separation was not given. Carr and Wagner attributed the asymmetrical hysteresis curve they observed in $\mathrm{Nb}-\mathrm{Ti}$ with 1.6- $\mathrm{m}$ filament diameter to relatively large surface currents [2]. Ghosh and Sampson studied fine-filament $\mathrm{Nb}-\mathrm{Ti}$ with filament diameters in the range 1-5 $\mu \mathrm{m}[3]$. They note that, for diameters less than $3 \mu \mathrm{m}$, the magnetization (and therefore hysteresis loss) is larger than expected from the criticalstate model. They attribute this to degradation of the magnitudes of critical current owing to filament necking or damage.

In this paper we show that certain $\mathrm{Nb}_{3} \mathrm{Sn}$ internal-tin conductors with filament diameters smaller than $5 \mu \mathrm{m}$ have effective filament diameters greater than expected from the critical-state model. The ratio of effective to actual $\mathrm{Nb}_{3} \mathrm{Sn}$ filament diameters appears to be a linear function of interfilament separation. The slope of the line is a function of the local area ratio of matrix material to $\mathrm{Nb}$ for each wire. The greater effective filament diameters appear to be a consequence of bridging between filaments.

\section{SAMPLE PREPARATION AND MEASUREMENT}

The multifilamentary $\mathrm{Nb}_{3} \mathrm{Sn}$ wires used in this study were composed of subelements containing 150 filaments each. The array of subelements was surrounded by a tantalum diffusion barrier. Unreacted $\mathrm{Nb}_{3} \mathrm{Sn}$ wires were wrapped 
on the threads of size 10-24 stainless steel screws. The thread pitch was such that the windings were not in contact with each other. The screws had been previously oxidized to prevent the wires from sticking to the screws. The internal-tin-process wires were reacted in vacuum, with cold ends out of the furnace, according to the following schedule: 1 day at $340^{\circ} \mathrm{C}$, 4 days at $580^{\circ} \mathrm{C}$, and 4 days at $700^{\circ} \mathrm{C}$. This schedule is adequate to fully react the wires for the filament diameters in this study [4]. The residual tin content of each wire after reaction was estimated by the manufacturer to be 8 wt.\%.

After reaction, the wire coils were unscrewed from the stainless screws and the long ends cut off. Each coil was about $1.3 \mathrm{~cm}$ in height. The wire volumes were measured using Archimedes' principle. The wire diameter was the same for each sample, $0.681 \mathrm{~mm}$. Thus, the wire length for each coil was obtained.

The average $\mathrm{Nb}$-filament diameters before reaction and number of filaments in each sample were provided by the manufacturer. The reacted filament diameters and total volume of $\mathrm{Nb}_{3} \mathrm{Sn}$ in each coil were calculated based on a presumed increase of $38 \%$ in filament cross-sectional area after reaction [5]. Local area ratios of matrix to $\mathrm{Nb}$ were determined by the manufacturer from the arrangement of the $\mathrm{Nb}$ rods in the billets before drawing: the $\mathrm{Nb}$ may be thought of as enclosed by adjacent hexagons and the cross-sectional areas of $\mathrm{Nb}$ and matrix material measured. The average center-to-center filament distance, $s$, may be determined from the local area ratio, $\mathrm{L}$, and $\mathrm{Nb}$ filament diameter, $d$, by the equation

$$
L=(2 \sqrt{3} / \pi)(s / d)^{2}-1 .
$$

The edge-to-edge $\mathrm{Nb}$ separation is simply $\mathrm{s}-\mathrm{d}$.

Table 1 gives relevant parameters for the six samples. Note that $\mathrm{Nb}$ diameter plus $\mathrm{Nb}$ separation equals $\mathrm{Nb}_{3} \mathrm{Sn}$ diameter plus $\mathrm{Nb}_{3} \mathrm{Sn}$ separation. 
Both sums are equivalent to the center-to-center filament distance (not shown). The matrix-to-Nb local area ratios of 1.5 and 1.8 correspond to area ratios for reacted $\mathrm{Nb}_{3} \mathrm{Sn}$ of 1.0 and 1.2 , respectively.

Magnetic moment was measured at $4.2 \pm 0.2 \mathrm{~K}$ with a vibrating-sample magnetometer in the axis of the coil (i.e., field transverse to the wire if we ignore thread pitch of about $5.5^{\circ}$ ). Maximum applied field was $1.6 \mathrm{MA} / \mathrm{m}$ $(20 \mathrm{kOe})$. There was no transport current and the coils were open-circuited. Magnetization was computed as magnetic moment per unit volume of $\mathrm{Nb}_{3} \mathrm{Sn}$ (i.e., not including the volume of the matrix material). Magnetization was plotted versus external (applied) magnetic field. A typical magnetic hysteresis loop for one of the samples (sample 18) is shown in Fig. 1.

\section{RESULTS}

Hysteresis loss was computed by numerically integrating the loop area, ignoring the initial branch. According to the critical-state model, for transverse field geometry [6]:

$$
\mathrm{W}=8 \mathrm{~J}_{\mathrm{c}} \mathrm{d}_{\text {eff }} \mu_{0} \mathrm{H}_{0} / 3 \pi \quad \text { (SI units) }
$$

Thus, an effective filament diameter, deff, may be defined that is a function of the hysteresis loss, $W$, for a maximum applied field, $H_{0}$. Since we did not have data for the critical current density, $\mathrm{J}_{c}$, at $1.6 \mathrm{MA} / \mathrm{m}(20 \mathrm{kOe})$, we deduced these $J_{c}$ based on the critical current of each wire measured at 6.4 $\mathrm{MA} / \mathrm{m}$ (80 kOe) together with the total $\mathrm{Nb}_{3} \mathrm{Sn}$ cross-sectional area and the measured value of the full-penetration field, $\mathrm{H}_{\mathrm{p}}$, at $1.6 \mathrm{MA} / \mathrm{m}$ (20 kOe). $\mathrm{J}_{\mathrm{c}}$, $\mathrm{H}_{\mathrm{p}}$, and filament diameter, $\mathrm{d}$, are related according to the critical-state mode1 [6]:

$$
\mathrm{H}_{\mathrm{p}}=\mathrm{d} \mathrm{J}_{\mathrm{c}} / \pi \quad \text { (SI units) }
$$

$H_{p}$ may be obtained as one-half the field required to reverse the magnetization 
[7]. From the hysteresis loops, $\mathrm{H}_{\mathrm{p}}$ at $1.6 \mathrm{MA} / \mathrm{m}(20 \mathrm{kOe})$ is roughly $75 \mathrm{kA} / \mathrm{m}$ (940 0e) for all the loops. This suggests a factor of 10 increase in $\mathrm{J}_{\mathrm{c}}$ compared to measured $J_{c}$ at $6.4 \mathrm{MA} / \mathrm{m}(80 \mathrm{kOej})$. Applying this factor of 10 to each conductor gives the values of $J_{c}$ shown in Table 2 . We then compute the effective filament diameters of the wires, and additionally, the ratio of the effective to actual $\mathrm{Nb}_{3} \mathrm{Sn}$ filament diameters.

Optical and scanning-electron microscopy revealed that some of the filaments in each wire were not entirely isolated but were connected by "bridges". An example of this is shown in Fig. 2. Such filaments had typically lost their original hexagonal spacing and aligned themselves in rows in the process of wire drawing [8].

\section{DISCUSSION}

As shown in Fig. 3, the relationship between actual and effective $\mathrm{Nb}_{3} \mathrm{Sn}$ diameters is not monotonic. However, some insight is obtained by plotting the ratio of effective to actual $\mathrm{Nb}_{3} \mathrm{Sn}$ diameters versus $\mathrm{Nb}_{3} \mathrm{Sn}$ interfilament separation (see Fig. 4). It appears that effective filament diameter is a function of both actual filament diameter and interfilament separation. Thus, loss per volume of $\mathrm{Nb}_{3} \mathrm{Sn}$ superconductor is a function of both parameters.

Further refinement is possible by distinguishing among those conductors with the same matrix-to-Nb local area ratios. These are identified in Figs. 3 and 4 for the two ratios. We see in Fig. 3 that there is less of an increase in effective filament diameter for the conductors with the larger local area ratio. However, we note that, in Fig. 4, the abscissa ( $\mathrm{Nb}_{3} \mathrm{Sn}$ interfilament separation) is not independent of local area ratio (see Eq. 1). The apparently linear dependence of the effective-to-actual diameter ratio on interfilament separation has no physical significance. 
A critical interfilament separation can be defined. It corresponds to the separation above which the hysteresis losses would depend on filament diameter as expected from the critical-state model. We determined the critical separation for reacted $\mathrm{Nb}_{3} \mathrm{Sn}$, as shown in Fig. 4, by linearly extrapolating the data to a unity value of effective-to-actual diameter ratio. The critical separation appears to be a function of the local area ratio. Critical values for the separation between reacted $\mathrm{Nb}_{3} \mathrm{Sn}$ filaments were about $1.6 \mu \mathrm{m}$ for an area ratio of 1.5 and about $2.0 \mu \mathrm{m}$ for a ratio of 1.8 . The corresponding critical values for the separation between unreacted $\mathrm{Nb}$ filaments were 2.4 and $1.5 \mu \mathrm{m}$, respectively.

\section{CONCLUSION}

Certain fine-filament superconductors made by the internal-tin process have effective filament diameters that are greater than actual filament diameters. The differences between effective and actual diameters increase as actual diameters decrease, the effect being more pronounced in those wires with the smaller local area ratio of matrix material to $\mathrm{Nb}$. When the ratio of effective to actual diameters is plotted as a function of edge-to-edge interfilament separation, a more refined picture emerges. The diameter ratio increases linearly with decreasing interfilament separation for each local area ratio. The larger-than-expected effective filament diameters are likely due to interfilament bridging in these wires.

For the practical purpose of conductor design, a critical interfilament separation can be determined. It corresponds to the spacing above which the hysteresis loss would depend on filament diameter as expected from the criticalstate model. The critical $\mathrm{Nb}_{3} \mathrm{Sn}$ interfilament separation for the conductors used in this study was about 1.6 and $2.0 \mu \mathrm{m}$ for matrix-to-Nb area ratios of 
1.5 and 1.8 , respectively. The critical separation is offered simply as a practical design parameter related to the critical-state model and for guidance in the manufacture of fine-filament internal-tin superconductors such as these.

\section{ACKNOWLEDGMENTS}

M. Suenaga made the high-field critical current measurements and generously shared samples of the unreacted wires. A. K. Ghosh astutely pointed out the importance of local area ratios. G. M. Ozeryansky provided valuable information on the physical characteristics of the wires. E. S. Pittman made the optical and scanning-electron micrographs. The wires were manufactured by Intermagnetics General Corporation [9]. The experimental work was sponsored by the Air Force Office of Scientific Research. Most of the results of this study were presented at the Fourth U.S.-Japan Workshop on High Field Superconducting Materials for Fusion, 1986. This workshop and the microanalysis were sponsored by the U.S. Department of Energy, Office of Fusion Energy.

\section{REFERENCES}

1. P. Dubots, A. Février, J. C. Renard, J. P. Tavergnier, J. Goyer, and Hoang Gia Ky, NbTi wires with ultra-fine filaments for 50-60 Hz use: Influence of the filament diameter upon losses, IEEE Trans. Magn. MAG-21, 177 (1985).

2. W. J. Carr, Jr, and G. R. Wagner, Hysteresis in a fine filament NbTi composite, in: "Advances in Cryogenic Engineering (Materials)," Vol. 30, A. F. Clark and R. P. Reed, eds., Plenum, New York (1984) p. 923.

3. A. K. Ghosh and W. B. Sampson, Magnetization and critical currents of NbT1 wires with fine filaments, in: "Advances in Cryogenic Engineering (Materials)," Vol. 32, R. P. Reed and A. F. Clark, eds., Plenum, New York (1986) p. 809.

4. A. K. Ghosh, private communication.

5. G. M. Ozeryansky, private communication. 
6. W. J. Carr, Jr., "AC Loss and Macroscopic Theory of Superconductors," Gordon and Breach, NY (1983) p. 67.

7. R. B. Goldfarb and A. F. Clark, Hysteretic losses in Nb-Ti superconductors, J. App1. Phys. 57, 3809 (1985).

8. Evidence for interfilament bridging in these wires was first presented by A. K. Ghosh and W. B. Sampson in: "Magnetization studies of multifilamentary $\mathrm{Nb}_{3} \mathrm{Sn}$ wires" at the Fourth U.S.-Japan Workshop on High Field Superconducting Materials for Fusion, 1986 (unpublished).

9. Certain commercial materials are identified to adequately specify the experimental study. In no case does such identification imply recommendation or endorsement by the National Bureau of Standards, nor does it imply that the material is the best available for the purpose.

\section{TABLES}

Table 1. Parameters for six $\mathrm{Nb}_{3} \mathrm{Sn}$ multifilamentary superconductors.

\begin{tabular}{rcccccccc} 
Sample & $\begin{array}{c}\mathrm{Nb} \\
\text { Diam. } \\
(\mu \mathrm{m})\end{array}$ & $\begin{array}{l}\mathrm{Nb}_{3} \mathrm{Sn} \\
\text { Diam. } \\
(\mu \mathrm{m})\end{array}$ & $\begin{array}{l}\text { Local } \\
\text { Area } \\
\text { Ratio }\end{array}$ & $\begin{array}{c}\mathrm{Nb} \\
\text { Sep. } \\
(\mu \mathrm{m})\end{array}$ & $\begin{array}{c}\mathrm{Nb}_{3} \mathrm{Sn} \\
\text { Sep. } \\
(\mu \mathrm{m})\end{array}$ & $\begin{array}{c}\text { No. } \\
\text { Fil. }\end{array}$ & $\begin{array}{c}\text { Length } \\
(\mathrm{cm})\end{array}$ & $\begin{array}{r}\text { Vol. } \\
\left.\mathrm{Nb}_{3} \mathrm{Sn}^{3}\right)\end{array}$ \\
\hline 3 & 4.2 & 4.9 & 1.5 & 2.1 & 1.4 & 2850 & 17.8 & 9.71 \\
6 & 4.0 & 4.7 & 1.8 & 2.4 & 1.7 & 2850 & 17.3 & 8.55 \\
9 & 3.0 & 3.5 & 1.5 & 1.5 & 1.0 & 5550 & 17.1 & 9.24 \\
12 & 2.8 & 3.3 & 1.8 & 1.7 & 1.2 & 5550 & 17.0 & 8.01 \\
15 & 2.3 & 2.7 & 1.5 & 1.2 & 0.8 & 9150 & 17.0 & 8.89 \\
18 & 2.2 & 2.6 & 1.8 & 1.3 & 0.9 & 9150 & 16.8 & 8.04 \\
\hline
\end{tabular}

Table 2. Hysteresis loss and effective filament diameters for $\mathrm{Nb}_{3} \mathrm{Sn}$.

\begin{tabular}{|c|c|c|c|c|}
\hline Sample & $\begin{array}{c}\text { Estimated } \\
\mathrm{J} \\
\left(\mathrm{GA} / \mathrm{m}^{2}\right)\end{array}$ & $\begin{array}{c}\mathrm{W} \\
\left(\mathrm{MJ} / \mathrm{m}^{3}\right)\end{array}$ & $\begin{array}{c}\text { Eff. } \mathrm{Nb}_{3} \mathrm{Sn} \\
\text { Fil. Diăm. } \\
(\mu \mathrm{m})\end{array}$ & $\begin{array}{c}\text { Eff./Actual } \\
\text { Diameter } \\
\text { Ratio }\end{array}$ \\
\hline 3 & 49.4 & 0.870 & 10.46 & 2.12 \\
\hline 6 & 50.6 & 0.714 & 8.37 & 1.78 \\
\hline 9 & 50.6 & 1.369 & 16.05 & 4.55 \\
\hline 12 & 54.3 & 0.885 & 9.67 & 2.94 \\
\hline 15 & 53.8 & 1.419 & 15.66 & 5.80 \\
\hline 18 & 51.9 & 0.805 & 9.20 & 3.56 \\
\hline
\end{tabular}




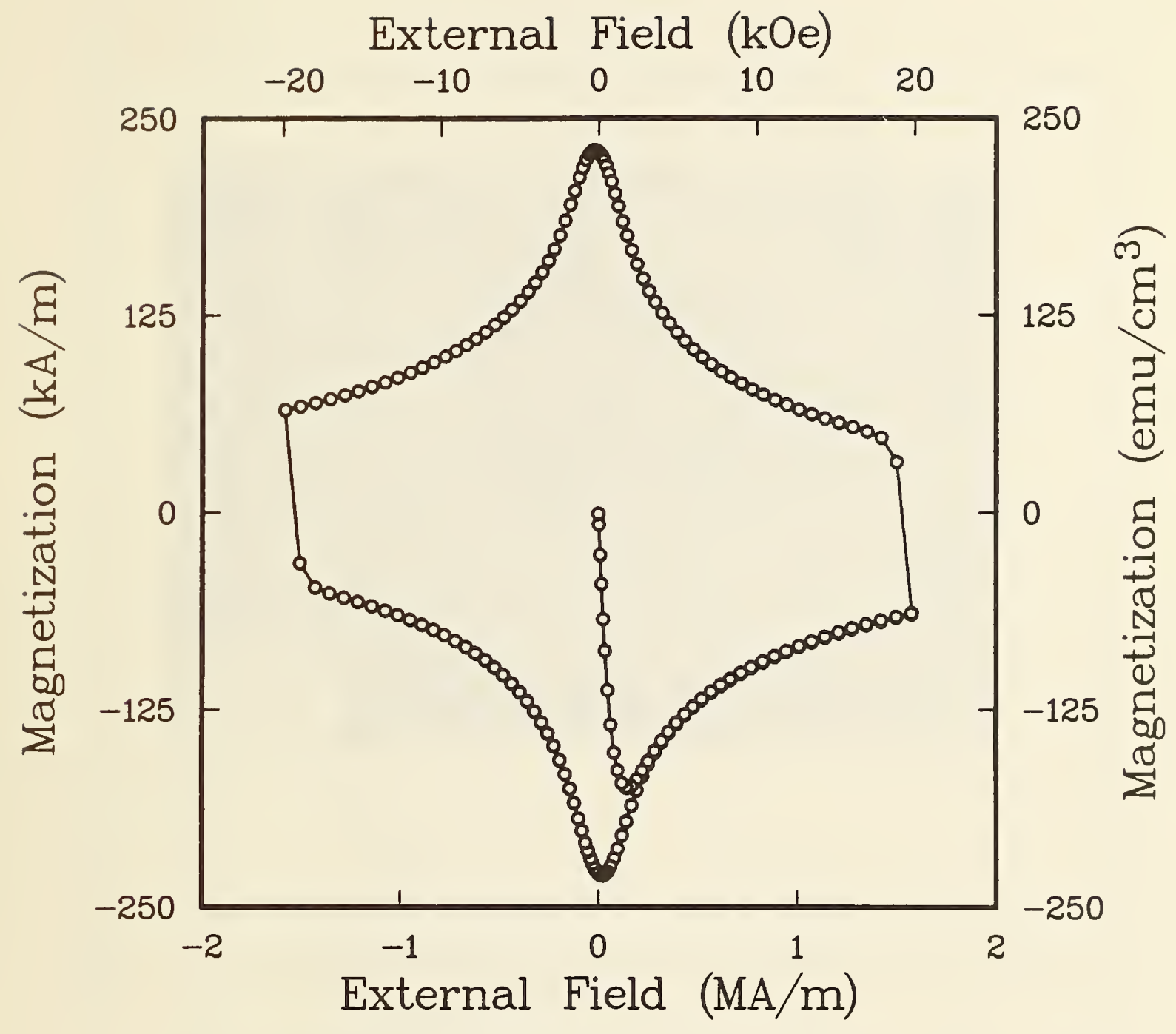

Figure 1. Typical hysteresis loop for a multifilamentary $\mathrm{Nb}_{3} \mathrm{Sn}$ wire made by the internal-tin process (sample 18). Magnetization was computed as magnetic moment per unit volume of $\mathrm{Nb}_{3} \mathrm{Sn}$. 


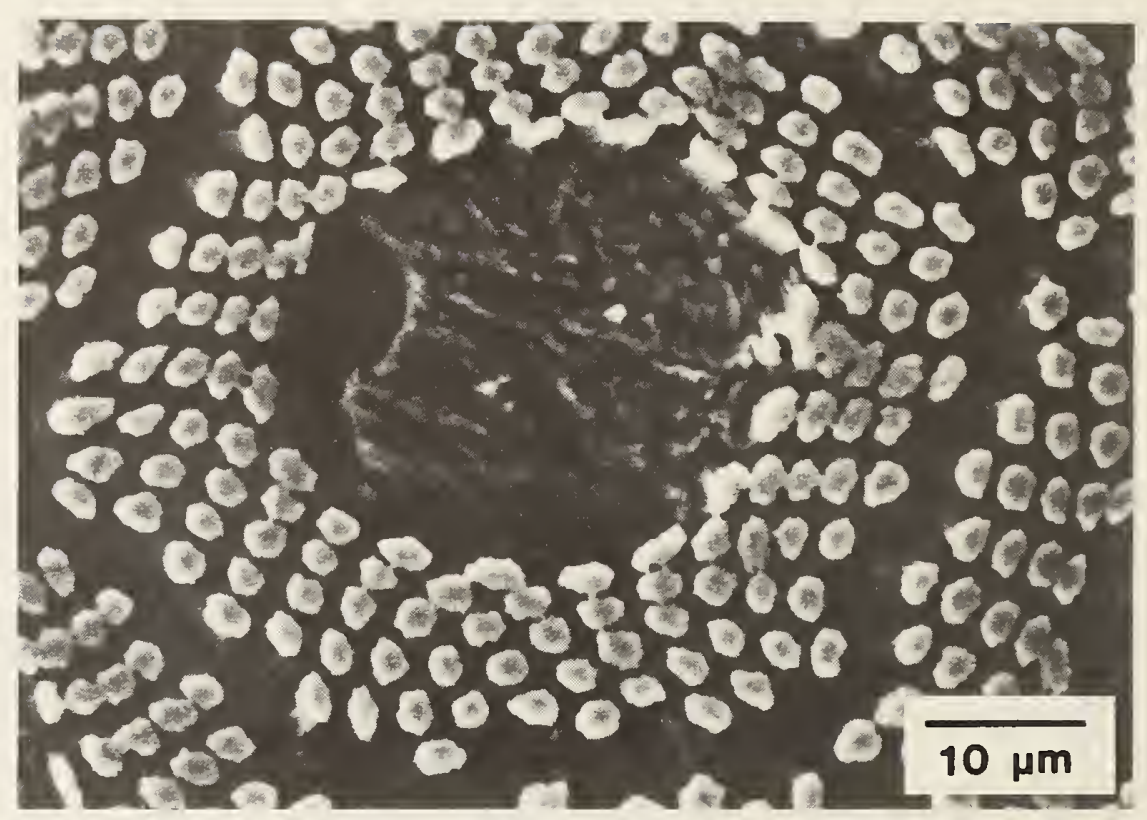

Figure 2. Typical scanning-electron micrograph showing some interfilament bridging (sample 18, center subelement). 


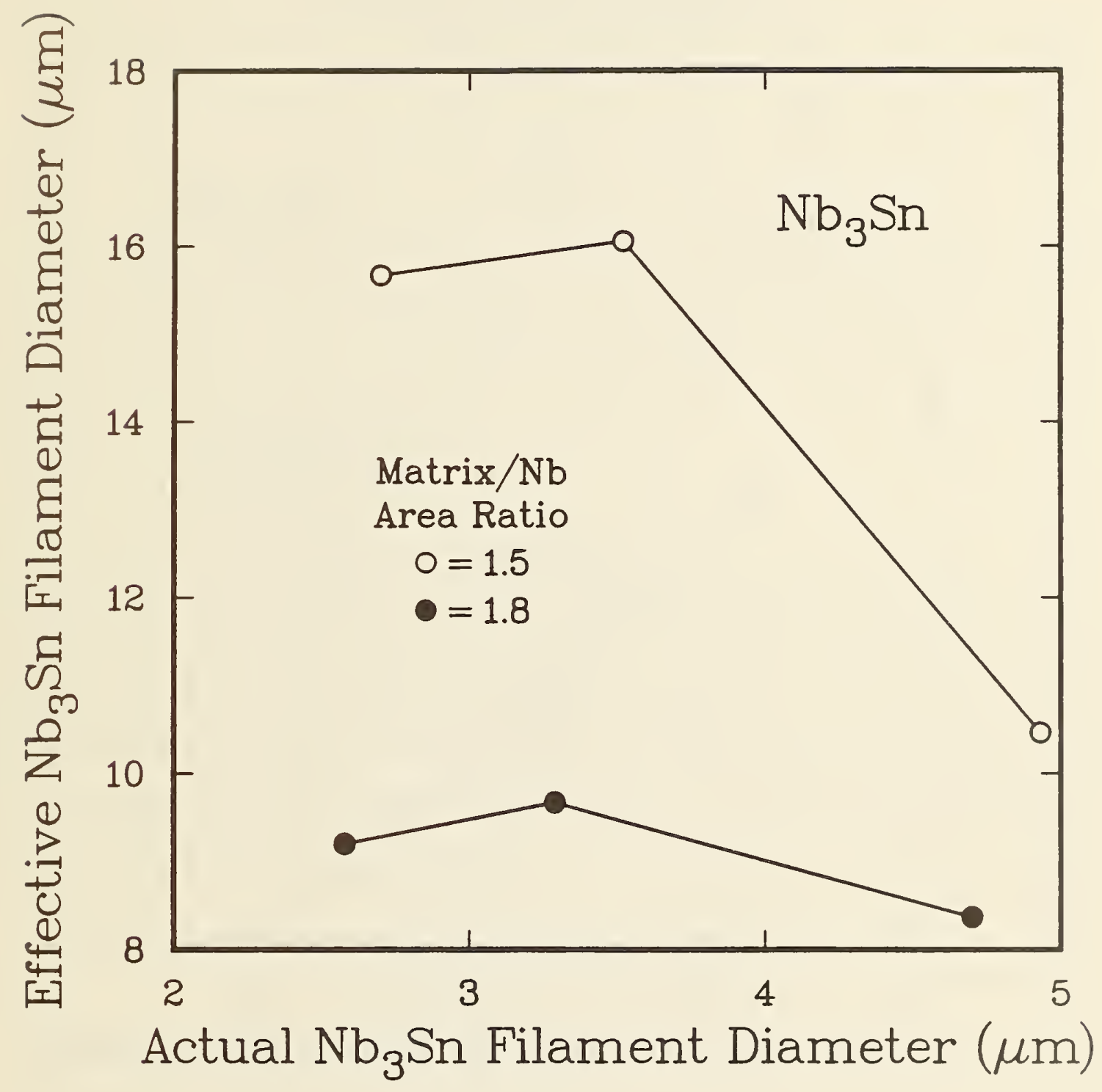

Figure 3. Effective filament diameter as a function of actual $\mathrm{Nb}_{3} \mathrm{Sn}_{\text {filament }}$ diameter for two local area ratios of matrix to $\mathrm{Nb}$. 


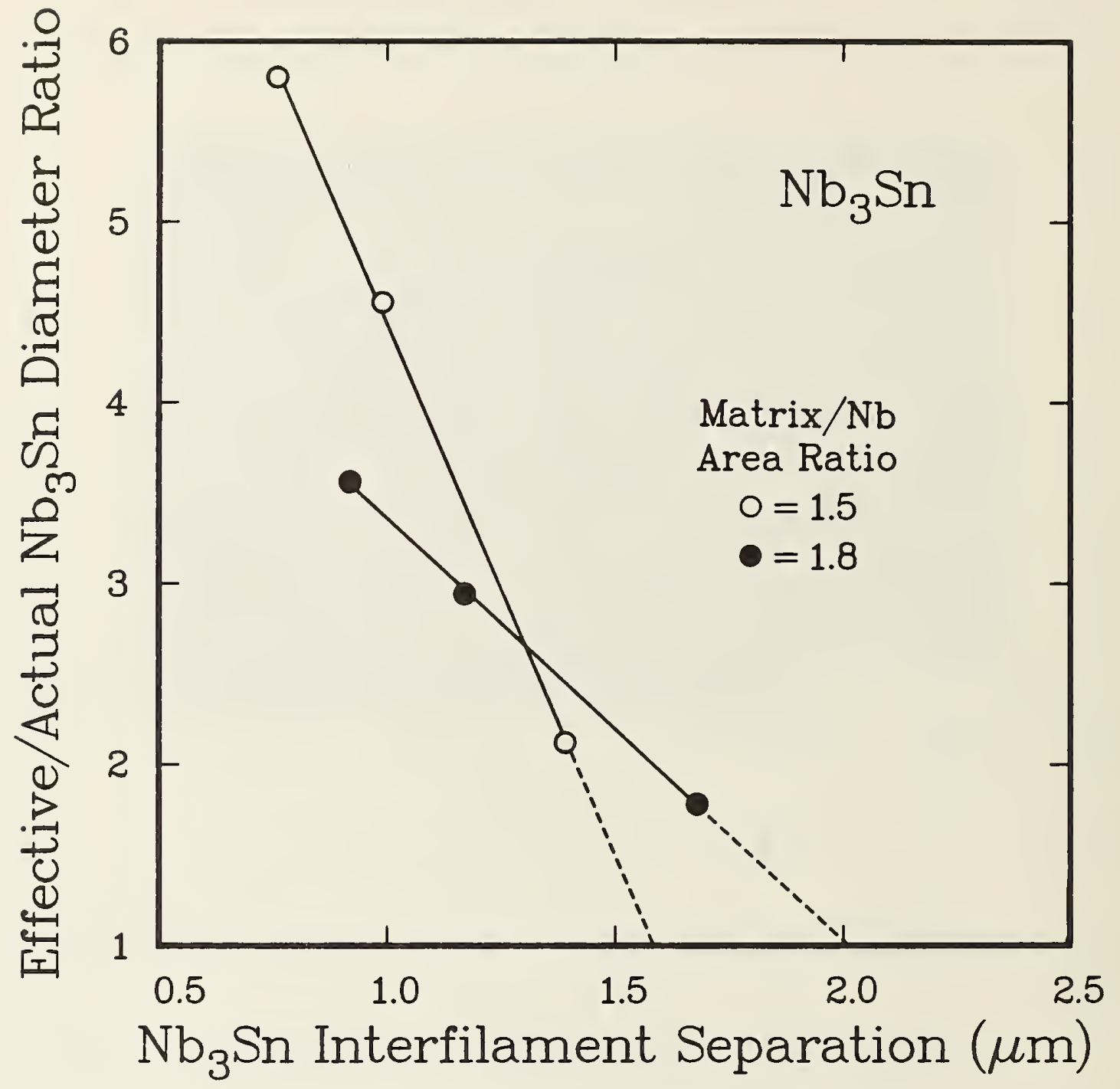

Figure 4. Ratio of effective to actual $\mathrm{Nb}_{3} \mathrm{Sn}$ filament diameter as a function of $\mathrm{Nb}_{3} \mathrm{Sn}$ interfilament separation for two local area ratios of matrix to $\mathrm{Nb}$. 


\author{
R. B. Goldfarb \\ Electromagnetic Technology Division \\ National Bureau of Standards \\ Boulder, Colorado 80303
}

\title{
ABSTRACT
}

This paper reviews some of the concepts needed for the correct analysis of magnetization data, both for magnetic materials and superconductors. Demagnetization factors, initial susceptibilities, and hysteresis losses are discussed.

\section{INTRODUCTION}

Magnetization measurements have acquired an important function in the measurement of ac losses in superconductors. Many of the traditional analysis methods used for magnetic materials apply to superconductors with the assumption of perfect diamagnetism. Some refinement is necessary for type-II and multifilamentary superconductors.

\section{DEMAGNETIZATION FACTORS}

The magnetization curve characteristic of a magnetic material is obtained by plotting magnetization, $M$, versus internal field, $\mathrm{H}_{\text {Int }}{ } \mathrm{H}_{\text {int }}$ is obtained by correcting the external applied field, $\mathrm{H}_{\text {ext }}$, by the demagnetization fleld, $\mathrm{H}_{\text {demag }}=\mathrm{DM}$, where $\mathrm{D}$ is the geometric demagnetization factor. In SI units,

$$
\mathrm{H}_{\text {int }} \equiv \mathrm{H}_{\text {ext }}-\mathrm{DM} \text {. }
$$

For a sphere, $\mathrm{D}=1 / 3$. For a long cylinder, with $\mathrm{H}_{\text {ext }}$ applied axially, $\mathrm{D}=0$; for $H_{\text {ext }}$ applied transversely, $D=1 / 2 . H_{\text {int }}$ corresponds to the field $H$ in 
the equation $B=\mu_{0}(H+M) . \quad H_{i n t}$ is sometimes referred to as the Maxwell field. Here we ignore any ac effects such as eddy currents.

\section{INITIAL SUSCEPTIBILITIES}

Often the initial slope of the magnetization curve is used for calibration of magnetometers. We define the internal susceptibility, $x_{\text {int }}$, as $\mathrm{dM} / \mathrm{dH}_{\text {int }}$ and the external susceptibility, $\chi_{\text {ext }}$, as $\mathrm{dM} / \mathrm{dH}_{\text {ext }}$. Thus, from Eq. 1 ,

$$
\begin{aligned}
& x_{\text {int }}=x_{\text {ext }} /\left(1-\mathrm{D} x_{\text {ext }}\right), \\
& x_{\text {ext }}=x_{\text {int }} /\left(1+D x_{\text {int }}\right) .
\end{aligned}
$$

Let us consider the case of a soft ferromagnet with a very large $x_{\text {int }}$. In a small applied field $\mathrm{H}_{\text {ext }}$, we would measure $\mathrm{M}$ such that, from Eq. 3, $\chi_{\text {ext }}=\mathrm{dM} / \mathrm{dH}_{\text {ext }}=1 / \mathrm{D}$.

We can treat a simple type-I superconductor as a perfectly diamagnetic material: $\chi_{\text {int }}=-1$. In an applied field $\mathrm{H}_{\text {ext }}$, from Eq. 3,

$$
\chi_{\text {ext }}=\mathrm{dM} / \mathrm{dH}_{\text {ext }}=1 /(\mathrm{D}-\mathrm{l}) \text {. }
$$

Thus, for a sphere, $\chi_{\text {ext }}=-3 / 2$. For a long cylinder axially, $\chi_{\text {ext }}=-1$; transversely, $x_{\text {ext }}=-2$.

An interesting case is that of an infinitely thin sheet of finite dimensions. For $\mathrm{H}_{\text {ext }}$ normal to the surface, $\mathrm{D}=1$. From Eq. 4, $x_{\text {ext }}$, and thus M, will approach infinity. While this seems unphysical at first, we note that $M$ is calculated as magnetic moment per unit volume, $V$. M gets infinitely large only as $\mathrm{V}$ approaches zero. Furthermore, for $\mathrm{H}_{\text {ext }}>0$, flux immediately begins to penetrate the sheet in this "intermediate" state; full penetration occurs at $\mathrm{H}=\mathrm{H}_{\mathrm{c}}$, the critical field.

For these cases, we plot M versus Hext in Fig. 1 [1]. Note that M versus $\mathrm{H}_{\text {int }}$ would be characteristic of the material, independent of geometry. The plot of $M$ versus $H_{i n t}$ would be the same as that for the axial cylinder $(D=0)$. 
The same initial $X_{\text {int }}$ would be obtained for a type-II superconductor. The lower critical field, $\mathrm{H}_{c l}$, is signaled when the initial M-versus-H int curve deviates from linearity, indicating flux penetration and the "mixed" state. (The intermediate state is also possible in type-II superconductors.)

\section{HYSTERESIS LOSS}

We now consider hysteresis loss in superconductors. Theoretical loss expressions are usually given in terms of the applied field, $\mathrm{H}_{\text {ext }}{ }^{\circ}$ While a hysteresis loop plotted as $M$ versus $\mathrm{H}_{\text {int }}$ is generally shaped differently from one plotted as $\mathrm{M}$ versus $\mathrm{H}_{\text {ext }}$, the areas enclosed by the loops are the same. This can be seen by integrating $\mathrm{H}_{\text {int }}$ as a function of $\mathrm{M}$ and referring to Eq. 1 , as we now show.

Consider a hysteresis loop plotted as $\mathrm{M}$ versus $\mathrm{H}_{\text {int }}$. Let the end points of the loop be denoted as 1 and 2. The two points are joined by curves $A$ and B. Using the usual convention of integrating $\mathrm{H}$ as a function of $\mathrm{M}$, the area of the loop enclosed by curves $A$ and $B$ is

$$
\begin{aligned}
W & =\int_{1}^{2} \mathrm{H}_{\text {int }}^{\mathrm{A}} \mathrm{dM}-\delta_{1}^{2} \mathrm{H}_{\text {int }}^{\mathrm{B}} \mathrm{dM} \\
& =\int_{1}^{2} \mathrm{H}_{\text {ext }}^{\mathrm{A}} \mathrm{dM}-\mathrm{D} \int_{1}^{2} \mathrm{M} \mathrm{dM}-\delta_{1}^{2} \mathrm{H}_{\text {ext }}^{\mathrm{B}} \mathrm{dM}+\mathrm{D} \int_{1}^{2} \mathrm{M} \mathrm{dM} \\
& =\int_{1}^{2} \mathrm{H}_{\text {ext }}^{\mathrm{A}} \mathrm{dM}-\delta_{1}^{2} \mathrm{H}_{\text {ext }}^{\mathrm{B}} \mathrm{dM} .
\end{aligned}
$$

Thus, the loop areas are the same for both $M$ versus $H_{\text {int }}$ and $M$ versus $H_{\text {ext }}$.

\section{MULTIFILAMENTARY SUPERCONDUCTORS}

The fields in the somewhat special case of a multifilamentary superconductor have been analyzed by Carr [2-4]. In the equations, M now refers to the magnetic moment per unit volume of superconductor, not including matrix material. Often, however, $M$ is expressed as magnetic moment per total 
volume and the volume fraction of superconductor is carried in the equations. For hysteresis calculations, the local field, H 1 oc, applied to each filament is used rather than $\mathrm{H}_{\text {ext }}$ applied to the composite conductor. $\mathrm{H}_{10 c}$ is sometimes referred to as the Lorentz or cavity field:

$$
\mathrm{H}_{\text {loc }} \equiv \mathrm{H}_{\text {int }}+\mathrm{DM} \text {. }
$$

For $\mathrm{H}_{\text {ext }}$ applied axially to the conductor (and filaments), $\mathrm{H}_{1 \mathrm{loc}}=\mathrm{H}_{\text {ext }}=\mathrm{H}_{\text {int }}$. For $\mathrm{H}_{\text {ext }}$ applied transversely, $\mathrm{H}_{\text {loc }}=\mathrm{H}_{\text {int }}+\mathrm{M} / 2$. For the special case when $\mathrm{H}_{\text {ext }}$ is changed slowly and there is no transport current, Eq. 1 applies: $\mathrm{H}_{\text {int }}=\mathrm{H}_{\text {ext }}-\mathrm{M} / 2$. Thus, $\mathrm{H}_{10 c}=\mathrm{H}_{\text {ext }}$. Therefore, we can continue to use $\mathrm{H}_{\text {ext }}$ in the hysteresis loss calculations for this special case. Similarly, $\chi_{1 o c}$, equal to $\mathrm{dM} / \mathrm{dH}_{10 c}$ for multifilamentary conductors, will equal $X_{\text {ext }}$. For the general transverse case, however, shielding effects prevent us from using $\mathrm{H}_{10 c}$ and $\mathrm{H}_{\text {ext }}$ interchangeab1y.

We summarize the equations for $\chi_{\text {int }}$ and $\chi_{\text {ext }}$ when there is no shielding and the volume fraction of superconductor, $\lambda$, is carried in the equations $[2,4]$. We have, for $\mathrm{H}_{\text {ext }}$ applied axially,

$$
x_{\text {int }}=x_{\text {ext }}=-\lambda \text {. }
$$

The expressions for $\mathrm{H}_{\text {ext }}$ applied transversely are

$$
\begin{aligned}
& x_{\text {int }}=-2 \lambda /(1+\lambda), \\
& x_{\text {ext }}=-2 \lambda .
\end{aligned}
$$

Equations 9 and 10 are related by Eqs. 2 and 3.

\section{EFFECTIVE DEMAGNETIZATION FACTOR FOR COILS}

Sumiyoshi et al. derived an effective demagnetization factor, $D_{\text {eff }}$, for a single-layer coil of multifilamentary superconductor parallel to the coil axis [5]. That is, $\mathrm{H}_{\text {ext }}$ is applied transversely to the conductor.

$$
D_{\text {eff }}=[1-\cos (\pi r / d)] /[\cosh (\pi r / d)-\cos (\pi r / d)]
$$


Here, $r$ is the radius of the filament bundle and $2 d$ is the center-to-center separation of the bundles. D eff takes into account the interaction between the turns of the coil. We assume that there is no current in the conductor. In the limiting case where $d \gg r, D_{\text {eff }}=1 / 2$, as for isolated transverse cylinders. In the other limit, $d=r, D_{\text {eff }}=0.1588$. Thus from Eq. 4, $X_{\text {ext }}$ can range from -2 to -1.189 .

The effect of coil-turn interaction has also been discussed by Carr et a1. [6], Zenkevitch and Romanyuk [7], and Campbe11 [8].

\section{CONCLUSION}

The correct analysis of magnetization data requires that one account for demagnetization factors and internal fields. This applies to magnetic materials as well as superconductors.

\section{ACKNOWLEDGMENT}

This work was sponsored by the Air Force Office of Scientific Research.

\section{REFERENCES}

1. E. A. Lynton, "Superconductivity," Methuen, London (1962) p. 25.

2. W. J. Carr, Jr., Electromagnetic theory for filamentary superconductors, Phys. Rev. B 11, 1547 (1975).

3. W. J. Carr, Jr., "AC Loss and Macroscopic Theory of Superconductors," Gordon and Breach (1983) pp. 97-101.

4. W. J. Carr, Jr. and G. R. Wagner, Hysteresis in a fine filament NbT1 composite, in: "Advances in Cryogenic Engineering (Materials)," Vol. 30, A. F. Clark and R. P. Reed, eds. (1984) pp. 923-30.

5. F. Sumiyoshi, F. Irie, and K. Yoshida, The effect of demagnetization on the eddy-current loss in a single-layered multifilamentary superconducting coil, J. App1. Phys. 51, 3807 (1980).

6. W. J. Carr, Jr., B Clawson, and W. Vogen, AC losses in superconducting solenoids, IEEE Trans. Magn. MAG-14, 617 (1978). 
7. V. B. Zenkevitch and A. S. Romanyuk, Effect of magnetic properties of a composite superconductor on the losses in a variable magnetic field. Part 3: Collective interaction of turns, Cryogenics 20, 79 (1980).

8. A. M. Campbe11, A general treatment of losses in multifilamentary superconductors, Cryogenics 22, 3 (1982). 


\section{Applied Field, $\mathrm{H}_{\text {ext }}$}

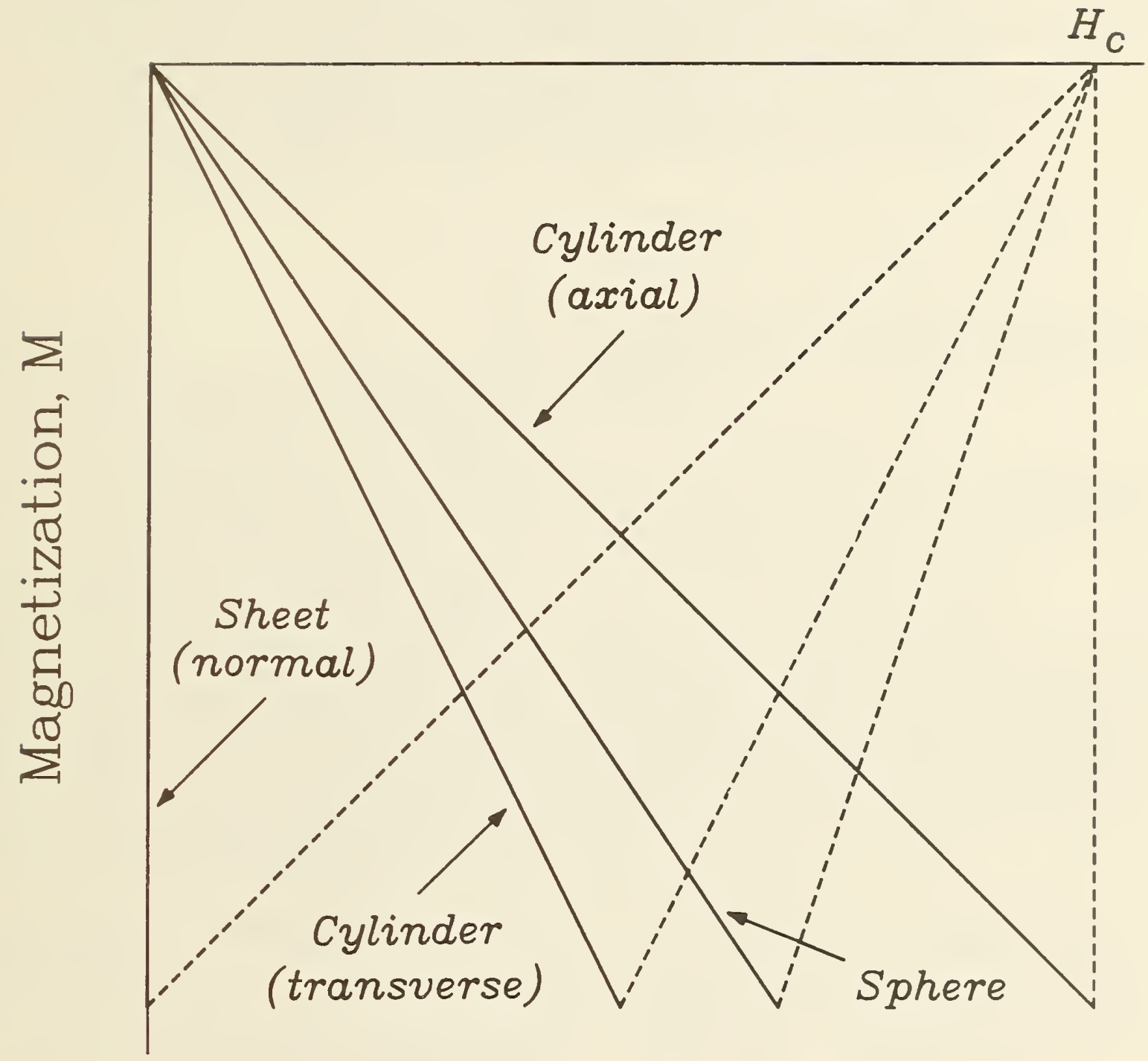

Figure 1. Magnetization versus external applied field for an ideal type-I superconductor of various geometries. The external susceptibilities are given by the initial slopes. The broken lines indicate flux penetration for the intermediate states. After Lynton [1]. 



\title{
Calibration of ac susceptometer for cylindrical specimens
}

\author{
R. B. Goldfarb and J. V. Minervini
}

Electromagnetic Technology Division, National Bureau of Standards, Boulder, Colorado 80303

(Received 11 November 1983; accepted for publication 30 January 1984)

The absolute magnetic susceptibility of cylindrical specimens is obtained with an ac susceptometer whose calibration is based on a calculation of mutual inductance. An axially magnetized cylinder is modeled as a solenoid of the same size. The mutual inductance between such a solenoid and a pickup coil of arbitrary dimensions is computed. The susceptibility is then a function of the mutual inductance, the cylinder length, the magnitude and frequency of the ac magnetizing field, and the voltage induced on the pickup coil. Demagnetization factor and eddycurrent effects are considered, an example is given, and pickup coil compensation is discussed. Other calibration methods are also presented.

PACS numbers: 07.55. $+\mathrm{x}$

\section{INTRODUCTION}

A useful method of measuring the magnetic susceptibility of nonferromagnetic materials employs an ac field source and a pickup coil. A typical circuit is shown in Fig. I. Such pickup coils usually require calibration with standards of similar size to that of the specimens under study, except for the case of thin pickup coils with ellipsoidal samples, whose dipolar fields allow a closed-form mathematical solution. ${ }^{1}$

A method of calibration of an ac susceptometer for relatively long cylindrical specimens of arbitrary dimensions, coaxial with a pickup coil, is based on a calculation of mutual inductance. The mutual inductance between two coaxial coils (inner and outer) may be numerically computed. Since the flux density distribution of a uniformly, longitudinally magnetized cylinder of uniform composition is the same as that of a solenoid of the same size, a cylindrical specimen may be modeled as an inner coil. The calculation of mutual inductance leads to the absolute magnetic volume susceptibility of the cylinder, when an ac field is applied, in terms of the emf induced on the outer pickup coil.

\section{CALIBRATION BY CALCULATION OF MUTUAL INDUCTANCE}

\section{A. Equivalent solenold}

In general, the flux density B may be thought of as due to Amperian currents of volume density $\nabla \times \mathbf{M}$ and surface density $\mathbf{M} \times \hat{n}$, where $\mathbf{M}$ is the magnetization and $\hat{n}$ is the unit vector normal to the surface. The flux density $B$ external to a cylinder of uniform axial magnetization $(\nabla \times \mathbf{M}=0)$ is equivalent to that of a model solenoid of the same size with ampere-turn density $N I / l$, where $M$ has units $\mathrm{A} / \mathrm{m}, N$ is the number of turns, $I$ is the current, and $l$ is the length:

$$
M=N I / l \text {. }
$$

The near field cannot be expressed in closed form, but may be computed by superposition of $\mathbf{B}$ due to elemental uniformly magnetized disks or elemental circular current loops for the cylinder or equivalent solenoid, respectively. The near field of a current loop is well known. ${ }^{2.3}$
The total magnetic flux (flux linkage) $\Phi$ sensed by the pickup coil may be calculated from either B or the vector potential A:

$$
\Phi=\iint \mathbf{B} \cdot d \mathbf{a}=\oint \mathbf{A} \cdot d \mathbf{s},
$$

where $d \mathbf{a}$ is the incremental area, $d \mathbf{s}$ is the incremental contour, and the integrations are over the entire pickup coil. The mutual inductance per solenoid turn is

$$
L *=L_{12} / N=\Phi / N I=\frac{1}{N I} \oint \mathbf{A} \cdot d \mathbf{s},
$$

where $L_{12}$ is the mutual inductance between the solenoid and the pickup coil. $L_{12}$ is proportional to $N ; L$ is independent of $N$ but depends on the geometries of the solenoid (i.e., specimen) and the pickup coil, and the number of turns on the pickup coil. A general mutual inductance calculation is detailed in Sec. I B. The emf induced in the pickup coil due to the solenoid is

$$
v=-d \Phi / d t=-L_{12} d I / d t .
$$

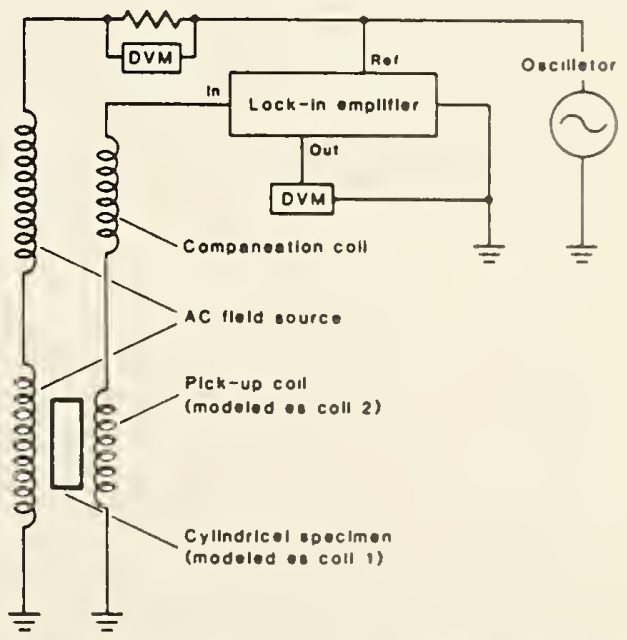

FiG. 1. One method [see number (6) in Table II] of measurnng ac susceplibil. ity. 
Converting current to magnetization using Eq. 1,

$$
v=-L * l d M / d t \text {. }
$$

To this point, the ac field source has not been part of the derivation. In fact, it has been and will continue to be assumed that the emf induced in the pickup coil by the field source is nulled (see Sec. II B). The ac field is assumed to be uniform. Substituting $M=\chi H$, where $\chi$ is the volume susceptibility (dimensionless), $H=H_{0} \cos 2 \pi f t$ is the applied ac magnetic field, and rearranging Eq. (5), the final result is obtained:

$$
\chi=\frac{v_{\mathrm{rms}}}{L * / 2 \pi f H_{\mathrm{rms}}},
$$

where $f$ is in hertz and $\chi$ is in SI units. To convert to cgs units, the value of $\chi$ is divided by $4 \pi$. The assumption of uniform $M$ and $H$ is a good one for relatively long cylinders characterized by small demagnetiztion factors (see Sec. I C).

\section{B. Mutual inductance of coaxial solenoids}

"The mutual inductance $\left[L_{12}\right.$ in Eq. (3)] may be calculated using computer techniques for the general case of coaxial, but not necessarily concentric, thick solenoids. Figure 2 shows the geometry and defines some of the variables. The mutual inductance is calculated by integrating $\mathbf{A}$, due to a current density $J$ in coil 1 , around the turns of coil 2 . The vector potential $\mathbf{A}$ has only a $\phi$ component. At the point $(r, \phi, z)$ in cylindrical coordinates, ${ }^{4}$

$$
\begin{aligned}
\mathbf{A}_{\phi}(r, z) & =\left.\frac{\mu_{0} J}{4 \pi} \int_{a_{11}}^{a_{12}} d a a \int_{0}^{2 \pi} d \theta \cos \theta \ln \left[\xi+\left(\xi^{2}+r^{2}+a^{2}-2 a r \cos \theta\right)^{1 / 2}\right]\right|_{\xi_{1}} ^{\xi_{2}} \\
& =\frac{\mu_{0} J}{4 \pi} \int_{a_{11}}^{a_{12}} d a a^{2} \int_{0}^{2 \pi} d \theta\left(\frac{\xi r \sin ^{2} \theta}{\left(a^{2}+r^{2}-2 a r \cos \theta\right)\left(\xi^{2}+r^{2}+a^{2}-2 a r \cos \theta\right)^{1 / 2}}\right) \xi_{\xi_{1}} \equiv \frac{\mu_{0} J}{4 \pi} \Lambda(r, z),
\end{aligned}
$$

where $\xi=z-\lambda, \xi_{1}=z-l / 2, \xi_{2}=z+l / 2$, and the cylindrical coordinates of each current element are $a, \theta, \lambda . J$ is assumed constant and is simply

$$
J=\frac{N I}{l\left(a_{12}-a_{11}\right)} .
$$

From the expression for $L_{12}$ in Eq. (3), and using Eqs. (7) and (8)

$$
L_{12}=\frac{\mu_{0} N}{4 \pi l\left(a_{12}-a_{11}\right)} \oint \Lambda(r, z) \cdot d \mathbf{s},
$$

where $I$ is canceled. For the purpose at hand, $a_{12} \gtrsim a_{11}=d / 2$, where $d$ is the specimen diameter. All that remains is to compute the contour integral of $\boldsymbol{\Lambda}$.

For purposes of computation, coil 2 is divided into $n \times m$ circular rings, usually not coincident with the actual windings (see Fig. 2). The radius of each ring is

$$
r_{i}=a_{21}+\left(i-\frac{1}{2}\right)\left(a_{22}-a_{21}\right) / n, \quad i=1,2, \ldots, n,
$$

and its position is

$$
z_{j}=z_{d}-\frac{1}{2} l_{2}+\left(j-\frac{1}{2}\right) l_{2} / m, \quad j=1,2, \ldots, m .
$$

The double integral $\mathbf{\Lambda}$ [given in Eq. (7)] is evaluated for each ring located at $\left(r_{i}, z_{j}\right)$ using a standard library routine. Then the contour integral of $\Lambda$ in Eq. (9) is simply

$$
\oint \Lambda(r, z) \cdot d s=\frac{N_{2}}{m n} \sum_{i=1}^{n} \sum_{j=1}^{m} 2 \pi r_{i} \Lambda\left(r_{i}, z_{j}\right),
$$

where $d s$ is $r d \phi$. The factor $N_{2} / m n$ is introduced to scale $L_{12}$ to reflect the actual number of turns in coil 2. If the coil displacement $z_{d}$ is zero (the usual case when the specimen cylinder is centered in the pickup coil), the index $j$ can run from 1 to $\mathrm{m} / 2$ and the result for $L_{12}$ doubled, thereby taking advantage of the axial symmetry. The number of $n \times m$ discrete segments should be chosen to optimize the tradeoff between accuracy and computation time.

Other procedures may be used to calculate $L_{12}$. Thincoil approximations are clearly suitable for the model solenoid and are often adequate for the pickup coil. ${ }^{5}$

\section{Demagnetization factor considerations}

When susceptibilities are large or when cylinders are not too long, the measured $\chi$ should be corrected for demagnetization fields

$$
\chi_{\text {int }}=\chi /(1-D \chi) \text {. }
$$

where $\chi_{1 n}$ is the "internal" susceptibility, corrected for demagnetization, and $D$ is the demagnetization factor $(0<D$ $<1$ in SI). Exact values of $D$ are obtainable only for ellipsoids. Average values for uniformly magnetized cylinders have been computed by Brown ${ }^{6.7}$ and $\mathrm{Crabtree}^{8}$ and are given in Table I. These "magnetometric" values are greater than those "ballistic" values reported by Bozorth and Chapin ${ }^{9}$ for highly permeable rods. The latter were experimentally determined and based on the magnetization at the middle of a rod rather than an average over the entire volume. Note that the approximation of uniform longitudinal mag-

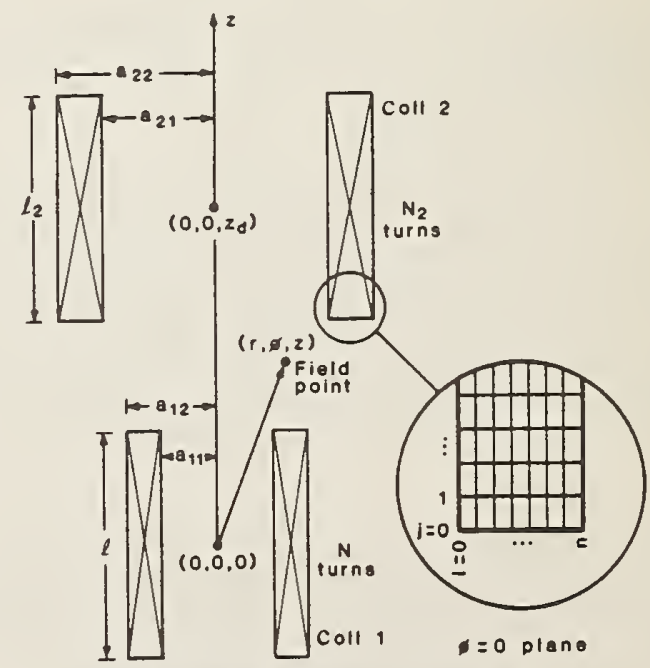

FiG. 2. Geometry for mutual inductance calculations. 
netization is realistic only in the cases of materials with small susceptibiluties, or relatively long cylinders characterized by small demagnetization factors. Therefore, calculations with cylinders are alrays approximate to some degree.

\section{Eddy current considerations}

The eddy currents induced in a conducting material exposed to an alternating magnetic field are a function of the matenal's susceptibility, resistivity, and geometry. These currents give rise to an internal field which differs from the applied feld in magnitude and phase. For accurate susceptibility measurements, these deviations should be minimized.

Zijlstra ${ }^{10}$ examines the case of an infinitely long cylinder subject to an ac axial field. The deviations in field magnitude and phase are a function of the reduced radius

$$
a_{0}=d / \sqrt{2} \delta
$$

where $d$ is the cylinder diameter and $\delta$ is the skin depth,

$$
\delta=(\rho / \pi f \mu)^{1}=
$$

where $\rho$ is the material resistivity, $f$ is the frequency, and $\mu$ is the permeability equal to $\mu_{0}(1-\chi)$, where $\mu_{0}$ is the permeability of free space.

The analysis shor's that magnitude errors in $\chi$ are less than $3 \%$ when $a_{0}<0.9$ and that errors in both magnitude ant phase are negligible when $a_{0}<0.2$. The restriction on $a_{0}$ may be met by reducing $d$ and $f$, since $\rho$ and $\mu$ are materials properties.

\section{EXPERIMENT}

\section{A. Example}

The dependence of $L$ * upon a cylinder's length and diameter was computed for a specific pickup coil for illustra. tive purposes. A plot is shown in Fig. 3. The normalization of the variables applies to this particular coil only.

The room temperature susceptibility of a sample of AISI-type 316 stainless steel tas measured using this coil.

TABLE 1. Longitudinal demagnetization factors $D$ for crlinders as a func-

\begin{tabular}{|c|c|c|c|c|c|}
\hline $1 / 0$ & $D$ & $1 / d$ & $D$ & $1 / d$ & $D$ \\
\hline 0.0 & 1.000 & 2.0 & 0.181 & 1.0 & 0.0978 \\
\hline 0.1 & 0.796 & 2.1 & 0.174 & 4.1 & 0.0956 \\
\hline 0.2 & 0.630 & 2.2 & 0.167 & 1.2 & 0.0935 \\
\hline 0.3 & 0.594 & 2.3 & 0.161 & 1.3 & 0.0914 \\
\hline 0.4 & 0.528 & 24 & 0.155 & 4.4 & 0.0895 \\
\hline 0.5 & 0.474 & 2.5 & 0.149 & 45 & 0.0876 \\
\hline 0.6 & 0.430 & 2.6 & 0.144 & 4.6 & 0.0858 \\
\hline 0.7 & 0.393 & 2.7 & 0.140 & 4.7 & 0.0841 \\
\hline 0.8 & 0.361 & 2.8 & 0.135 & 4.8 & 0.0824 \\
\hline 0.9 & 0.334 & 2.9 & 0.131 & 4.9 & 0.0808 \\
\hline 1.0 & 0.311 & 3.0 & 0.127 & 5.0 & 0.0793 \\
\hline 1.1 & 0.291 & 3.1 & 0.123 & 5.5 & 0.0723 \\
\hline 1.2 & 0.273 & 3.2 & 0.120 & 6.0 & 0.0666 \\
\hline 1.3 & $0.25 \%$ & 3.3 & 0.116 & 6.5 & 0.0616 \\
\hline 1.4 & 0.242 & 3.4 & 0.113 & 7.0 & 0.0573 \\
\hline 1.5 & 0.230 & 3.5 & 0.110 & -.5 & 0.0536 \\
\hline 1.6 & 0.218 & 3.6 & 0.107 & 8.0 & 0.0503 \\
\hline 1.7 & 0.207 & 3.7 & 0.105 & 8.5 & 0.0473 \\
\hline 1.8 & 0.198 & 3.8 & 0.102 & 9.0 & $0.04=7$ \\
\hline 1.9 & 0.189 & 3.9 & 0.100 & 10.0 & 0.0403 \\
\hline
\end{tabular}
tion of the ratio of length to diameter //d [after Crabtree / Ref. 31].
The result was verified with a SQUID susceptometer. A cylinder of length $10.2 \mathrm{~cm}$ and diameter $1.2 \mathrm{~cm}$ Hias prepared. $L$ * was computed to be $14 \mu \mathrm{H}$ for the combination of cylin. der and pickup coil. An as field of $570-\mathrm{A} / \mathrm{m}$ ms at $100 \mathrm{~Hz}$ was applied. $\chi$ tras found to be $2.9 \times 10^{-3}$ (SI). This a pproximates the smallest values of susceptibility which can be accurately measured with the present apparatus. A small piece of steel was obtained from the same rod stock for SQUID measurement. Using a density of $7.958 \mathrm{z} / \mathrm{cm}^{3},{ }^{11} \chi$ was $3.0 \times 10^{-3}$, in good agreement with the mutual inductance method. Taking a resistivity of $75 \mu \Omega \mathrm{cm},{ }^{12}$ and applying the eddy-current criterion of Sec. I D, $a_{0}$ is found to be 0.195 , which is very acceptable.

\section{B. Coil compensation}

As mentioned in Sec. II A, the background emf of the pickup coil with no sample present needs to be subtracted from the measured emf with the sample in place. This may be done by the various methods shown in Table II. Methods 4 , $(5)$, and (6) seem to be satisfactory; method 6), illustrated in Fig. 1, is the least expensive and most straightformard.

\section{OTHER CALIBRATION METHODS}

\section{A. Change in self-inductance}

A variation of the method described in Sec. I A is that of relating the change in self-inductance of a pickup coil, after a specimen is inserted, to the magnetic susceptibility of the specimen. This technique may be used with a commercial inductance meter equipped with a convenient zero offset. Such devices may be thought of as applying a sinusoidal current to a test coil and measuring the voltage across it. The following equations apply:

$$
v_{s}=-L_{s} \frac{d I}{d t},
$$

where $L_{5}$ is the self-inductance,

$$
\begin{aligned}
& I=I_{0} \cos 2 \pi f i, \\
& v_{s m s}=2 \pi f I_{\text {rms }} L_{s} .
\end{aligned}
$$

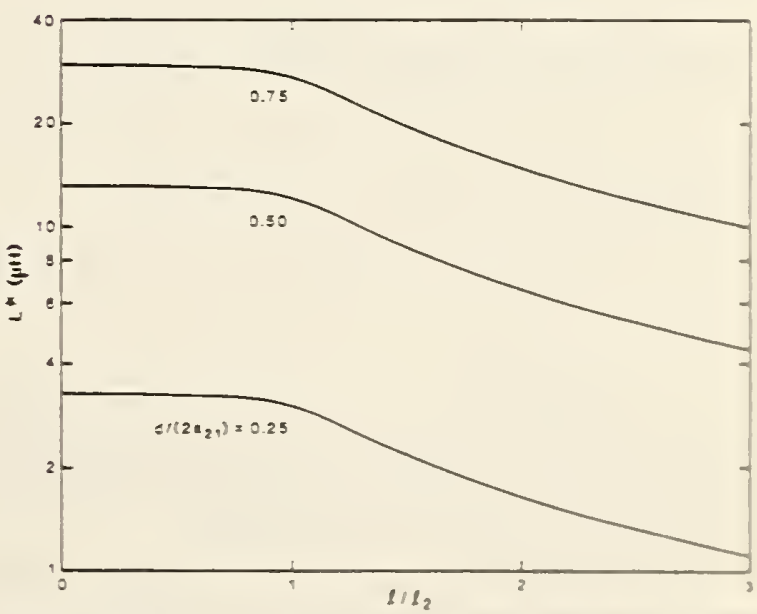

FIG. 3. Dependence of $L$ 'upon cylinder length and diameier The puchup coil parameters are: $a_{z 1}=119 \mathrm{am} . a_{z:}=133 \mathrm{~mm} .=1=\mathrm{mm}$ $v_{2}=6042_{2}=0$. 


\begin{tabular}{lll}
\hline & Method of coil compensation & Remarks \\
\hline (1) & Subtract dc out put of lock-in amplifier for empty pickup coil & Simple; poor resolution because $\Delta v / v$ is small \\
(2) & Null dc output of lock-in amplifier using internal offset & Simple; offset works only over limited range \\
(3) & Subtract ac signal of pickup coil using digital recording oscilloscope & Any phase shift caused by eddy currents gives errors \\
(4) & Subtract rms level of ac signal of pickup coil using digital oscilloscope & Digital processing and noise filtering needed \\
(5) & Subtract an ac waveform equal to that of empty pickup coil, using a & Need stable phase-lock phase shifter with variable gain; \\
(6) & differential amplifier, before input to lock-in amplifier & eddy-current phase shifts give errors \\
\hline
\end{tabular}

From Eq. (6), the sample contribution to the voltage is

$$
v_{\mathrm{rms}}=L * / \chi 2 \pi f H_{\mathrm{rms}} \text {. }
$$

The field $H_{\text {rms }}$ is proportional to the current in the coil

$$
H_{\text {rms }}=c I_{\text {rms }} \text {, }
$$

where $c$ is a constant of dimension $m^{-1}$. The total voltage is

$$
\begin{aligned}
v_{s, \mathrm{rms}}+v_{\mathrm{rms}} & =2 \pi f I_{\mathrm{rms}}\left(L_{s}+c L * l \chi\right) \\
& \equiv 2 \pi f I_{\mathrm{rms}}\left(L_{s}+\Delta L\right) .
\end{aligned}
$$

The volume susceptibility is obtained from the increase in inductance $\Delta L$ when the specimen is inserted in the coil

$$
\chi=\frac{\Delta L}{c L=l} .
$$

This method, relying on the coil for both field and pickup, is less sensitive than the method in Sec. I A.

\section{B. Calibration with standards}

It is often desirable to calibrate susceptometers experimentally, which requires the use of standards. The resulting calibration is strictly valid only for specimens of the same size and shape as the standard used.

\section{Materials with known susceptibility}

The NBS Office of Standard Reference Materials sells four susceptibility standards: $\mathrm{Al}, \mathrm{Pt}, \mathrm{Pd}$, and $\mathrm{MnF}_{2}$, with $\chi$ ranging from $2 \times 10^{-5}$ to $6 \times 10^{-3}$ (SI) at room temperature. ${ }^{13}$ They are available in various forms.

\section{Soft ferromagnets with "infinite" internal susceptibility and known demagnetization factor}

An example is a spherical sample of Gd near its Curie temperature. Some provision for cooling is needed to experimentally obtain the maximum pickup voltage.

The susceptibility $\chi$ is generally proportional to the pickup coil voltage $v$, and inversely proportional to the sample volume $V$, the ac field $H$, and its frequency $f$ :

$$
\chi=\alpha v / V f H .
$$

The empirical calibration constant $\alpha$ is obtained by measuring the pickup coil voltage $v_{0}$ for a sphere of volume $V_{0}$ and demagnetization factor $1 / 3$ in a field $H_{0}$ of frequency $f_{0}$. Assuming an infinite $\chi_{\text {Int }}$, Eq. (13) yields

$$
1-D \chi_{0}=0 \text {, }
$$

whence the measured susceptibility $\chi_{0}=3$. Thus,

$$
\alpha=3 V_{0} f_{0} H_{0} / v_{0} \text {. }
$$

\section{Superconducting materials with known demagnetization factor}

An example is a spherical sample of $\mathrm{Nb}$ below its critical temperature. The ability to cool to cryogenic temperatures is required. The perfect diamagnetism $\left(\chi_{\mathrm{in}}=-1\right)$ of superconductors arises from the Meissner effect. From Eq. (13),

$$
\chi_{0}=D \chi_{0}-1 \text {, }
$$

and for the sphere, $\chi_{0}=-3 / 2$, or $3 / 2$ but $180^{\circ}$ out of phase. Equation (23) applies with

$$
\alpha=3 V_{0} f_{0} H_{0} / 2 v_{0} \text {. }
$$

Similar calibrations may be done, of course, with cylindrical standards using the approximate demagnetization factors in Table I. Methods of preparing spheres are described in Ref. 14.

\section{ACKNOWLEDGMENTS}

F. R. Fickett, S. M. Goodnick, C. A. Hamilton, and D. A. Krueger commented critically and valuably on the manuscript. The work was partially funded by the Air Force Office of Scientific Research.

'See, for example, the result given in W. R. Abel, A. C. Anderson, and J. C. Wheatley, Rev. Sc1. Instrum. 35, 444 (1964).

${ }^{2} J$. D. Jackson, Classical Electrodynamics (Wiley, New York, 1962), pp. 142 and 143.

${ }^{3}$ W. R. Smythe, Static and Dynamic Electricity, 3rd ed. (McGraw-Hill, New York, 1968), pp. 290 and 291.

${ }^{4}$ The derivation of the vector potential for a thick solenoid may be found in G. V. Brown, L. Flax, E. C. Itean, and J. C. Laurence, NASA Tech. Report No. TR R-170, December 1963, available at NTIS, Springfield, Virginia, N64-15331.

${ }^{3}$ Formulas and tables for the mutual inductance of coaxial, single-layer coils may be found in F. W. Grover, Inductance Calculations (Van Nostrand, New York, 1946), Chap. 15; E. B. Rosa and F. W. Grover, Bull. Bur. Stand. 8, 1 (1912).

'W. F. Brown, Jr., Am. J. Phys. 28, 542 (1960).

${ }^{7}$ W. F. Brown, Jr., Magnetostatic Principles in Ferromagnetism (NorthHolland, Amsterdam, 1962), pp. 187-192. The magnetometric demagnetization factors may be obtained from the self-inductance of the model solenoid.

${ }^{H}$ G. W. Crabtree, Phys. Rev. B 16, 1117 (1977).

${ }^{9}$ R. M. Bozorth and D. M. Chapin J. Appl. Phys. 13, 320 (1942).

${ }^{10} \mathrm{H}$. Zijlstra, Experimental Methods in Magnetism (North-Holland, Amsterdam, 1967), Vol. 2, pp. 72-79.

"'H. M. Ledbetter, Met. Sci. 14, 595 (1980).

${ }^{12}$ F. R. Fickett, in Materials at Low Temperatures, edited by R. P. Reed and A. F. Clark (American Society for Metals, Metals Park, Ohio, 1983), Chap. 5, p. 197.

${ }^{13}$ NBS Spec. Publ. 260 (Office of Standard Reference Materials, National Bureau of Standards, Washington, D. C., 1981).

14J. N. Paranto and C. E. Patton, Rev. Sci. Instrum. 52, 262 (1981). 


\author{
R. G. Benson, R. B. Goldfarb, and E. S. Pittman \\ Electromagnetic Technology Division \\ National Bureau of Standards \\ Boulder, Colorado 80303
}

\begin{abstract}
A multifunction circuit is described that protects, in the event of a quench, instruments connected or coupled to a superconducting magnet.
\end{abstract}

\title{
INTRODUCTION
}

Most laboratory superconducting magnets are suitably protected against damage if they revert to the normal state (quench). Often it is desirable to provide protection for instruments connected or coupled to such a magnet. Such protection is provided by a circuit that performs three functions: sends an interrupt command to a computer via an interface card, (2) protects an analog-to-digital (A/D) card that monitors the magnet voltage from large voltages generated during a quench, and (3) shorts the output of a digital-toanalog (D/A) programming-voltage card and thus nulls the output of the magnet current supply. A diode bank that protects a magnet power supply is also described.

\section{QUENCH DETECTION CIRCUIT}

A superconducting magnet in our laboratory is powered by a constantcurrent supply. This power supply, programmed with the dc voltage output of a D/A card, is bipolar and referenced to ground. The D/A card is controlled by a microcomputer. The magnet voltage, $\mathrm{L} d I / d t$, is sensed by an $A / D$ card which 
in turn is connected to the computer. By monitoring this voltage, the computer is able to determine when the magnet has finished charging or discharging.

In the event of a quench, we wish to: (1) inform the computer that a quench has occurred by enabling the interrupt card, (2) protect the A/D card against possible high magnet voltages, and (3) bring the power supply output to zero by nulling the programming voltage of the current supply.

We designed and constructed a circuit to perform these tasks. The input is connected across the magnet. The circuit's input impedance is greater than $500 \mathrm{k} \Omega$. A comparator-threshold adjustment sets the voltage criterion for a quench $(\mathrm{e} . \mathrm{g} ., 3.5 \mathrm{~V})$. A time-constant adjustment prevents the quench detector from triggering on random, transient voltage spikes. This sets a time delay of, typically, 10 to $250 \mathrm{~ms}$ for actual quench detection. When a quench is detected, an LED turns on. Once the magnet voltage has decreased to below the quench-detection threshold, pressing the RESET button rearms the circuit.

The circuit schematic is shown in Fig. 1. There are three outputs: INTERRUPT, A/D OUT, and D/A OUT. (1) When a quench is detected, a logical "l" is sent to the interrupt card. (2) A/D OUT normally sends the magnet voltage to the A/D card. In the event of a quench, a relay breaks this connection. Additional protection is provided by a series fuse. Finally, two Zener diodes, D3, in parallel with the output prevent the magnitude of the output voltage from exceeding $12 \mathrm{~V}$. (3) D/A OUT is normally an open switch in parallel with the output of the D/A card. When a quench occurs, Relay A closes, forcing the programming voltage of the magnet current supply to zero. (The D/A card is internally current limited.)

The circuit is divided into several stages: input protect, absolute value, voltage comparator, latch logic, and output stages. 
Input protect. Large voltage spikes dissipate power in resistor R1. The input voltage to the rest of the circuit is limited to about $10 \mathrm{~V}$ by the two Zener diodes D1.

Absolute value. The absolute value stage uses two operational amplifiers, $A 1$ and $A 2$, and has a positive output with unity gain. For positive input voltages, diode D2 is reverse biased, A2 is effectively removed from the circuit, and $\mathrm{Al}$ is a unity-gain amplifier. For negative voltages, D2 is forward biased, the positive input to $\mathrm{Al}$ is grounded, and $\mathrm{Al}$ acts as an inverter.

Voltage comparator. The comparator produces a low output of zero volts for inputs greater than the reference voltage and a high output of $4 \mathrm{~V}$ otherwise. The feedback resistor provides some hysteresis in the comparator. The QUENCH-THRESHOLD adjustment R2 sets the comparator reference voltage $V_{\text {ref }}$. The TIME-CONSTANT adjustment R3 is part of a simple RC filter.

Latch logic. When the circuit is turned on, the 10- $\mu \mathrm{F}$ capacitor Cl holds the CLEAR input to ground long enough to allow the flip-flop to start in the cleared state (Q low and $\bar{Q}$ high). After about $10 \mathrm{~ms}$, the CLEAR input goes high. It can be set low with the RESET button. When a quench is detected, the output of the voltage comparator goes low and SET becomes active, causing $Q$ to go high and $\bar{Q}$ low.

Output stages. When $Q$ is high, a logical " 1 " is sent to the interrupt card. Also, transistor $\mathrm{T} l$ is turned on, which lights the LED and closes Relay A. This in turn shorts D/A OUT, which zeros the programming voltage to the power supply. When $\bar{Q}$ is low, transistor T2 is turned off. This opens Relav $B$, which protects the A/D card. 
POWER SUPPLY PROTECTION

Power supplies designed for use with superconducting magnets are often built with quench protection. A quench is accompanied by large voltages (typically a few hundred volts) and currents of polarity opposite that of the charge current. Most power supplies are not designed to sink reverse current. In the case of a unipolar dc supply, adequate protection may be provided by a reverse-biased, heat-sinked power diode across the output terminals, in parallel with the magnet leads.

In the case of a bipolar supply, however, the forward voltage drop of the diode would be too small for negative-current operation; magnet charging voltages are often as great as $3 \mathrm{~V}$. We have constructed an array of heatsinked 1N3111 diodes to protect such bipolar supplies. The circuit is shown in Fig. 2. It is connected across the output of the power supply, in parallel with the magnet leads. The diode array does not conduct for typical magnet charging voltages. If quench voltages are large in either polarity, the array conducts, thereby protecting the power supply. The six diodes in series in either direction begin to conduct at $4 \mathrm{~V}$ and conduct well at $5 \mathrm{~V}$.

\section{ACKNOWLEDGEMENT}

This work was sponsored by the Air Force Office of Scientific Research. 


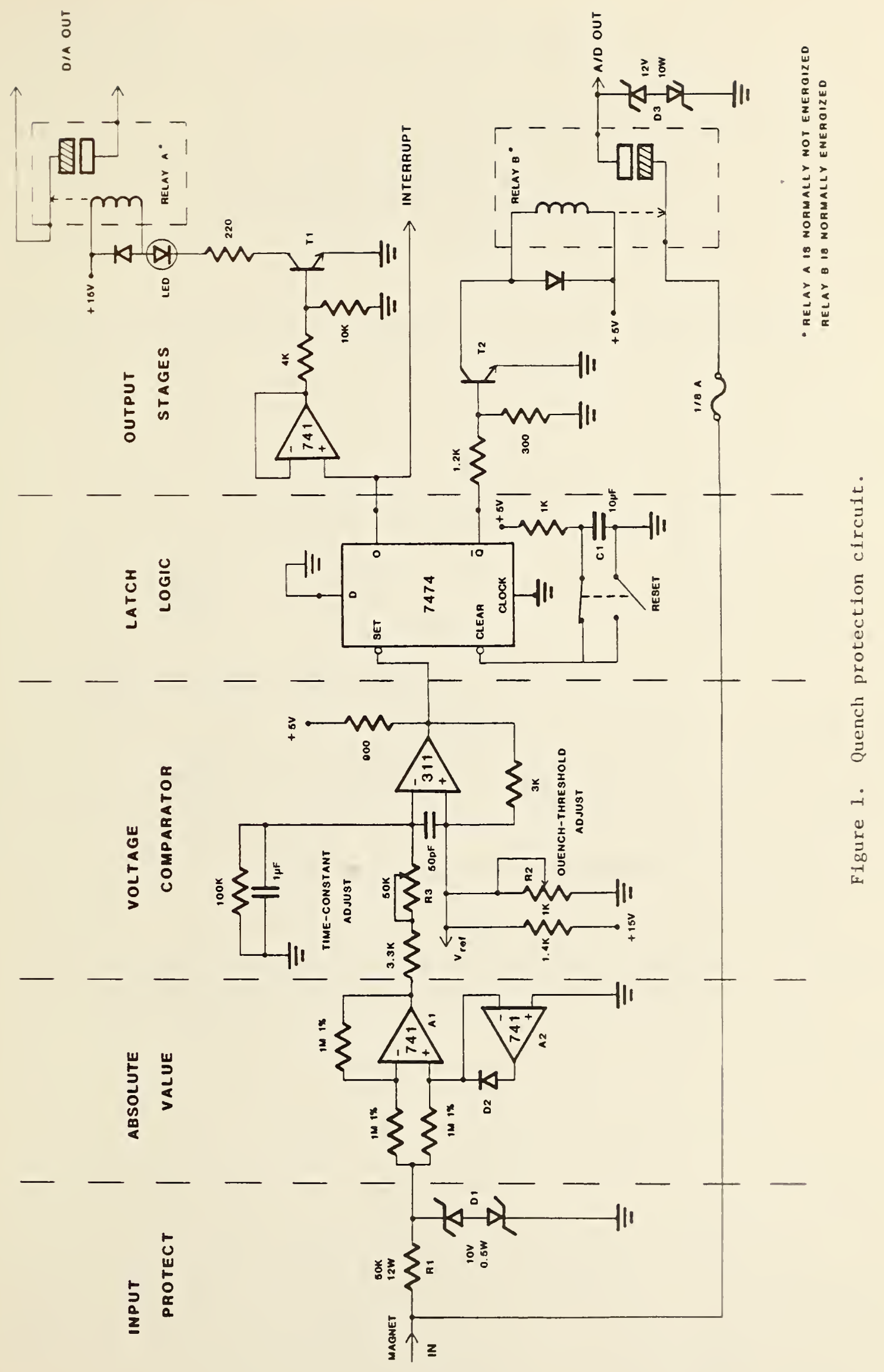




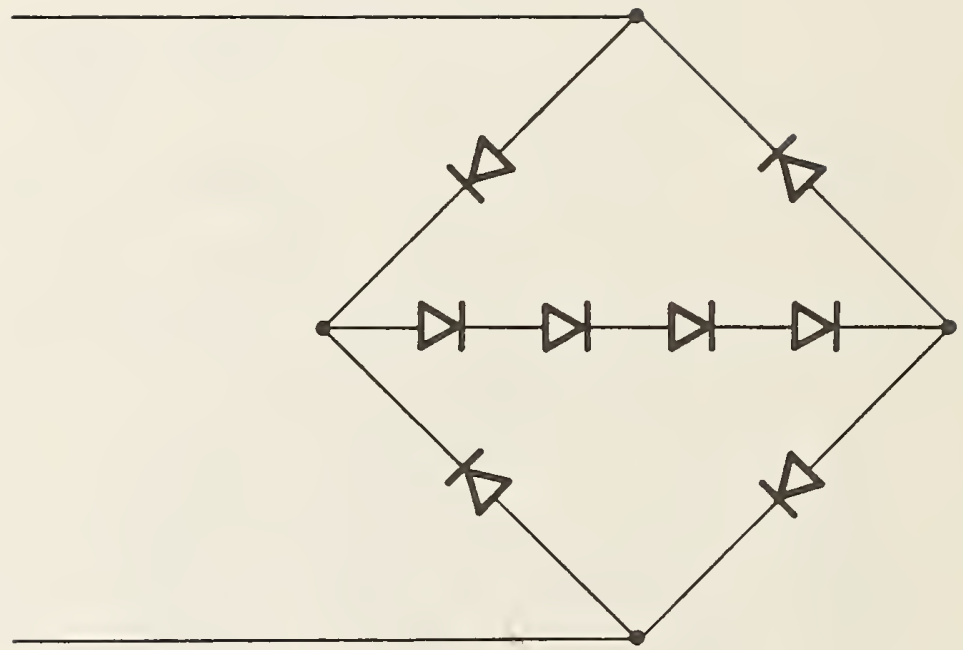

Figure 2. Diode array for power supply protection. 


\author{
R. B. Goldfarb \\ Electromagnetic Technology Division \\ National Bureau of Standards \\ Boulder, Colorado 80303
}

I. PHYSICAL CHARACTERISTICS OF MULTIFILAMENTARY Nb-Ti SUPERCONDUCTORS

We have found that, except for the number of $\mathrm{Nb}-\mathrm{Ti}$ filaments, superconductor wire manufacturers of ten do not reliably report the physical characteristics of their wires. For accurate magnetization and loss calculations, however, we must know the copper-to-superconductor volume ratio and the filament radius in addition to measured magnetic moment. It is also useful to know the density of the $\mathrm{Nb}-\mathrm{Ti}$ alloy. This note describes how we determine these parameters.

A 1.000-meter length of wire is stripped of its insulation. We measure its mass, mwire. Using Archimedes' principle, we determine its volume, Vire The wire is then soaked in a $50 \%$ solution of nitric acid and water to remove the copper, leaving only the Nb-Ti filaments. The filaments are rinsed and thoroughly dried. We then measure their mass, $\mathrm{m}_{\mathrm{fil}}$. We do not directly determine the volume of the filaments, $V_{f i l}$, because of the danger of trapping air bubbles upon immersion in water. Instead, we calculate the mass of copper, $\mathrm{m}_{\mathrm{Cu}}=\mathrm{m}_{\text {wire }}-\mathrm{m}_{\mathrm{fil}}$, and use the known density of pure $\mathrm{Cu}\left(8.93 \mathrm{~g} / \mathrm{cm}^{3}\right)$ to calculate the volume of copper, $\mathrm{V}_{\mathrm{Cu}}$. Then, $\mathrm{V}_{\mathrm{fil}}=\mathrm{V}_{\text {wire }}-\mathrm{V}_{\mathrm{Cu}}$.

The copper-to-superconductor volume ratio is then $\mathrm{V}_{\mathrm{Cu}} / \mathrm{V}_{\mathrm{fil}}$. The density of the $\mathrm{Nb}-\mathrm{Ti}$ alloy is $\mathrm{m}_{\mathrm{fil}} / \mathrm{V}_{\mathrm{fil}}$. The filament radius is $\left(\mathrm{V}_{\mathrm{fil}} / \pi \mathrm{NL}\right)^{\frac{1}{2}}$, where $\mathrm{N}$ is the number of filaments given by the manufacturer and $\mathrm{L}$ is the length $(1.000 \mathrm{~m})$. 


\section{CONVERSION OF ATOMIC AND WEIGHT PERCENTS}

Let the atomic masses of the elements be denoted by $A_{i}$, the atomic percents be denoted by $a_{i}$, and the weight percents be denoted by $w_{i}$. By definition, $\sum a_{i}=1$ and $\sum w_{i}=1$.

To convert atomic to weight percent:

$$
w_{i}=a_{i} A_{i} / \Sigma a_{j} A_{j} \cdot
$$

The average atomic mass of the alloy is $\bar{A}$ :

$$
\bar{A} \equiv \Sigma a_{j} A_{j} \text {. }
$$

Thus,

$$
w_{i}=a_{i} A_{i} / \bar{A} \text {. }
$$

To convert weight to atomic percent:

$$
a_{i}=\left(w_{i} / A_{i}\right) / \Sigma\left(w_{j} / A_{j}\right) \text {. }
$$

As pointed out by H. M. Ledbetter (private communication), substituting Eq. 4 into Eq. 2 gives

$$
\bar{A}=\left[\Sigma\left(w_{j} / A_{j}\right)\right]^{-1} \text {. }
$$

Thus,

$$
a_{i}=\left(w_{i} / A_{i}\right) \bar{A}
$$

\section{DENSITIES OF SUBSTITUTIONAL BINARY ALLOYS}

Often we wish to deduce the density of a binary alloy by interpolation from the densities of the pure elements. There are two approaches. The first is to assume that both elements have the same atomic volumes. We then interpolate by substituting the atomic mass of one for the atomic mass of the other. The second approach is to assume the same atomic masses. We then interpolate by substituting the atomic volumes. Both methods are presented below, applied to the Nb-Ti system. In this example, where the atomic masses of $\mathrm{Nb}$ and $\mathrm{Ti}$ are known to be very different, the first approach is better. 
Symbols

Subscripts indicate element 1 or 2

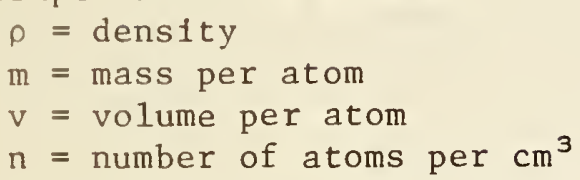

$\mathrm{q}=$ number of atoms per $\mathrm{g}$

$\mathrm{a}=$ atomic percent element 1

$\mathrm{w}=$ weight percent element 1

Same Atomic Volumes

There is the same number of atoms per $\mathrm{cm}^{3}$ for elements 1 and $2\left(\mathrm{n}_{1}=\mathrm{n}_{2}\right)$. The atomic mass of one is substituted for the atomic mass of the other.

$$
\begin{aligned}
& \rho=\mathrm{nm} \\
& \begin{aligned}
\rho_{\mathrm{a} 110 \mathrm{y}} & =\mathrm{n}\left[\mathrm{am}_{1}+(1-\mathrm{a}) \mathrm{m}_{2}\right] \\
& =\mathrm{a} \rho_{1}+(1-\mathrm{a}) \rho_{2}
\end{aligned}
\end{aligned}
$$

For example, $\rho_{\mathrm{Nb}}=8.57 \mathrm{~g} / \mathrm{cm}^{3}$ and $\rho_{\mathrm{Ti}}=4.51 \mathrm{~g} / \mathrm{cm}^{3}$. A "standard" alloy composition is $46.5 \mathrm{wt} . \% \mathrm{Ti}=63.0$ at.\% $\mathrm{T} i$. Thus,

$$
\rho_{\mathrm{NbTi}}=6.012 \mathrm{~g} / \mathrm{cm}^{3}
$$

This compares favorably with a measured density of $6.004 \mathrm{~g} / \mathrm{cm}^{3}$.

\section{$\underline{\text { Same Atomic Masses }}$}

There is the same number of atoms per $g$ for elements 1 and $2\left(q_{1}=q_{2}\right)$. The atomic volume of one is substituted for the atomic volume of the other.

$$
\begin{aligned}
& \rho^{-1}=q v \\
& \begin{aligned}
\rho_{\mathrm{a} 110 y}^{-1} & =q\left[u v_{1}+(1-u) v_{2}\right] \\
& =u / \rho_{1}+(1-u) / \rho_{2}
\end{aligned} \\
& \rho_{\text {a1loy }}=\rho_{1} \rho_{2} /\left[\left(\rho_{1}+u\left(\rho_{2}-\rho_{1}\right)\right]\right.
\end{aligned}
$$

For the example of $\mathrm{Nb}-\mathrm{Ti}$ of "standard" composition, we would obtain an inaccurate estimate: $\rho_{\mathrm{NbTi}}=5.784 \mathrm{~g} / \mathrm{cm}^{3}$. The first method, assuming equal atomic volumes for the elements, is more suitable.

If the densities of certain alloy compositions are known, further refinement is possible by interpolating between them instead of the densities of the pure elements. 

UNITS FOR MAGNETIC PROPERTIES

\begin{tabular}{|c|c|c|c|c|}
\hline Quanitity & Symbol & Gaussian $\&$ cgs emu $^{a}$ & $\begin{array}{r}\text { Conversion } \\
\text { factor, } \mathrm{C}^{b}\end{array}$ & SI \& rationalized $\mathrm{mks}^{c}$ \\
\hline $\begin{array}{l}\text { Magnetic flux density. } \\
\text { magnetıc induction }\end{array}$ & $B$ & gauss $(\mathrm{G}){ }^{d}$ & $10^{-4}$ & tesla $(\mathrm{T}), \mathrm{Wb} / \mathrm{m}^{2}$ \\
\hline Magnetic tlux & $\Phi$ & maxwell $(\mathrm{Mx}), \mathrm{G} \cdot \mathrm{cm}^{2}$ & $10^{-8}$ & weber $(\mathrm{Wb})$, volt second $(\mathrm{V} \cdot \mathrm{s})$ \\
\hline $\begin{array}{l}\text { Magnetic potential difference, } \\
\text { magnetomotive force }\end{array}$ & $U, F$ & gilbert $(\mathrm{Gb})$ & $10 / 4 \pi$ & ampere $(\mathrm{A})$ \\
\hline $\begin{array}{l}\text { Magnetic field strength, } \\
\text { magnetizing force }\end{array}$ & $H$ & oersted $(\mathrm{Oe}),{ }^{e} \mathrm{~Gb} / \mathrm{cm}$ & $10^{3} / 4 \pi$ & $\mathrm{A} / \mathrm{m}^{f}$ \\
\hline (Volume) magnetization ${ }^{g}$ & . & $\mathrm{emu} / \mathrm{cm}^{3 h}$ & $10^{3}$ & $\mathrm{~A} / \mathrm{m}$ \\
\hline (Volume) magnetization & $4 \pi M$ & G & $10^{3} / 4 \pi$ & $\mathrm{A} / \mathrm{m}$ \\
\hline $\begin{array}{l}\text { Magnetic polarization, } \\
\text { intensity of magnetization }\end{array}$ & $J . I$ & $\mathrm{emu} / \mathrm{cm}^{3}$ & $4 \pi \times 10^{-4}$ & $\mathrm{~T}, \mathrm{~Wb} / \mathrm{m}^{2 l}$ \\
\hline (Mass) magnetization & $\sigma, M$ & $\mathrm{emu} / \mathrm{g}$ & $\frac{1}{4 \pi \times 10^{-7}}$ & $\begin{array}{l}A \cdot m^{2} / k g \\
W b \cdot m / k g\end{array}$ \\
\hline Magnetic moment & $m$ & emu, erg/G & $10^{-3}$ & $A \cdot m^{2}$, joule per tesla $(J / T)$ \\
\hline Magnetic dipole moment & $j$ & emu, erg/G & $4 \pi \times 10^{-10}$ & $\mathrm{~Wb} \cdot \mathrm{m}^{l}$ \\
\hline (Volume) susceptibility & $\chi, \kappa$ & dimensionless, $\mathrm{emu} / \mathrm{cm}^{3}$ & $\begin{array}{l}4 \pi \\
(4 \pi)^{2} \times 10^{-7}\end{array}$ & $\begin{array}{l}\text { dimensionless } \\
\text { henry per meter }(\mathrm{H} / \mathrm{m}), \mathrm{Wb} /(\mathrm{A} \cdot \mathrm{m})\end{array}$ \\
\hline (Mass) susceptibility & $\chi_{\rho}, \kappa_{\rho}$ & $\mathrm{cm}^{3} / \mathrm{g}, \mathrm{emu} / \mathrm{g}$ & $\begin{array}{l}4 \pi \times 10^{-3} \\
(4 \pi)^{2} \times 10^{-10}\end{array}$ & $\begin{array}{l}\mathrm{m}^{3} / \mathrm{kg} \\
\mathrm{H} \cdot \mathrm{m}^{2} / \mathrm{kg}\end{array}$ \\
\hline (Molar) susceptibility & $\chi_{\mathrm{mol}}, \kappa_{\mathrm{mol}}$ & $\mathrm{cm}^{3} / \mathrm{mol}, \mathrm{emu} / \mathrm{mol}$ & $\begin{array}{l}4 \pi \times 10^{-6} \\
(4 \pi)^{2} \times 10^{-13}\end{array}$ & $\begin{array}{l}\mathrm{m}^{3} / \mathrm{mol} \\
\mathrm{H} \cdot \mathrm{m}^{2} / \mathrm{mol}\end{array}$ \\
\hline Permeability & $\mu$ & dimensionless & $4 \pi \times 10^{-7}$ & $\mathrm{H} / \mathrm{m}, \mathrm{Wb} /(\mathrm{A} \cdot \mathrm{m})$ \\
\hline Relative permeability ${ }^{j}$ & $\mu_{r}$ & not defined & & dimensionless \\
\hline $\begin{array}{l}\text { (Volume) energy density, } \\
\text { energy product }^{k}\end{array}$ & $W$ & $\mathrm{erg} / \mathrm{cm}^{3}$ & $10^{-1}$ & $\mathrm{~J} / \mathrm{m}^{3}$ \\
\hline Demagnetization factor & $D, N$ & dimensionless & $1 / 4 \pi$ & dimensionless \\
\hline
\end{tabular}

a. Gaussian units and cgs emu are the same for magnetic properties. The defining relation is $B=H+4 \pi \cdot M$

b. Multiply a number in Gaussian units by $C$ to convert it to $S I$ (e.g., $1 \mathrm{G} \times 10^{-4} \mathrm{~T} / \mathrm{G}=10^{-4} \mathrm{~T}$ ).

c. SI (Systeme International d'Unités) has been adopted by the National Bureau of Standards. Where two conversion factors are given, the upper one is recognized under, or consistent with, SI and is based on the definition $B=\mu_{0}(H-W)$, where $\mu_{0}=4 \pi \times 10^{-7} \mathrm{H} / \mathrm{m}$. The lower one is not recognized under SI and is based on the definition $B=\mu_{0} H+J, u$ here the $i \mathrm{mbol}$ $I$ is often used in place of $J$.

d. I gauss $=10^{5} \operatorname{gamma}(\gamma)$.

e. Both oersted and gauss are expressed as $\mathrm{cm}^{-1 / 2} \cdot \mathrm{g}^{1 / 2} \cdot \mathrm{s}^{-1}$ in terms of base units

f. A/m was often expressed as "ampere-turn per meter" when used for magnetic field strength.

g. Magnetic moment per unit volume.

$h$. The designation "emu" is not a unit.

i. Recognized under SI, even though based on the definition $B=\mu_{0} H+J$. See footnote $c$

j. $\mu_{\mathrm{r}}=\mu / \mu_{0}=1+\chi$, all in SI. $\mu_{\mathrm{r}}$ is equal to Gaussian $\mu$.

k. $B \cdot H$ and $\mu_{0} M \cdot H$ have SI units $\mathrm{J} / \mathrm{m}^{3} ; M \cdot H$ and $B \cdot H / 4 \pi$ have Gaussian units $\mathrm{erg} / \mathrm{cm}^{3}$.

R. B. Goldfarb and F. R. Fickett, U.S. Department of Commerce, National Bureau of Standards, Boulder, Colorado 20.303 , W/3r,h 14.8 NBS Special Publication 696 For sale by the Superintendent of Documents, U.S. Government Printıng Office. Washınglon. DC :04n? 

REPORT DOCUMENTATION PAGE

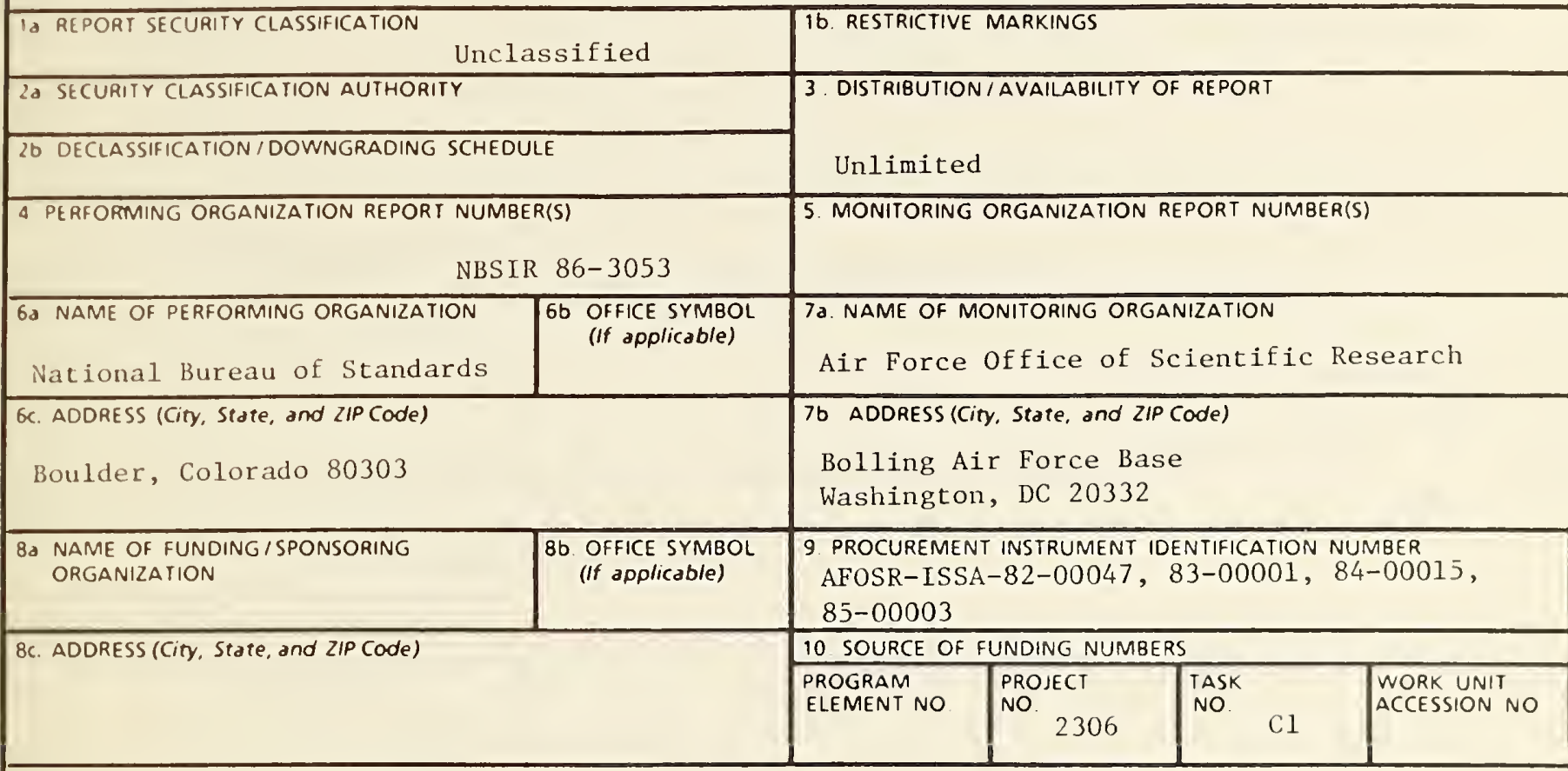

11 TITLE (include Security Classification)

TRANSIENT LOSSES IN SUPERCONDUCTORS (Unclassified)

12 PERSONAL AUTHOR(S)

Goldfarb, R. B. (Editor)

\begin{tabular}{|c|c|c|c|c|}
\hline $\begin{array}{c}\text { 13a TYPE OF REPORT } \\
\text { Final Report }\end{array}$ & $\begin{array}{c}\text { 136. TIME COVERED } \\
\text { FROM } 10 / 82\end{array}$ & TO DATE OF REPORT (Year, MONTh, Day) \\
1986 June & $\begin{array}{c}\text { 15 PAGE COUNT } \\
72\end{array}$
\end{tabular}

16 SUPPLEMENTARY NOTATION

\begin{tabular}{|c|c|c|}
\hline \multicolumn{3}{|c|}{ COSATI CODES } \\
\hline FIELD & GROUP & SUB-GROUP \\
\hline 20 & 03 & \\
\hline 20 & 12 & \\
\hline
\end{tabular}

18 SUBJECT TERMS (Continue on reverse if necessary and identify by block number) ac losses; hysteresis; magnetization; magnetometers; niobium-tin; niobium-titanium; superconductors; susceptibility; susceptometers; transient losses

19 ABSTRACT

Under steady-state conditions, there are no losses in superconducting wires. However, when subjected to alternating or transient magnetic fields or transport currents, losses in type-II superconductors can become significant. This report deals with hysteresis losses at $4 \mathrm{~K}$ measured by magnetization and complex magnetic susceptibility. The theoretical and experimental relationships between ac susceptibility and magnetization as functions of dc field were examined in terms of the critical-state model as developed by Carr and Clem. Minor-loop hysteresis loss was shown to be obtainable by direct measurement of loop area, from the imaginary component of ac susceptibility, and from the reversible susceptibility plus the critical current density or fullpenetration field. Hysteresis and transport losses measured simultaneously in a $\mathrm{Nb}-\mathrm{T} 1$ superconducting coil were found to agree substantially with the predictions of Minervini's two-dimensional model. Hysteresis loss measurements in a series of fine-filament $\mathrm{Nb}_{3} \mathrm{Sn}$ superconductors showed that the effective filament diameter is a function of interfilament separation and local area ratio of matrix material to $\mathrm{Nb}$. A review of internal fields in superconductors showed the importance of demagnetization factors and internal fields for the correct analysis of magnetic data. A theoretical method of calibrating ac susceptometers for cylindrical specimens, which is based on a mutualinductance calculation, was developed.

\begin{tabular}{|c|c|c|c|}
\hline $\begin{array}{l}20 \text { DISTRIBUTION / AVAILABILITY OF ABSTRACT } \\
\text { WUNCLASSIFIED/UNLIMITED } \square \text { SAME AS RPT }\end{array}$ & $\square$ DTIC USERS & 21 ABSTRACT SECURITY CLASSIFICAI & Unclassif ied \\
\hline $\begin{array}{r}\text { 22a NAME OF RESPONSIBLE INDIVIDUAL } \\
\text { Harold Weinstock }\end{array}$ & & $\begin{array}{l}\text { 22b TELEPHONE (Include Area Code) } \\
\text { (202) 767-4933 }\end{array}$ & $\begin{array}{c}22 \mathrm{C} \text { OFFICE SYMBOL } \\
\text { AFOSR/NE }\end{array}$ \\
\hline
\end{tabular}





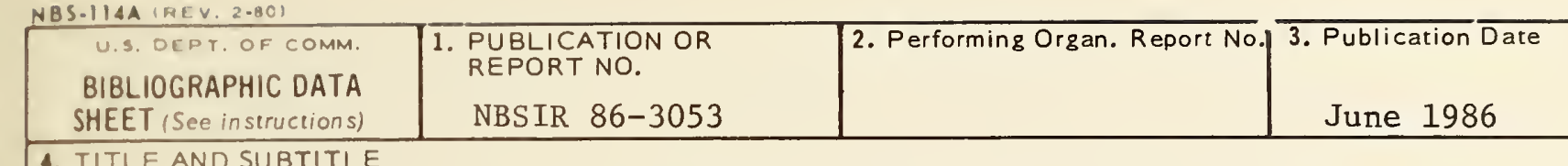

4. TITLE AND SUBTITLE

Transient Losses in Superconductors

5. $A \cup T H O R(S)$

R. B. Goldfarb, Editor

6. PERFORMING ORGANIZATION (If joint or other than NBS, see instructions)

NATIONAL BUREAU OF STANDARDS

DEPARTMENT OF COMMERCE

WASHINGTON, D.C. 20234

7. Contract/Grant No.
8. Type of Report \& Period Covered
Final Report
1 Oct 1982 - 30 Sep 1985

9. SPONSORING ORGANIZATION NAME AND COMPLETE ADDRESS (Street, City, State, $\overline{\text { ZIP) }}$

Air Force Office of Scientific Research

Bolling Air Force Base

Washington, DC 20332

10. SUPPLEMENTARY NOTES

-7 Document describes a computer program; SF-185, FIPS Software Summary, is attached.

11. ABSTRACT (A 200-word or less factual summary of most significant information. If document includes a significant bibliography or literature survey. mention it here)

Under steady-state conditions, there are no losses in superconducting wires. However, when subjected to alternating or transient magnetic fields or transport currents, losses in type-II superconductors can become significant. This report deals with hysteresis losses at $4 \mathrm{~K}$ measured by magnetization and complex magnetic susceptibility. The theoretical and experimental relationships between ac susceptibility and magnetization as functions of dc field were examined in terms of the critical-state model as developed by Carr and Clem. Minor-loop hysteresis loss was shown to be obtainable by direct measurement of loop area, from the imaginary component of ac susceptibility, and from the reversible susceptibility plus the critical current density or fullpenetration field. Hysteresis and transport losses measured simultaneously in a $\mathrm{Nb-Ti}$ superconducting coil were found to agree substantially with the predictions of Minervini's two-dimensional model. Hysteresis loss measurements in a series of fine-filament $\mathrm{Nb}_{3} \mathrm{Sn}$ superconductors showed that the effective filament diameter is a function of interfilament separation and local area ratio of matrix material to $\mathrm{Nb}$. A review of internal fields in superconductors showed the importance of demagnetization factors and internal fields for the correct analysis of magnetic data. A theoretical method of calibrating ac susceptometers for cylindrical specimens, which is based on a mutualinductance calculation, was developed.

12. KEY WORDS (Six to twelve entries; alphabetical order; capitalize only proper names; and separate key words ty semicolons)

ac losses; hysteresis; magnetization; magnetometers; niobium-tin; niobium-titanium; superconductors; susceptibility; susceptometers; transient losses.

13. AVAILABILITY

[.] Unlimited

For Official Distribution. Do Not Release to NTIS

Order From Superintendent of Documents, U.S. Government Printing Office, Washington, D.C. 20402.

14. NO. OF

PRINTED PAGES 72

15. Price

Order From National Technical Information Service (NTIS), Springfield, VA. 2216I 


